UNIVERSIDADE DE SÃO PAULO

FACULDADE DE ECONOMIA, ADMINISTRAÇÃO E CONTABILIDADE PROGRAMA DE PÓS-GRADUAÇÃO EM ECONOMIA

\title{
O IMPACTO DA POLÍTICA FISCAL SOBRE A ATIVIDADE ECONÔMICA AO LONGO DO CICLO ECONÔMICO: EVIDÊNCIAS PARA O BRASIL
}

Aluno: Renan Santos Alves Orientação Acadêmica: Prof. Dra. Fabiana Fontes Rocha 
Prof. Dr. Marcos Antonio Zago

Reitor da Universidade de São Paulo

Prof. Dr. Adalberto Américo Fishmann

Diretor da Faculdade de Economia, Administração e Contabilidade

Prof. Dr. Eduardo Amaral Haddad

Chefe do Departamento de Economia

Prof. Dr. Ariaster Baumgratz Chimeli

Coordenador do Programa de Pós-Graduação em Economia 


\section{Renan Santos Alves}

\section{O IMPACTO DA POLÍTICA FISCAL SOBRE A ATIVIDADE ECONÔMICA AO LONGO DO CICLO ECONÔMICO: EVIDÊNCIAS PARA O BRASIL}

Dissertação apresentada ao Programa de PósGraduação em Economia do Departamento de Economia da Faculdade de Economia, Administração e Contabilidade da Universidade de São Paulo, como requisito parcial para a obtenção do título de Mestre em Ciências.

Orientadora: Prof. Dra. Fabiana Fontes Rocha

Versão Corrigida

(versão original disponível na Faculdade de Economia, Administração e Contabilidade)

São Paulo

2017 
Alves, Renan Santos

O impacto da política fiscal sobre a atividade econômica ao longo do ciclo econômico: evidências para o Brasil / Renan Santos Alves. -São Paulo, 2017.

$115 \mathrm{p}$.

Dissertação (Mestrado) - Universidade de São Paulo, 2017.

Orientador: Fabiana Fontes Rocha.

1. Política fiscal 2. Multiplicadores fiscais 3. Ciclo econômico I. Universidade de São Paulo. Faculdade de Economia, Administração e Contabilidade. II. Título. 
Dedico aos meus pais José, Salete e ao meu irmão Douglas 



\section{AGRADECIMENTOS}

Dedico esta dissertação a minha família, em especial ao meu pai, José e a minha mãe Salete, que sempre me motivaram a buscar este sonho de concluir o mestrado e que sempre estivaram comigo e me apoiaram incondicionalmente em todas as situações. Ao meu irmão Douglas, que sempre me ajudou quando eu estava com dificuldades e que me incentivou a procurar soluções.

À minha orientadora, professora Fabiana Rocha, eu agradeço a orientação e a dedicação. Sou muito grato por ela ter me recebido em sua sala quando eu mais precisava e por ter me motivado na escolha do tema. Orientou-me da melhor forma possível. Seus comentários, sugestões e críticas foram muito importantes para minha formação como economista e pesquisador.

Agradeço aos professores Vera Lúcia Fava, Mauro Rodrigues e Raphael Corbi pelos comentários e sugestões durante a qualificação e durante a avaliação de progresso da dissertação.

Também devo um agradecimento especial ao professor Márcio Nakane pela orientação no começo do mestrado. E ao professor André Chagas, professor e amigo.

Agradeço ainda aos professores do IPE/USP pela dedicação e empenho na minha formação. Gostaria de registrar dois agradecimentos especiais, ao professor Pedro Duarte, meu professor da graduação e da pós, pelo melhor curso da pós-graduação e pelas palavras de incentivo durante o mestrado e também ao professor David Turchick, pelas conversas que me mostraram como trilhar melhor o caminho da pós-graduação.

Agradeço também aos colaboradores do departamento, Pinho e Leka.

Aos meus colegas da pós-graduação, a minha turma, ingressante de 2015 foi uma enorme satisfação e grande divertimento ter passado estes últimos anos com todos. Em especial agradeço ao Fábio Tieppo e Thiago Nascimento, pela convivência e conversa. Aos meus colegas de doutorado que me ajudaram, me ensinaram a mexer com a base de dados e me deram ideias Ricardo Sabaddini, Robson Perreira, Fernanda Batolla, Gian e ZiDanilo. Agradecimento especial aos meus colegas de graduação da FEA e que me acompanharam no mestrado, Robison Francisco e Arthur Viaro, foi muito bom passar estes anos ao lado de vocês. 
Não posso deixar de agradecer os meus colegas de estágio da FIPE, Rodolfo e Leopoldo, que me ajudaram na preparação da Anpec, e ao pessoal da Tendências e do Itaú BBA onde trabalhei depois.

Por fim e não menos importante, gostaria de agradecer à FIPE e à CAPES pelo auxílio financeiro durante o mestrado. 
"If you're trying to achieve, there will be roadblocks. I've had them; everybody has had them. But obstacles don't have to stop you. If you run into a wall, don't turn around and give up. Figure out how to climb it, go through it, or work around it." Michael Jordan 



\section{RESUMO}

O objetivo deste trabalho é investigar se os multiplicadores de gastos do governo diferem de acordo com o estado do ciclo de negócios para o período 1999: I- 2016: II. Para tanto é utilizado o Método de Projeção Local de Jordà para estimar as funções resposta ao impulso e os multiplicadores fiscais sob dois regimes diferentes: recessão e expansão. Para definir os diferentes regimes foram utilizadas as variáveis comumente usadas na literatura (o hiato do produto, o nível de utilização da capacidade instalada, a taxa de crescimento do PIB, a taxa de desemprego), além da datação oficial de ciclos do CODACE. A estimação do modelo não linear resulta em multiplicadores de gastos do governo, após um e dois anos, maiores nos períodos de recessão do que nos períodos de expansão, independentemente da variável escolhida para diferenciar os regimes. Porém, os multiplicadores obtidos não parecem ser diferentes estatisticamente entre os regimes. Infelizmente, como observado por Ramey e Zubairy (2017) a existência de séries históricas é fundamental para a estimação dos multiplicadores fiscais e sua ausência para a economia brasileira limita muito o que é possível dizer sobre o assunto.

Palavras-chave: Multiplicador Fiscal, Política Fiscal, Projeção Local, Modelos não Lineares. 



\begin{abstract}
This paper aims to investigate whether government spending multipliers are different according to the state of the business cycle for the Brazilian economy during the period 1999:I-2016:II. In order to do so we use Jordà's Local Projection Method to estimate impulse response functions and fiscal multipliers under two different regimes: recession and expansion. To define the different regimes we use several variables commonly used in the literature: the output gap, the capacity utilization level, the GDP growth rate, the unemployment rate and CODACE. The nonlinear model estimations result in larger multipliers, after one and two years, in periods of economic recession than in periods of economic expansion, regardless of the variable chosen to differentiate regimes. However, the multipliers do not seem to be statistically different between regimes. Unfortunately, as observed by Ramey and Zubairy (2017), long historical series are fundamental for the adequate estimation of fiscal multipliers and their absence for the Brazilian economy does not allow anyone to say much about the subject.
\end{abstract}

Key-words: Fiscal Multipliers, Fiscal Policy, Local Projections, Nonlinear Models. 



\section{LISTA DE ILUSTRAÇÕES}

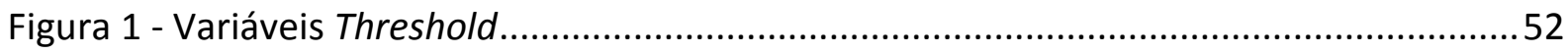

Figura 2 - Teste de Relevância de Instrumento entre os Estados de Slack .............................53

Figura 3 - Função Resposta ao Impulso do Modelo Linear: Despesa Primária e PIB ...............55

Figura 4 - Função Resposta ao Impulso do Modelo Não Linear: Threshold Hiato ....................58

Figura 5 - Função Resposta ao Impulso do Modelo Não Linear: Threshold $\mathrm{NUCl}$....................59

Figura 6 - Função Resposta ao Impulso do Modelo Não Linear: Threshold Taxa de

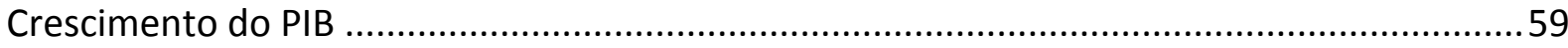

Figura 7 - Função Resposta ao Impulso do Modelo Não Linear: Threshold Taxa de

Desemprego

Figura 8 - Função Resposta ao Impulso do Modelo Não Linear: Threshold Datação da

CODACE. 60

Figura 9 - Teste de Robustez: Threshold Smooth Transition ................................................63

Figura 10 - Função Resposta ao Impulso do Modelo Linear: Carga Tributária Líquida.............73

Figura 11 - Função Resposta ao Impulso da Carga Tributária Líquida do Modelo Não Linear:

Threshold Hiato.

Figura 12 - Função Resposta ao Impulso da Carga Tributária Líquida do Modelo Não Linear:

Threshold $\mathrm{NUCl}$

Figura 13 - Função Resposta ao Impulso da Carga Tributária Líquida do Modelo Não Linear:

Threshold Taxa de Crescimento do PIB

Figura 14 - Função Resposta ao Impulso da Carga Tributária Líquida do Modelo Não Linear:

Threshold Taxa de Desemprego

Figura 15 - Função Resposta ao Impulso da Carga Tributária Líquida do Modelo Não Linear:

Threshold Datação da CODACE

Figura 16 - Função Resposta ao Impulso do Modelo Linear: Consumo Privado e Investimento

Figura 17 - Função Resposta ao Impulso do Consumo Privado e do Investimento no Modelo

Não Linear: Threshold Hiato 79

Figura 18 - Função Resposta ao Impulso do Consumo Privado e do Investimento no Modelo Não Linear: Threshold NUCl

Figura 19 - Função Resposta ao Impulso do Consumo Privado e do Investimento no Modelo Não Linear: Threshold Taxa de Crescimento do PIB .80 
Figura 20 - Função Resposta ao Impulso do Consumo Privado e do Investimento no Modelo Não Linear: Threshold Taxa de Desemprego

Figura 21 - Função Resposta ao Impulso do Consumo Privado e do Investimento no Modelo Não Linear: Threshold Datação da CODACE 81

Figura 22 - Função Resposta ao Impulso do Modelo Linear: Exportação e Importação 82

Figura 23 - Função Resposta ao Impulso da Exportação e da Importação no Modelo Não

Linear: Threshold Hiato 85

Figura 24 - Função Resposta ao Impulso da Exportação e da Importação no Modelo Não

Linear: Threshold NUCl. 85

Figura 25 - Função Resposta ao Impulso da Exportação e da Importação no Modelo Não

Linear: Threshold Taxa de Crescimento do PIB.

Figura 26 - Função Resposta ao Impulso da Exportação e da Importação no Modelo Não

Linear: Threshold Taxa de Desemprego.....

Figura 27 - Função Resposta ao Impulso da Exportação e da Importação no Modelo Não

Linear: Threshold Datação da CODACE 87

Figura 28 - Variável Threshold..... 99

Figura 29 - Função Resposta ao Impulso do Modelo Linear com Tendência: Despesa Primária e PIB 100

Figura 30 - Função Resposta ao Impulso do Modelo Não Linear, com Tendência: Threshold Hiato 100

Figura 31 - Função Resposta ao Impulso do Modelo Não Linear, com Tendência: Threshold $\mathrm{NUCl}$

Figura 32 - Função Resposta ao Impulso do Modelo Não Linear, com Tendência: Threshold Taxa de Crescimento do PIB..... 101

Figura 33 - Função Resposta ao Impulso do Modelo Não Linear, com Tendência: Threshold

Taxa de Desemprego...... 102

Figura 34 - Função Resposta ao Impulso do Modelo Não Linear, com Tendência: Threshold

Datação da CODACE.

Figura 35 - Função Resposta ao Impulso do Modelo Linear com PIB Potencial: Despesa

Primária e PIB

Figura 36 - Função Resposta ao Impulso do Modelo Não Linear, com PIB Potencial: Threshold Hiato 103 
Figura 37 - Função Resposta ao Impulso do Modelo Não Linear, com PIB Potencial: Threshold $\mathrm{NUCl}$

Figura 38 - Função Resposta ao Impulso do Modelo Não Linear, com PIB Potencial: Threshold Taxa de Crescimento do PIB 104

Figura 39 - Função Resposta ao Impulso do Modelo Não Linear, com PIB Potencial: Threshold Taxa de Desemprego 105

Figura 40 - Função Resposta ao Impulso do Modelo Não Linear, com PIB Potencial: Threshold Datação da CODACE 105

Figura 41 - Função Resposta ao Impulso do Modelo Não Linear: Variável de Transição Hiato 106

Figura 42 - Função Resposta ao Impulso do Modelo Não Linear: Variável de Transição NUCl

Figura 43 - Função Resposta ao Impulso do Modelo Não Linear: Variável de Transição Taxa de Crescimento do PIB

Figura 44 - Função Resposta ao Impulso do Modelo Não Linear: Variável de Transição Taxa de Desemprego

Figura 45 - Função Resposta ao Impulso do Modelo Linear até 2014.1: Despesa Primária e PIB. 108

Figura 46 - Função Resposta ao Impulso do Modelo Não Linear até 2014.1: Threshold Hiato 108

Figura 47 - Função Resposta ao Impulso do Modelo Não Linear até 2014.1: Threshold NUCl

Figura 48 - Função Resposta ao Impulso do Modelo Não Linear até 2014.1: Threshold Taxa de Crescimento do PIB 109

Figura 49 - Função Resposta ao Impulso do Modelo Não Linear até 2014.1: Threshold Taxa de

Desemprego 110

Figura 50 - Função Resposta ao Impulso do Modelo Não Linear até 2014.1: Threshold Datação da CODACE

Figura 51 - Função Resposta ao Impulso do Modelo Linear, deflacionado pelo Deflator do PIB: Despesa Primária e PIB

Figura 52 - Função Resposta ao Impulso do Modelo Não Linear deflacionado pelo Deflator do PIB: Threshold Hiato 
Figura 53 - Função Resposta ao Impulso do Modelo Não Linear deflacionado pelo Deflator do PIB: Threshold NUCI

Figura 54 - Função Resposta ao Impulso do Modelo Não Linear deflacionado pelo Deflator do PIB: Threshold Taxa de Crescimento do PIB

Figura 55 - Função Resposta ao Impulso do Modelo Não Linear deflacionado pelo Deflator do PIB: Threshold Taxa de Desemprego 113

Figura 56 - Função Resposta ao Impulso do Modelo Linear, deflacionado pelo Deflator do PIB e com a carga tributária bruta: Despesa Primária e PIB 113

Figura 58 - Função Resposta ao Impulso do Modelo Não Linear deflacionado pelo Deflator do PIB e com a carga tributária bruta: Threshold Hiato 114

Figura 59 - Função Resposta ao Impulso do Modelo Não Linear deflacionado pelo Deflator do PIB e com a carga tributária bruta: Threshold NUCl 114 Figura 60 - Função Resposta ao Impulso do Modelo Não Linear deflacionado pelo Deflator do PIB e com a carga tributária bruta: Threshold Taxa de Crescimento do PIB 115 Figura 61 - Função Resposta ao Impulso do Modelo Não Linear deflacionado pelo Deflator do PIB e com a carga tributária bruta: Threshold Taxa de Desemprego 115 


\section{LISTAS DE TABELAS}

Tabela 1 - Multiplicadores Fiscais para o Brasil - Modelo Linear ...........................................33

Tabela 2 - Multiplicadores Fiscais para o Brasil - Modelo Não Linear.....................................41

Tabela 3 - Estimação dos Thresholds e Máxima Verossimilhança ............................................51

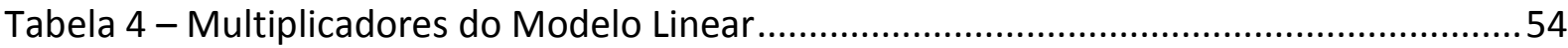

Tabela 5 - Multiplicadores do Modelo Não Linear ................................................................56

Tabela 6 - Teste para Verificação de Diferença entre os Regimes dos Multiplicadores ...........57

Tabela 7 - Multiplicadores do Modelo Linear - Testes de Robustez ......................................64

Tabela 8 - Multiplicadores de Impacto do Modelo Não Linear - Testes de Robustez .............64

Tabela 9 - Multiplicadores de 4 trimestres do Modelo Não Linear - Testes de Robustez ........65

Tabela 10 - Multiplicadores de 8 trimestres do Modelo Não Linear - Testes de Robustez .....66

Tabela 11 - Multiplicadores do Modelo Linear - Teste de Robustez, deflacionado pelo

Deflator do PIB

Tabela 12 - Multiplicadores do Modelo Não Linear- Testes de Robustez, deflacionado pelo Deflator do PIB.

Tabela 13 - Multiplicadores do Modelo Linear - Teste de Robustez Carga Tributária Bruta...69

Tabela 14 - Multiplicadores do Modelo Não Linear- Testes de Robustez Carga Tributária

Bruta

Tabela 15 - Multiplicadores da Carga Tributária Líquida do Modelo Linear ...........................72

Tabela 16 - Multiplicadores da Carga Tributária Líquida do Não Modelo Linear ....................72

Tabela 17 - Multiplicadores do Consumo e do Investimento do Modelo Linear......................76

Tabela 18 - Multiplicadores do Consumo do Não Modelo Linear...........................................78

Tabela 19 - Multiplicadores do Investimento do Não Modelo Linear .....................................78

Tabela 20 - Multiplicadores da Exportação e da Importação do Modelo Linear ......................82

Tabela 21 - Multiplicadores da Exportação do Modelo Não Linear ........................................83

Tabela 22 - Multiplicadores da Importação do Modelo Não Linear .......................................... 83

Tabela 23 - Estimação do Threshold e Máxima Verossimilhança ...........................................98

Tabela 24 - Multiplicadores do Modelo Não Linear com Hiato via Função de Produção.........99 



\section{SUMÁRIO}

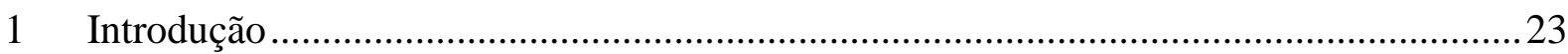

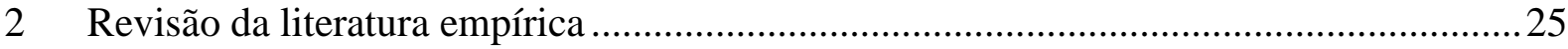

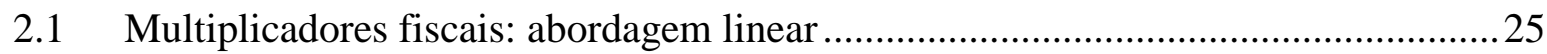

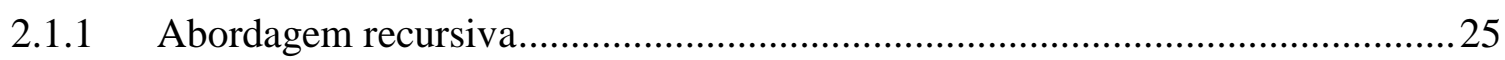

2.1.2 VAR estrutural (Structural VAR - SVAR) ................................................... 26

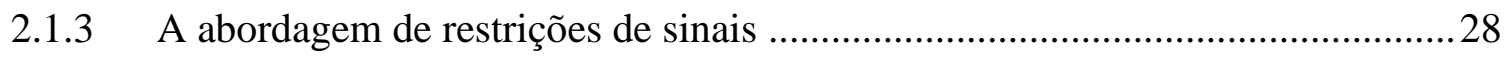

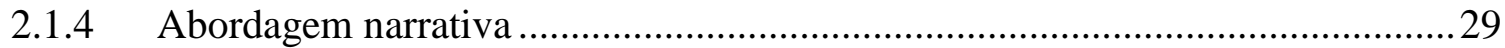

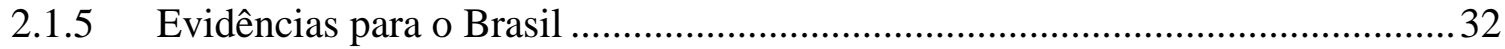

2.2 Multiplicadores fiscais: modelos não lineares .......................................................... 33

2.2.1 VAR com parâmetros variáveis no tempo com volatilidade estocástica.............34

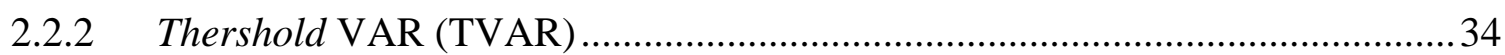

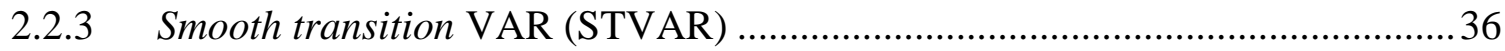

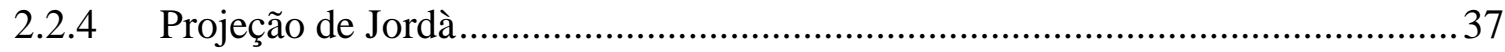

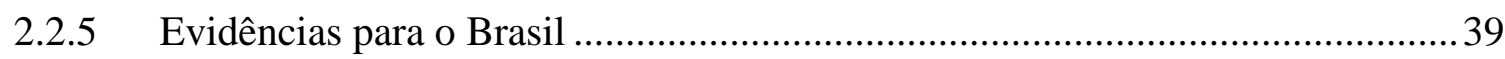

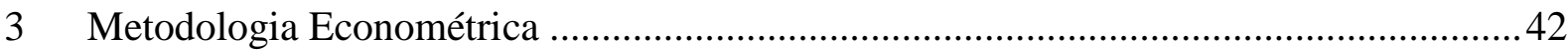

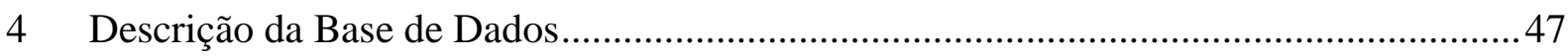

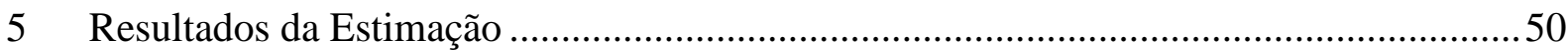

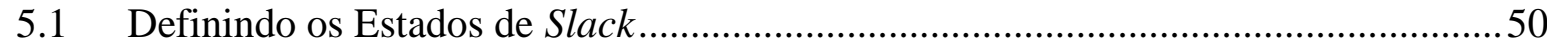

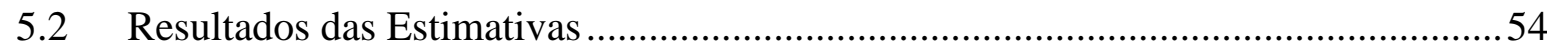

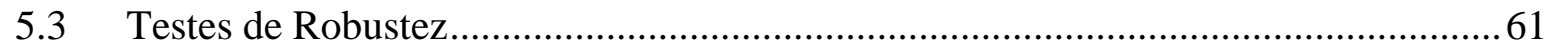

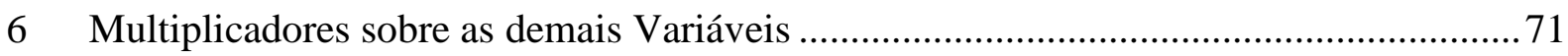

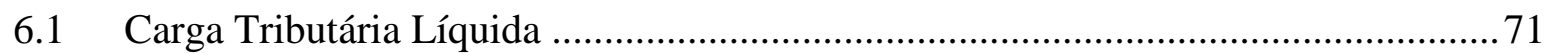

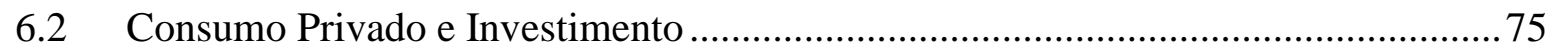

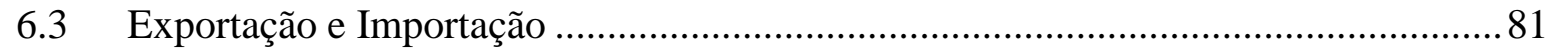

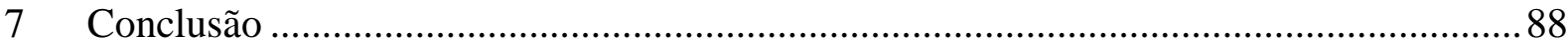

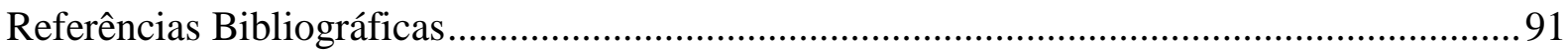

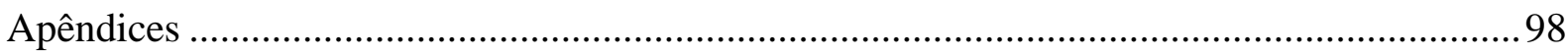

A.1 - Hiato do Produto Potencial via Função de Produção .................................................. 98

A.2 - Funções Resposta ao Impulso dos Testes de Robustez ............................................ 100 



\section{Introdução}

A incapacidade da política monetária de lidar com a contração de demanda que se seguiu à eclosão da crise financeira de 2008/2009 fez com que pacotes de estímulos físcais fossem introduzidos em vários países do mundo. A crença de que esses pacotes seriam fundamentais para ajudar a recuperação econômica foi ampliada devido ao fato de que muitos países tinham atingido o zero lower bound, não havendo possibilidade de reduções adicionais das taxas de juros pelos seus bancos centrais.

O Brasil obviamente não saiu ileso da crise, tendo sido observada em 2009 uma queda de $0,12 \%$ no PIB. Para estimular o consumo, e com isso a economia, foi adotada política anticíclica com aumento de gastos (remuneração de funcionários públicos, por exemplo) e redução de tributos (principalmente desonerações tributárias).

Diante dos resultados esperados, e não concretizados, da política anticíclica adotada, a primeira questão que surge é: a de quais seriam os efeitos da política fiscal sobre o crescimento econômico no Brasil? Qual afinal é o tamanho dos multiplicadores de gastos públicos? Uma segunda questão, derivada da primeira, é a de se os efeitos dos multiplicadores de gastos do governo sobre o produto dependem do estado do ciclo econômico. O objetivo desta dissertação é responder estas duas questões, no que se refere ao período 1999-2016, uma vez que são relevantes do ponto de vista da política macroeconômica, são controversas do ponto de vista teórico e empírico e são pouco exploradas para o caso brasileiro.

A visão keynesiana tradicional da política fiscal tem sido sistematicamente desafiada. De acordo com a hipótese da equivalência ricardiana, os agentes privados descontam plenamente a redução (aumentos) nas alíquotas de impostos futuras que resultarão de reduções (aumentos) permanentes nos gastos do governo no presente, implicando multiplicadores fiscais iguais a zero. A literatura antikeynesiana enfatiza que expectativas sobre as obrigações futuras com impostos e efeitos de credibilidade podem gerar contrações (expansões) fiscais expansionistas (contracionistas), ou seja, multiplicadores fiscais negativos. $\mathrm{Na}$ verdade, efeitos keynesianos tradicionais seriam esperados em tempos normais (sem crise), enquanto efeitos não keynesianos seriam esperados quando há dúvidas sobre a sustentabilidade das finanças públicas.

Argumentos teóricos do lado da oferta e do lado da demanda são usados para explicar a observação de não linearidades. Do lado da oferta, a substituição do gasto privado pelo gasto público (efeito crowding-out padrão) ocorreria em períodos em que o produto está 
acima do seu potencial. Já em períodos em que o hiato do produto é negativo e há excesso de capacidade produtiva na economia, essa substituição ocorre menos, o que permite à política fiscal estimular o uso de fatores que estão ociosos. Do lado da demanda, quando a razão dívida pública/PIB atinge um valor crítico, os agentes percebem que não poderão transferir a carga tributária para as próximas gerações se tornando antikeynesianos (Sutherland (1997)); um ajustamento fiscal forte pode reduzir o prêmio de risco embutido nas taxas de juros de países com dívidas públicas altas ou crescentes, melhorando assim as expectativas dos investidores; o tamanho e a composição do ajustamento fiscal sinalizam o comprometimento do governo e assim mudam as expectativas (Alesina e Perotti (1997); Giavazzi e Pagano (1990)).

A literatura empírica segue a literatura teórica, não gerando consenso a respeito do impacto da política fiscal sobre a atividade econômica. Aqui a interdependência entre os desenvolvimentos fiscais e econômicos será tratada através de modelos de vetores autorregressivos (VAR) em que a identificação dos choques discricionários de política fiscal é feita utilizando o método de projeção local de Jordá (2005). Este método tem como vantagem a estimação de funções de resposta a impulso, projetando diretamente uma variável de interesse sobre as defasagens das variáveis que compõem o VAR. Além disso, permite incorporar facilmente as não linearidades.

Esta dissertação está organizada em 7 seções, além desta Introdução. A seção 2 faz uma revisão da evidência empírica sobre os efeitos da política fiscal sobre a atividade econômica e sobre a sensibilidade da resposta ao estágio do ciclo. A seção 3 apresenta brevemente a metodologia econométrica a ser utilizada. A seção 4 discute os dados a serem utilizados, enquanto a seção 5 mostra os principais resultados econométricos e apresenta alguns testes de robustez. A seção 6 apresenta estimativas dos multiplicadores dos gastos sobre os componentes do produto (consumo, investimento, exportações e importações) e sobre a carga tributária. Finalmente, a seção 7 resume os principais resultados. 


\section{Revisão da literatura empírica}

\subsection{Multiplicadores fiscais: abordagem linear}

A literatura empírica sobre os efeitos dos choques de política fiscal sobre as variáveis macroeconômicas consiste basicamente de 4 tipos de modelos: i) modelos macroeconométricos de previsão, que se baseiam em relações entre variáveis econômicas agregadas definidas pela teoria; ii) modelos de séries temporais; iii) modelos dinâmicos de equilíbrio geral estocástico (modelos DSGE); iv) modelos microeconométricos que procuram lidar explicitamente com a endogeneidade do gasto do governo.

Os trabalhos que utilizam a abordagem de séries temporais, por sua vez, se diferenciam por adotarem diferentes formas para identificar os choques fiscais discricionários. ${ }^{1}$ São essas:

\subsubsection{Abordagem recursiva}

A abordagem recursiva introduzida por Sims (1980) requer uma ordenação causal das variáveis que compõem o modelo (decomposição de Cholesky) em que a variável que é ordenada primeira responde apenas aos seus próprios choques exógenos. A ordenação das variáveis cumpre então um papel crucial para definir a direção da relação causal. Como não há um critério que explique teoricamente como ordenar as variáveis e nem as premissas por trás de qualquer ordenação, a tarefa de escolher que variável deve vir incialmente não é trivial.

Fatás e Mihov (2001) estudam os efeitos dinâmicos dos gastos do governo sobre a economia americana, encontrando um multiplicador de gastos maior do que um e com forte impacto sobre os componentes do produto privado (consumo e investimento). O efeito dos gastos governamentais sobre o deflator do PIB é decrescente, porém insignificante, e o efeito sobre a taxa de juros é significativo.

Castro (2006) apresenta evidências de que inovações positivas das despesas públicas na Espanha elevam o produto, o consumo privado e o investimento, gerando multiplicadores acima de um no curto prazo. No médio prazo, porém, os efeitos já são negativos. Por outro lado, embora as inovações nos impostos líquidos elevem o produto, o consumo privado e o investimento, resultam em multiplicadores menores do que um. O deflator do PIB responde negativamente a choques de impostos líquidos e positivamente a choques nas despesas do

\footnotetext{
${ }^{1}$ Para uma discussão mais formalizada das abordagens de identificação, ver Caldara e Kamps (2008).
} 
governo. As taxas de juros, por sua vez, se elevam com aumentos em ambos os choques fiscais.

\subsubsection{VAR estrutural (Structural VAR - SVAR)}

A segunda abordagem se baseia em informação institucional sobre os impostos e sistemas de transferências e foi originalmente formulada por Blanchard e Perotti (2002). Eles investigam os efeitos dinâmicos dos gastos do governo e dos impostos sobre o produto dos Estados Unidos depois da Segunda Guerra Mundial. Os resultados encontrados indicam que choques positivos nos gastos do governo têm efeito positivo sobre o produto, enquanto choques positivos de impostos têm efeito negativo sobre o produto. A política fiscal teria, assim, impactos claramente keynesianos. Os multiplicadores são, contudo, pequenos, geralmente próximos de um.

A identificação dos choques fiscais é feita assumindo-se que a política fiscal discricionária responde ao produto dentro do período de um trimestre (por exemplo, os impostos não devem reagir dentro de um determinado período - normalmente um trimestre - aos demais choques da economia), que as respostas de políticas não discricionárias ao produto são consistentes com estimativas auxiliares das elasticidades das variáveis fiscais em relação à atividade econômica e que inovações nas variáveis fiscais não previstas pelo VAR constituem inovações não previstas da política fiscal ${ }^{2}$.

Perotti (2005) estende a análise de Blanchard e Perotti (2002), avaliando os efeitos da política fiscal sobre a atividade econômica, a taxa de inflação e a taxa de juros em cinco países (Estados Unidos, Reino Unido, Canadá, Austrália e Alemanha). Os resultados obtidos apontam para multiplicadores de gastos do governo positivos e maiores do que um somente para os Estados Unidos. Os efeitos dos choques de corte de impostos e aumentos de gastos se reduzem com o passar do tempo. Não são observados efeitos positivos dos choques de gastos sobre a taxa real e nominal de juros no período anterior a 1980. Finalmente, os efeitos da política fiscal sobre os preços dependem da elasticidade-preço das receitas e dos gastos do governo, de tal forma que os efeitos positivos dos gastos do governo frequentemente permanecem pequenos e pouco significantes.

\footnotetext{
${ }^{2}$ Conforme apontado por Perotti (2007), a forma reduzida aponta três componentes. Primeiro, os estabilizadores automáticos, isto quer dizer, respostas automáticas dos gastos do governo e dos impostos em relação ao produto (ou inflação e taxa de juros, se estas forem adicionadas ao modelo); segundo, a resposta da política fiscal discricionária, inovações em outras variáveis endógenas; e por fim, respostas aleatórias a choques de política fiscal discricionária.
} 
Vários trabalhos utilizam a abordagem de Blanchard e Perotti (2002) para analisar os efeitos da política fiscal em outras economias que não a americana: Alemanha (Heppke-Falk et al. (2006)), Itália (Giordano et al. (2007)), Espanha (Castro e de Cos (2008)), países da Zona do Euro (Burriel et al. (2010)) e Croácia (Ravnik e Zilic (2011)). ${ }^{3}$

Os principais resultados obtidos indicam que os efeitos da política fiscal são mais fortes no curto prazo, desaparecendo depois de alguns trimestres. De maneira geral, choques positivos na despesa pública aumentam o produto no curto prazo, mas com pouco efeito ao longo dos trimestres, enquanto que os choques de receitas têm pouco efeito sobre a produção. Desta forma, parece existir evidência de que os efeitos sobre a atividade econômica das elevações dos gastos do governo são maiores do que os efeitos de reduções de impostos. Para a Croácia, contudo, um choque positivo nos gastos diminui o produto como resultado do efeito crowding out sobre o investimento privado. Aumentos de gastos públicos geram ainda aumentos na inflação. Para a Alemanha e a Itália, não são encontrados efeitos significativos da política fiscal sobre as taxas de juros, enquanto que para a Espanha e a Croácia os aumentos de gastos do governo aumentam a taxa de juros e os aumentos de impostos reduzem a taxa de juros.

Favero e Giavazzi (2007) incorporam na abordagem Blanchard-Perotti uma equação para dinâmica da dívida pública dos Estados Unidos. Os autores argumentam que os choques fiscais podem ser enviesados caso a dívida pública seja omitida nas equações de gastos e receitas do VAR e não se considere a evolução da dívida com base nas variáveis fiscais ${ }^{4}$. Os autores concluem que a dívida enfraquece os efeitos das alterações fiscais sobre o produto.

Mertens e Ravn (2011) propõem uma abordagem de VAR estrutural para os Estados Unidos em que os agentes usam os efeitos de antecipação de choques de gastos do governo. Os resultados indicam que tanto o consumo quanto a produção aumentam em resposta a um aumento permanente e inesperado nos gastos do governo. O resultado encontrado mais interessante é um crescimento no consumo após um aumento do gasto governo, mesmo este tendo sido previsto pelos agentes, o que destoa do estabelecido pela teoria econômica ${ }^{5}$.

\footnotetext{
${ }^{3}$ Todos esses trabalhos utilizam observações longas, de pelo menos 20 anos, em base trimestral (exceto o trabalho sobre a Croácia, que utiliza dados mensais devido à pequena quantidade de observações). A base de dados utilizada pelos autores basicamente foram PIB real, taxa de inflação, expressa pelo deflator do PIB, taxa de juros nominal de curto prazo, despesas real do governo e impostos líquidos do governo.

${ }^{4}$ Com exceção do trabalho feito para Espanha, que constata um aumento do déficit público no médio prazo provocado por uma política fiscal de estímulo à atividade econômica, nenhum dos outros trabalhos estuda os efeitos dos choques fiscais sobre a dívida pública.

${ }^{5}$ Beestma (2008) ressalta uma dificuldade com a abordagem do VAR. No caso de eventos fiscais, estes podem ser antecipados, antes mesmo de serem computados. Tal antecipação pode provocar um comportamento no setor privado antes do evento. Por exemplo, o governo anuncia, com antecedência, um aumento nas despesas. Logo
} 


\subsubsection{A abordagem de restrições de sinais}

A terceira abordagem impõe restrições no formato das funções de resposta a impulso, seguindo a metodologia proposta inicialmente por Uhlig (2005) para identificar choques de política monetária, conhecida como VAR com restrição de sinais.

Mountford e Uhlig (2009) utilizam o método de Uhlig (2005), para avaliar os efeitos dos choques de política fiscal para a economia americana. Eles definem três tipos de choques: i) um choque de ciclo de negócio que move conjuntamente produto, consumo, investimento não residencial, e receitas do governo; ii) um choque de política monetária ortogonal ao choque de ciclo de negócio que move as taxas de juros para cima e as reservas e preços para baixo; iii) os choques de política fiscal, ortogonais aos choques de política monetária e de ciclo de negócios, compostos por choques de gastos e choques de receitas do governo.

Os principais resultados obtidos apontam que os choques de gastos do governo têm pouco efeito sobre o produto e provocam efeitos crowding out no investimento. O maior efeito no produto ocorre devido ao choque de redução de receitas. O multiplicador de impostos é maior do que o encontrado por Blanchard e Perotti (2002), enquanto o multiplicador de gastos é menor. Não são encontrados movimentos significantes no consumo e a política monetária não é essencial para estimar a dinâmica da política fiscal.

Canova e Pappa (2007) estudam os efeitos fiscais em 47 estados americanos e nove países da União Europeia. Um choque de gastos é identificado impondo uma correlação positiva entre gasto e déficit, e uma correlação positiva entre gasto e produto. São identificados dois tipos de choques de despesas. Os primeiros, financiados pela criação de títulos, produzem movimentos positivos nas despesas regionais, no produto e no déficit. Os segundos, financiados por distorção na tributação, não alteram o déficit, mas produzem movimentos negativos nas despesas e no produto. A política fiscal gera ainda efeitos modestos, mas significantes sobre a dispersão de preços. Os choques fiscais expansionistas, quando financiados via déficit, aumentam os diferenciais de preços, enquanto que os choques fiscais com orçamentos equilibrados diminuem a dispersão de preços. Assim, caso diferenças de preços regionais seja uma preocupação, seria indicada a imposição de limites para o tamanho da política fiscal regional.

Pappa (2009) concentra sua avaliação na análise de choques de gastos, buscando encontrar o melhor modelo de equilíbrio geral capaz de explicar a dinâmica das variáveis do

após o anúncio, o efeito riqueza negativo provoca uma redução do consumo. Após cair, o consumo começa a subir. Para o pesquisador, o problema pode ocorrer com uma inferência equivocada, pois no instante do anúncio da política, os dados ainda não estão disponíveis. 
mercado de trabalho em resposta aos choques de política fiscal. Ela caracteriza um conjunto de restrições, tanto no modelo de ciclos econômicos reais quanto no novo modelo Keynesiano, para 48 estados americanos. De maneira geral, encontra evidência de que os choques de gastos provocam aumentos nos salários reais e no emprego total, indicando que os modelos com rigidez de preços explicariam melhor a dinâmica do mercado de trabalho.

\subsubsection{Abordagem narrativa}

$\mathrm{Na}$ abordagem narrativa, procura-se evitar o problema de identificação que caracteriza a análise VAR utilizando episódios fiscais que podem ser considerados exógenos ao estado da economia.

Ramey e Shapiro (1998) estudam a reação da economia dos Estados Unidos a aumentos expressivos nos gastos militares resultantes de guerras e ameaças de guerras. Para isto, utilizam três períodos em que os Estados Unidos aumentaram o armamento de seu exército: a Guerra da Coréia, a Guerra do Vietnã e a expansão fiscal de Reagan ${ }^{6}$. Estes eventos são tratados como aumentos exógenos nos gastos do governo. Os resultados mostram grandes aumentos nos gastos do governo com defesa, por outro lado, forte queda nos gastos não relacionados a este fator. O produto total cresce, no entanto, o PIB privado primeiramente sobe, mas logo em seguida cai. O investimento não residencial, por outro lado, apresenta forte aumento, enquanto o investimento residencial cai. No que diz respeito a mudanças em setores específicos, o consumo de bens duráveis aumenta inicialmente e posteriormente cai, enquanto o consumo de bens não duráveis e serviços cai. Por fim, mudanças setoriais podem provocar alterações no emprego e divergências nos salários pagos entre setores.

Edelberg, Eichenbaum e Fisher (1999) utilizam essa "abordagem narrativa" para estimar os efeitos dos gastos do governo sobre a economia norte-americana. No modelo base deles, é utilizado o que se denomina como "episódios Ramey-Shapiro", além de dummies, que correspondem a eventos políticos que levaram a importantes gastos militares. Os resultados foram muito semelhantes aos originais. Um aumento inesperado nas despesas do governo leva a aumentos no emprego, produção e investimento não residencial; quedas nos salários reais e no investimento residencial, e quedas, após pequeno atraso, no consumo de bens duráveis, não duráveis e serviços.

Burnside, Eichenbaum e Fisher (2004) estendem o trabalho de Edelberg, Eichenbaum e Fisher (1999) ao permitir respostas econômicas diferentes das dummies que caracterizam os

\footnotetext{
${ }^{6}$ Estes eventos são chamados na literatura de "episódios Ramey-Shapiro".
} 
episódios Ramey-Shapiro. Os autores permitem movimentos nas compras do governo, e também, nos impostos sobre o trabalho e sobre o capital. Os resultados encontrados indicam que os choques de política fiscal são seguidos por reduções persistentes nos salários reais e aumentos nos impostos sobre o trabalho, gastos do governo e horas trabalhadas. Os aumentos no investimento são de curto prazo e os movimentos no consumo privado são pequenos.

Conforme ressaltado por Perotti (2005), a abordagem narrativa tem a vantagem de não requerer a introdução de outra identificação (e eventualmente premissas arbitrárias). No entanto, fornece uma representação nítida do que acontece após um choque de gastos (com defesa) somente se os episódios Ramey-Shapiro forem de fato exógenos e se a economia não for atingida por outros choques importantes na mesma época em que ocorrem os choques de gastos. Além disso, as análises ficam restritas a choques de gastos com defesa, com o que não podem responder a outras questões relevantes sobre os efeitos dinâmicos de outros choques fiscais, tais como choques nos impostos ou choques em outros gastos que não defesa.

Ramey (2011b) vai além dos episódios Ramey-Shapiro e constrói uma nova medida da variável notícia sobre gastos militares que mede a variação no valor presente líquido esperado dos gastos militares futuros baseada em relatos de jornais. Além dos três eventos iniciais de Ramey e Shapiro (1998), Ramey (2011b) acrescenta os ataques terroristas de 11 de setembro. Ela encontra evidência de que os gastos com defesa explicam quase toda a volatilidade dos gastos do governo e que estes dois gastos juntos podem ser antecipados. Os choques no VAR padrão, por sua vez, não revelam notícias sobre os gastos com defesa com precisão. Já os episódios Ramey-Shapiro Granger-causam choques no VAR.

Romer e Romer (2010) avaliam as causas e as consequências das mudanças no nível de impostos nos Estados Unidos no período pós-guerra. Os autores constroem uma série de mudanças exógenas de impostos a partir de relatórios parlamentares. Com isto, conseguem identificar o tamanho, o tempo e a motivação para todas as principais ações de política fiscal durante o período estudado. Os resultados encontrados assinalam para grandes efeitos sobre o produto, causadas por alterações fiscais. Os autores encontram que aumento de impostos de um por cento do PIB reduzem o PIB real em cerca de três por cento.

Finalmente, Mertens e Ravn (2014) sugerem supor uma série baseada na evidência narrativa como uma dimensão do ruído do verdadeiro choque fiscal não observado, por meio da associação dos choques não antecipados sobre a receita total. Para isto, eles combinam o modelo VAR estrutural padrão com a identificação narrativa. A hipótese-chave para identificação é a de que os choques fiscais se correlacionam com as medidas narrativas, porém são ortogonais em relação a outros choques estruturais. Os resultados encontrados 
mostram que os multiplicadores fiscais de impacto são ao redor de dois e chegam até três, após seis trimestres.

Mais recentemente, alguns autores passaram a utilizar a metodologia de painel com VAR para avaliar os impactos da política fiscal.

Ilzetzki, Mendoza e Vegh (2013) utilizam um painel com VAR estrutural, Beestima e Giuliodori (2011) usam o VAR com decomposição de Cholesky e Corsetti et al. (2012).

Ilzetzki, Mendoza e Vegh (2013) avaliam um painel composto de 44 países, 20 de alta renda e os demais em desenvolvimento, entre os anos de 1960 e 2007, a partir de um VAR estrutural. Encontram os seguintes resultados principais: o grau de desenvolvimento do país é um fator determinante para o tamanho do multiplicador, quanto mais desenvolvido for o país, maior será o multiplicador; os países que adotam regimes cambiais flexíveis possuem multiplicadores menores e até mesmo negativos, em comparação com os que adotam regimes cambiais pré-determinados; a abertura comercial também é outro fator determinante do tamanho do multiplicador, pois países mais fechados ao comércio internacional possuem multiplicadores de longo prazo próximos de um, enquanto países mais abertos têm multiplicadores negativos; países com elevada dívida do governo central apresentam multiplicadores negativos no longo prazo; multiplicadores relacionados ao gasto com investimento do governo em países em desenvolvimento são positivos e maiores do que um no longo prazo e maiores do que o multiplicador de consumo do governo.

Beestima e Giuliodori (2011), por sua vez, avaliam um painel composto por países da União Europeia a partir de um VAR com decomposição de Cholesky. Encontram evidência de um efeito positivo do aumento de gastos sobre o produto, com multiplicador na média, maior do que um. Os efeitos sobre os setores externos indicam valorização da taxa real de câmbio e deterioração da balança comercial, com aumento das importações e redução das exportações. Por fim, há uma elevação do déficit público e nos componentes privados do produto (consumo e investimento) após as inovações de gastos dos governos.

Com o uso de dados em painel para averiguar os efeitos não lineares da política fiscal para uma amostra de 17 países da OCDE, Corsetti et al. (2012), a depender do regime de taxa de câmbio, o nível da dívida pública e do déficit e a presença de crises financeiras. Os autores fazem uma análise em duas etapas. Na primeira, fazem regressões individuais para cada um dos países dos gastos do governo em seus determinantes e obtêm estimativas dos choques estruturais dos gastos do governo. Na segunda, estimam multiplicadores fiscais a partir de um painel com variáveis macroeconômicas e interações de variáveis dummy regime cambial, situação das finanças públicas e crises financeiras com os choques estruturais. Os resultados 
evidenciam que os multiplicadores são maiores em países com regime de câmbio fixo, finanças públicas em ordem e sofrendo crises financeiras.

\subsubsection{Evidências para o Brasil}

Como ressaltado anteriormente, a literatura sobre multiplicadores fiscais para o Brasil é bastante escassa.

Usando a abordagem Blanchard-Perotti, Peres (2007) descreve os efeitos dinâmicos da política fiscal sobre a atividade econômica brasileira depois do Plano Real ${ }^{7}$. A política fiscal apresenta efeitos keynesianos, com multiplicadores de gastos positivos e de receitas negativos. E também, e os multiplicadores de gastos são maiores do que os de impostos. Os efeitos dos choques fiscais sobre o produto são pequenos e pouco persistentes. Os choques de investimentos possuem efeitos mais duradouros e mais eficientes do que os choques no consumo.

Mendonça, Medrano e Sachsida (2009) seguem de perto o artigo de Mountford e Uhlig (2009) para distinguir os choques fiscais. O produto se reduz em resposta a uma inovação positiva nos gastos do governo, o consumo privado sobe, mas o investimento sofre efeito crowding out e cai. $\mathrm{O}$ aumento inesperado das receitas do governo também reduz o produto no curto prazo, entretanto o efeito torna-se positivo no longo prazo, talvez pelos agentes enxergarem este aumento como um sinal de que o governo controla o déficit público.

Cavalcanti e Silva (2010) se baseiam no trabalho de Favero e Giavazzi (2007) e incorporaram na análise a dinâmica da dívida pública, de forma a comparar as funções impulso resposta com e sem a presença da evolução da dívida. Quando a dívida não faz parte do VAR, o produto tem resposta positiva a inovações de gastos positivos, mas quando a dívida é incorporada ao VAR, a resposta do produto é próxima de zero. Os efeitos das receitas tributárias, por sua vez, são pouco significantes. Quando a dívida está ausente, o resultado sobre o produto tem sinal esperado; quando a evolução da dívida é incorporada, o efeito dos choques de receita é nulo.

Matheson e Pereira (2016) estimam o multiplicador tanto do gasto público quanto do crédito público, majoritariamente do $\mathrm{BNDES}^{8}$. Em termos gerais, os multiplicadores tanto do gasto do governo quanto dos créditos públicos são iguais, próximos aos observados em outros

\footnotetext{
${ }^{7}$ Em Peres e Ellery (2009) também adaptam a metodologia Blanchard-Perotti e encontram resultados similares. ${ }^{8}$ Os empréstimos dos bancos públicos cresceram fortemente, principalmente após a crise financeira internacional e durante o governo Dilma Roussef. As transferências via BNDES foram o quantitative easing "em terras tropicais".
} 
países emergentes, mas menores do que os observados em países desenvolvidos. Além disso, os efeitos são maiores no curto prazo, desaparecendo após oito trimestres.

No trabalho mais recente para o Brasil, utilizando metodologia do VAR estrutural e do VAR com restrição de sinal, Holland, Marçal e Mendonça (2017) estudam os efeitos dos multiplicadores de gastos do governo sobre o produto, utilizando duas especificações distintas. Uma primeira, com três variáveis, produto, impostos e gastos do governo, e a segunda em que os autores acrescentam taxa de juros e inflação ao modelo. $\mathrm{O}$ artigo encontra multiplicadores de gastos pequenos, similar aos demais trabalhos aplicados ao país, e os resultados são robustos a outras especificações do modelo.

A tabela a seguir apresenta um resumo dos multiplicadores de gastos do governo, encontrados no Brasil, utilizando a metodologia dos modelos linear.

Tabela 1 - Multiplicadores Fiscais para o Brasil - Modelo

\begin{tabular}{cccc}
\multicolumn{4}{c}{ Linear } \\
\hline \hline Estudo & Metodologia & Amostra & $\begin{array}{c}\text { Multiplicador } \\
\text { Fiscal } \\
\text { 4timestres }\end{array}$ \\
\hline Peres (2007) & $\begin{array}{c}\text { VAR } \\
\text { Estrutural }\end{array}$ & $1995: 1-2004: 4$ & $-0,0013$ \\
\hline $\begin{array}{c}\text { Mendonça, } \\
\text { Medrano } \\
\text { e Sachsida } \\
\text { (2009) }\end{array}$ & $\begin{array}{c}\text { Restrição de } \\
\text { Sinal }\end{array}$ & $1995: 1-2008: 4$ & $\begin{array}{c}77,1 \% \text { de chance } \\
\text { do PIB contrair }\end{array}$ \\
\hline $\begin{array}{c}\text { Cavalcanti e } \\
\text { Silva (2010) }\end{array}$ & VAR & $1995: 1-2008: 4$ & 0 \\
\hline $\begin{array}{c}\text { Matheson e } \\
\text { Pereira (2016) }\end{array}$ & $\begin{array}{c}\text { Decomposição } \\
\text { de Cholesky }\end{array}$ & $1999: 2014$ & Entre 0 e 0,5 \\
\hline $\begin{array}{c}\text { Holland, Marçal } \\
\text { e Mendonça } \\
(2017)\end{array}$ & $\begin{array}{c}\text { VAR Estrutural } \\
\text { e Restrição de } \\
\text { Sinal }\end{array}$ & $1997: 2014$ & 0,36 \\
\hline \hline
\end{tabular}

Fonte: Elaboração Própria.

Nota: São os multiplicadores de gastos do governo, nos trabalhos empíricos aplicados ao Brasil.

\subsection{Multiplicadores fiscais: modelos não lineares}

Mais recentemente a literatura empírica que avalia os efeitos de choques de política fiscal tem se concentrado em investigar a dependência dos multiplicadores fiscais ao estado 
do ciclo econômico. Assim, os multiplicadores fiscais são diferenciados entre as recessões e expansões da economia ${ }^{9}$.

A fim de obter multiplicadores dependentes do estado do ciclo em geral são utilizadas as seguintes metodologias econométricas (Warmedinger, Westphal e Cos (2015)):

\subsubsection{VAR com parâmetros variáveis no tempo com volatilidade estocástica}

Kirchner, Cimadomo e Hauptmeier (2010) avaliam os efeitos de choques fiscais nos países da Zona do Euro. As estimativas com parâmetros fixos no tempo revelam que os choques de gastos do governo têm efeitos de curto prazo expansionistas sobre o produto e seus componentes, porém no longo prazo seu impacto é moderado ou mesmo negativo. A abordagem variável no tempo produz multiplicadores de gastos do governo sobre o PIB real e o consumo privado, que diminuem com o passar dos anos. Os multiplicadores de longo prazo perdem efeito. A eficácia da política fiscal em estimular a atividade econômica tornou-se especialmente fraca no período mais recente.

Trabalho similar foi feito por Pereira e Lopes (2010) para a economia americana entre 1965 e 2009. Os autores constatam que os efeitos dos impostos líquidos sobre o produto sofrem uma queda a partir da década de 1970, apresentando novo enfraquecimento nos anos 2000. Já os efeitos das despesas do governo diminuem de intensidade de forma suave ao longo do período da amostra.

\subsubsection{Thershold VAR (TVAR)}

Para avaliar os multiplicadores fiscais na Alemanha, Baum e Koester (2011) utilizam a metodologia TVAR, empregando a mesma especificação de Blanchard-Perotti e utilizando o hiato do produto como variável limiar. Encontram evidência de que o estado do ciclo de negócios importa para o efeito de choques fiscais. Os multiplicadores de gastos são maiores

\footnotetext{
${ }^{9}$ Diversos trabalhos recorrem a modelos VAR ou modelos DSGE para definir agregados fiscais e estimá-los, com a intenção de responder qual é o multiplicador de gastos do governo ou de impostos (como pode ser visto em Ramey (2011a)). Embora, conforme argumenta Parker (2011), quantificar os multiplicadores através destes modelos, pode apresentar dois problemas. O primeiro inconveniente refere-se ao fato de que o multiplicador é independente da conjuntura econômica, ou seja, quando a economia está em recessão ou quando está em boom, a política fiscal é eficiente. Pela construção do modelo, a resposta ao impulso proveniente de um choque fiscal inesperado e exógeno é independente do estado do ciclo econômico. Dessa forma, tanto o VAR, quanto os modelos DSGE padecem do mesmo problema, o multiplicador é independente da conjuntura econômica. Com relação ao segundo problema, o modelo linear não permite que o multiplicador seja dependente do tamanho do estímulo. O multiplicador marginal e o total devem divergir, sendo que o primeiro é menor, mas os estudos econométricos estimam os efeitos marginais.
} 
em tempos de hiato do produto negativo (recessões), mas, com efeito, muito limitado quando o hiato do produto é positivo.

Baum, Poplawski-Ribeiro e Weber (2012) analisam seis países do G7 (exceto a Itália), utilizando tanto o hiato do produto quanto o crescimento do PIB como variáveis limiar. Concluem que a posição do ciclo de negócios afeta o impacto da política fiscal sobre o produto. Os multiplicadores fiscais tendem a serem maiores nas recessões do que nas expansões, independentemente da variável utilizada para definir o limiar. Os autores argumentam que as descobertas sobre o impacto da política fiscal sobre o produto, a depender do estado do ciclo econômico, têm importantes consequências na escolha do tipo de ajuste fiscal. No regime de recessão econômica, no momento em que choque fiscal é implementado, um choque fiscal negativo antecipado terá um impacto maior sobre o produto, no curto prazo, do que um ajuste gradual.

Batini, Callegari e Melina (2012) utilizam o crescimento do PIB como variável limiar para estudar os efeitos dos multiplicadores nos Estados Unidos, Japão e Zona do Euro. Eles também incluíram no modelo a taxa de juros a fim de verificar a influência da política monetária sobre o produto. Os multiplicadores das despesas fiscais são significativamente maiores nas crises do que em períodos de retomada do crescimento; a probabilidade de que uma consolidação fiscal iniciada em uma recessão se aprofunde ou prolongue a crise é quase duas vezes maior do que a probabilidade de uma consolidação começar em uma recuperação; a implementação de consolidações orçamentárias em períodos de crescimento positivo do produto reduz significativamente o impacto sobre o produto; e medidas que melhoram a credibilidade e durabilidade das consolidações fiscais podem aumentar os efeitos positivos de confiança, aliviando o custo de consolidações futuras.

Mittinik e Semmeler (2012) estimam um modelo threshold bivariado (emprego e produto) para os Estados Unidos; em que a variável limiar é a taxa de crescimento do produto. Mais uma vez os multiplicadores fiscais são maiores no regime de baixa atividade econômica do que no regime de alta atividade econômica.

Poirier (2014) constrói um modelo TVAR para investigar os efeitos da política fiscal em Portugal usando como variável limiar o hiato do produto. O multiplicador dos gastos do governo é maior em períodos de recessão do que em períodos de expansão. Além disso, os multiplicadores de receita são menores do que os multiplicadores de gastos.

Fazzari, Morley e Panovska (2015) utilizam um modelo vetorial autorregressivo estrutural com limiar para avaliar os efeitos dos gastos do governo sobre o produto nos Estados Unidos. São testadas diferentes opções para variável threshold, como nível da 
capacidade instalada, hiato do produto, crescimento do emprego. A variável utilização da capacidade instalada parece como a melhor para captar períodos de recessão econômica. Aumentos nas compras do governo geram efeitos positivos grandes e persistentes sobre o produto quando a economia está operando com baixa utilização da capacidade. ${ }^{10}$

\subsubsection{Smooth transition VAR (STVAR)}

Auerbach e Gorodnichenko (2012) encontram evidências de que nos Estados Unidos políticas que aumentam os gastos possuem efeitos maiores em estimular atividade econômica em períodos de recessões do que em períodos de expansões. Em períodos de recessão os multiplicadores dos gastos são de cerca de 1,5 a 2, enquanto nos períodos de expansão esses multiplicadores são aproximadamente zero. Ao estimar os multiplicadores para variáveis desagregadas da despesa do governo, encontram que o maior multiplicador refere-se aos gastos militares. Mostram ainda que controlando por previsões em tempo real as variáveis fiscais, nos períodos de recessão, os multiplicadores tendem a serem maiores.

Cos e Moral-Benito (2016) empregam a metodologia de Auerbach e Gorodnichenko (2012) para mensurar os multiplicadores fiscais na Espanha. Eles adotam três critérios para definir os regimes: recessão/expansão, situação das finanças públicas e saúde do setor bancário. O multiplicador pode ficar acima de 1 quando a economia espanhola está em recessão. No entanto, o multiplicador de gastos pode ser menor do que um ou negativo quando há problemas nas finanças públicas. Em situações de restrições de liquidez, provenientes de estresses no setor financeiro, o multiplicador de gastos aumenta, podendo ser até maior do que um.

\footnotetext{
${ }^{10}$ Alguns trabalhos utilizam a metodologia de threshold VAR para examinar os efeitos da política fiscal em tempos de estresse financeiro. Afonso, Baxa e Slavik (2011) encontram para os Estados Unidos, Reino Unido, Alemanha e Itália que: o modelo não linear tendo como variável limiar um indicador de estresse financeiro é adequado; as respostas do PIB a um choque fiscal são na sua maioria positivas em ambos os regimes de estresse financeiro; a não linearidade na resposta do PIB a um choque fiscal está associada principalmente com o comportamento diferente através de regimes; e o tamanho dos multiplicadores fiscais evoluiu ao longo do tempo e é maior do que a média durante a crise em todos os países, exceto no Reino Unido. Ferraresi, Roventini e Fagiolo (2015) supõem que a política fiscal nos Estados Unidos é mais bem sucedida para estimular a atividade econômica quando as condições no mercado de crédito são mais apertadas (as empresas encontram mais dificuldades em tomar crédito para financiar investimento). Nestas condições, políticas fiscais expansionistas são preferíveis para restaurar o crescimento econômico e para estabilizar os mercados de crédito. Encontra evidência de existência de não linearidade no caso brasileiro. Tanto a renda privada quanto o produto mostram respostas positivas a choques fiscais nos dois regimes, sendo os efeitos maiores nos períodos de restrição de liquidez.
} 
Para economia grega, Monokroussos e Thomakos (2012) empregam modelos estruturais SVAR para estimar os multiplicadores fiscais de gastos do governo e modelos STVAR para avaliar a dependência dos efeitos da política fiscal à conjuntura econômica. Os modelos SVAR indicam multiplicadores positivos, mas menores do que um. Os modelos STVAR, baseados em Auerbach e Gorodnichenko (2012) implicam multiplicadores elevados (maiores do que um) quando a economia grega está em recessão e multiplicadores negativos e insignificantes em períodos de expansão.

Vale aqui destacar ainda dois trabalhos que são relevantes para entender a transmissão das mudanças da política fiscal sobre a atividade econômica. O primeiro se refere à questão da confiança como um meio pelo qual um choque de gastos do governo pode afetar a atividade econômica. Neste sentido, o artigo de Bachmann e Sims (2012) estima um modelo VAR com uma medida de gasto do governo, uma medida empírica da confiança do consumidor e o produto. A principal descoberta deste artigo é que a resposta endógena da medida de confiança do consumidor explica quase todo o estímulo do produto, em períodos de recessão, enquanto que seu papel é menor em períodos normais.

Caggiano et al. (2015) incluem na análise uma medida de notícias fiscais, isto é feito abordando a antecipação dos choques fiscais por meio previsões fiscais e somas das revisões das expectativas dos gastos fiscais. A antecipação dos choques fiscais parece promover uma reação significativa sobre o produto, mas esta reação não varia entre os estados da economia (recessão e expansão). Os multiplicadores fiscais em recessão são maiores que um, e os choques de gastos em contração diminuem as chances de a econômica permanecer em recessão.

\subsubsection{Projeção de Jordà}

Mais recentemente, alguns artigos utilizam o método de projeção local de Jordà (2005) para identificar os choques de gastos do governo. A vantagem deste método é permitir estimar as funções de resposta a impulso projetando diretamente uma variável de interesse sobre as defasagens das variáveis que normalmente entram em um $\mathrm{VAR}^{11}$.

Auerbach e Gorodnichenko (2013) estendem seu primeiro artigo estimando os multiplicadores para os países da OCDE, utilizando observações reais e dados de previsão. Os autores são os pioneiros em estimar as funções respostas ao impulso utilizando o método de projeção de Jordà (2005). Os resultados corroboram os encontrados anteriormente: os

\footnotetext{
${ }^{11}$ Este método evita as restrições presentes na análise VAR, além de acomodar facilmente as não linearidades.
} 
multiplicadores de gastos do governo são maiores em recessão e quando as despesas do governo são controladas por previsões reais.

Para investigar se os multiplicadores de gastos do governo nos Estados Unidos e no Canadá são maiores durante períodos de recessão econômica, Owyang, Ramey e Zubairy (2013) utilizam como variável threshold a taxa de desemprego. Os resultados apontam que para os Estados Unidos não há multiplicadores mais elevados em períodos de taxa de desemprego elevada (acima do limiar), porém para o Canadá os multiplicadores são maiores em períodos de crise.

Riera-Crichton, Vegh e Vuletin (2015) avaliam a questão da assimetria dos efeitos da política fiscal na OCDE, em que um aumento dos gastos do governo quando a economia está em pleno emprego não deveria ter o mesmo efeito quando há reduções. Os multiplicadores são computados durante períodos de booms e de recessões extremas. Além disso, são consideradas situações em que os gastos do governo estão ora subindo, ora descendo. Os autores concluem que quando a economia se encontra em uma recessão típica o multiplicador de gastos é maior do que quando está em recessão extrema. O que levanta a questão sobre o debate na Zona do Euro, de que os resultados aqui encontrados sugerem que o remédio pode ser pior do que a doença, no sentido que a razão dívida/PIB poderia de fato aumentar, no momento do impacto fiscal, como resultado de uma política de consolidação fiscal.

Ramey e Zubairy (2017) classificam a economia americana de duas formas: (i) quando está em recessão, definida por uma taxa de desemprego abaixo de um limiar e (ii) quando as taxas de juros estão próximas de zero. Não encontram evidências de que os multiplicadores são maiores nem quando a economia está em recessão e nem quando a taxa de juros está próxima de zero.

Ramey e Zubairy (2015) utilizam a projeção de Jordà (2005) para estudar os efeitos dos gastos do governo sobre a economia canadense. A variável utilizada para medir os choques fiscais são os gastos militares. No caso em que não há distinção entre os regimes, o multiplicador de gastos do governo é igual a 0,5 . No caso não linear, em que a recessão é definida por uma taxa de desemprego acima de determinado threshold, o multiplicador é maior do que 1 , enquanto que nos períodos de baixa taxa de desemprego, o multiplicador é menor do que 0,5 .

Biolsi (2017) emprega as abordagens narrativas de Ramey e Zubairy (2017), para despesas com militares, e Romer e Romer (2010) para impostos, para estimar os multiplicadores fiscais. $\mathrm{O}$ autor permite que a variável threshold, taxa de desemprego, varie para definir quais são os períodos em que a economia dos EUA está em boom ou em recessão. 
Os resultados mostraram que o aumento da taxa de desemprego, nos períodos de recessão levaram os multiplicadores de gastos maiores, embora não significativamente maiores do que um e com relação aos multiplicadores de impostos, o autor argumenta que os resultados foram não precisos, devido ao problema com o instrumento, utilizado para ser o choque de impostos.

Belinga e Ngouana (2015) examinam como o estado da política monetária influencia a resposta do produto a choques de gastos do governo. Os choques fiscais são identificados por meio dos erros de previsão da taxa de crescimento dos gastos do governo. O multiplicador de gastos do governo aparece maior quando a política monetária é acomodatícia (3,96 após oito trimestres) do que quando ela é não acomodatícia (-1,97 após oito trimestres). Além disso, o efeito sobre o consumo privado pode depender do quanto à política monetária é acomodatícia.

Miyamoto, Nguyen e Sergeyev (2017) estudam os efeitos dos choques fiscais no Japão, em períodos em que a taxa de juros nominal está próxima de zero. Nos períodos normais, o multiplicador fiscal de impacto é 0,7 , ao passo que em tempos de armadilha da liquidez, o multiplicador é 1,5. Ao longo do tempo, o multiplicador aumenta para 2, quando a taxa de juros está próxima de zero e torna-se negativa nos demais períodos. Os autores também estudam os efeitos dos choques fiscais sobre as demais variáveis. O multiplicador do consumo é positivo em períodos de taxa de juros próxima de zero e negativo nos demais períodos, ao passo que o multiplicador do investimento é positivo em ambos os períodos. A taxa de desemprego diminui nos trimestres de baixas taxas de juros nominais e não responde muito nos períodos normais.

ÇEBI e Ozdemir (2016), do banco central da Turquia, investigam os efeitos das variações cíclicas dos gastos do governo. Os autores estimam as variações dos multiplicadores fiscais, sob dois regimes diferentes: de alto e baixo crescimento do PIB. Os autores observam que os multiplicadores de investimento público tendem a ter efeitos mais persistentes e maiores sobre o produto do que os multiplicadores de consumo do governo.

\subsubsection{Evidências para o Brasil}

A literatura sobre multiplicadores fiscais no Brasil, utilizando modelos não lineares, é um grande desafio, pois, conforme Gobetti, Orair e Siqueira (2016), estes modelos demandam mais dos dados, além disso, no país há uma escassez de dados sobre séries de finanças públicas. A seguir, os poucos trabalhos aplicados para o Brasil, utilizando metodologias empíricas capazes de captar os efeitos não lineares da política fiscal. 
Os dois primeiros trabalhos, Pires (2014) e Castelo-Branco, Lima e Paula (2015), utilizam um modelo VAR com mudança de regime (Markov Switching). Pires (2014) avalia os multiplicadores fiscais do consumo do governo, investimento público e da carga tributária líquida, por meio deste modelo de mudança de regime, o qual é capaz de captar os efeitos dos ciclos econômicos e de períodos de alta e baixa volatilidade. Os resultados mostram que os multiplicadores são mais significativos em períodos de baixa volatilidade, o multiplicador da carga tributária é significativo e negativo, o do investimento público é maior do que um; por outro lado, o multiplicador do consumo do governo não foi significativo.

Castelo-Branco, Lima e Paula (2015) também usam um modelo Markov Switching, com VAR bayesiano para também estudar os multiplicadores do consumo da administração pública, investimento público e da carga tributária líquida. Encontram resultados similares ao de Pires (2014), choques do investimento público provocam maiores efeitos sobre o produto.

Para o Brasil, Siqueira (2015) emprega a metodologia de vetores autorregressivos não lineares, seguindo Auerbach e Gorodnichenko (2012), em que a economia transita entre dois regimes, baseado se o ano em vigor é ou não um ano que tem eleição. O objetivo do trabalho foi fazer uma análise empírica da política fiscal juntamente com elementos de ciclo político. Para a política fiscal, ele utilizou a variável investimento público. Os resultados indicam que o investimento público estimula o produto, porém contrai o investimento privado, isto independente do ciclo político. Além disso, o autor encontra que os investimentos públicos são altamente influenciados pelo calendário eleitoral.

O trabalho premiado Gobetti, Orair e Siqueira (2016) utiliza também a metodologia de vetores autorregressivos não lineares, seguindo Auerbach e Gorodnichenko (2012) e se destaca por dois fatores. Primeiro, pela construção de uma base com frequência mensal para o conjunto da administração pública, entre 2002 e 2016; e segundo, a estimativa de multiplicadores fiscais para os diferentes tipos de gastos do governo. Os resultados encontrados confirmam as evidências da literatura internacional, os multiplicadores fiscais divergirem de acordo com o ciclo econômico. Em períodos de recessão, as respostas do produto são mais intensas (maiores do que um) para os seguintes tipos de choques de gastos do governo: aquisições de ativos fixos, benefícios social e pessoal, porém, nas expansões, os choques dessas mesmas despesas não são significativos. Por outro lado, o comportamento das respostas do produto aos choques dos subsídios e das demais despesas evidenciou-se não ser significativas ou apresentaram apenas choques iniciais com baixa persistência, tanto no regime recessivo quanto no regime expansivo. 
Holland, Marçal e Mendonça (2017) estimam um threshold (TVAR) para o período 1997-2014, em que a variável limiar é a taxa de crescimento do produto. Ao contrário da literatura, encontram multiplicadores maiores no regime de alta taxa de crescimento embora não significativos. Os autores afirmam que a trajetória crescente da despesa primária e o alto nível do gasto como porcentagem do PIB contribuem para diminuir o efeito da política fiscal sobre o produto no Brasil.

Grüdtner e Aragon (2017) também utilizam o STVAR seguindo Caggiano et al. (2015), o qual incorpora as críticas feitas por Ramey e Zubairy (2017) ao trabalho de Auerbach e Gorodnichenko (2012). Os autores encontram que os multiplicadores de gastos do governo (consumo mais investimento do governo) não diferem entre os regimes de recessão e de expansão. Em contração econômica, após um choque de gastos do governo, o produto e os gastos aumentam, enquanto que em expansão, o choque de gastos não tem efeito sobre o produto e sobre o próprio gasto do governo.

A Tabela 2 a seguir mostra um resumo dos multiplicadores fiscais encontrados no Brasil, utilizando as metodologias de modelos não lineares.

Tabela 2 - Multiplicadores Fiscais para o Brasil - Modelo Não Linear

\begin{tabular}{|c|c|c|c|c|}
\hline Estudo & Metodologia & Amostra & $\begin{array}{l}\text { Variável } \\
\text { Fiscal }\end{array}$ & $\begin{array}{l}\text { Multiplicador } \\
\text { Fiscal }\end{array}$ \\
\hline \multirow{3}{*}{ Pires (2014) } & \multirow{3}{*}{$\begin{array}{l}\text { Markov } \\
\text { Switching }\end{array}$} & \multirow{3}{*}{$1996: 2-2012: 4$} & Consumo do Governo & $\begin{array}{c}\text { Não foi } \\
\text { significativo }\end{array}$ \\
\hline & & & Carga Tributária Líquida & entre $-0,2$ e $-0,3$ \\
\hline & & & Investimento Público & entre 1,4 e 1,7 \\
\hline \multirow{3}{*}{$\begin{array}{c}\text { Castelo-Branco, } \\
\text { Lima e Paula } \\
(2015)\end{array}$} & \multirow{3}{*}{$\begin{array}{l}\text { Markov } \\
\text { Switching }\end{array}$} & \multirow{3}{*}{ 1999:2012 } & Consumo do Governo & entre 0,45 e 0,60 \\
\hline & & & Carga Tributária Líquida & $-0,35$ \\
\hline & & & Investimento Público & entre 1,02 e 1,35 \\
\hline Siqueira (2015) & STVAR & 1995:2014 & Investimento Público & $\begin{array}{l}\text { Pré Eleitoral: 2,17 } \\
\text { Pós Eleitoral: }-2,54\end{array}$ \\
\hline $\begin{array}{c}\text { Gobetti, Orair } \\
\text { e Siqueira } \\
(2016) \\
\end{array}$ & STVAR & 2002:2016 & Despesa Primária & $\begin{array}{l}\text { Recessão: } 2,23 \\
\text { Expansão: } 0,15\end{array}$ \\
\hline $\begin{array}{c}\text { Holland, Marçal } \\
\text { e Mendonça } \\
\text { (2017) }\end{array}$ & TVAR & 1997:2014 & Despesa Primária & $\begin{array}{c}\text { Recessão: } 0,02 \\
\text { Expansão: } 0,082\end{array}$ \\
\hline $\begin{array}{c}\text { Grüdtner } \\
\text { e Aragon (2017) }\end{array}$ & STVAR & 1999:2015 & $\begin{array}{l}\text { Consumo mais } \\
\text { Investimento do } \\
\text { Governo }\end{array}$ & $\begin{array}{l}\text { Recessão: } 1,09 \\
\text { Expansão: } 0,47\end{array}$ \\
\hline
\end{tabular}

Fonte: Elaboração Própria 


\section{Metodologia Econométrica}

Para estimar as funções resposta ao impulso e os multiplicadores fiscais será utilizado o método de projeção local de Jordà (2005), aplicado inicialmente para calcular multiplicadores fiscais que dependem do estado da economia por Auerbach e Gorodnichenko (2013), e em seguida utilizado por Owyang, Ramey e Zubairy (2013) e Ramey e Zubairy (2017). O método de Projeção Local de Jordà (2005) projeta o valor da variável dependente deslocada $h$ períodos à frente, no conjunto de informações disponível no instante $t$. Deste modo, essas projeções são locais para cada horizonte.

O método de Projeção Local de Jordà (2005) simplesmente requer a estimação de uma série de regressões para cada horizonte $h$ para cada uma das variáveis de interesse, como por exemplo, o produto $^{12}$. Foi definido o uso de um horizonte $H=20$ trimestres. O modelo linear toma a seguinte forma:

$$
\tilde{X}_{\mathrm{t}+\mathrm{h}}=\alpha_{h}+\psi(L) \mathbf{z}_{t-1}+\beta_{h} \text { choque }_{t}+\varepsilon_{t+h}
$$

onde $\tilde{X}_{t+h}$ é a variável de interesse, representado por: PIB, gastos do governo, impostos, consumo, investimento, exportações e importações. $\mathrm{O}$ vetor $\mathbf{z}_{t-1}$ contém as variáveis de controle que usualmente compõem o "VAR fiscal", o log do produto real, o log dos gastos do governo reais e o $\log$ dos impostos reais. $\psi(L)$ é um polinômio do operador defasagem de ordem 1 e choque $_{t}$ é o choque fiscal identificado ${ }^{13}$. O choque fiscal é dado simplesmente pelos gastos do governo no instante $t$, uma vez que as variáveis de controle $\mathbf{z}$ incluem o produto, os gastos do governo e a carga tributária liquida defasados um período ${ }^{14}$. Usa-se, desta forma, o procedimento de Blanchard e Perotti (B-P) (2002) para identificar os choques fiscais ${ }^{15}$.

\footnotetext{
${ }^{12} \mathrm{O}$ método de projeção local não impõe que sejam usadas variáveis de controle na equação (1), caso o choque seja exógeno e não serialmente correlacionado. Entretanto, controles adicionais ajudam a reduzir a variância dos resíduos, tornando os erros padrão do $\beta_{h}$ menores. Por isso, foi adicionado $\psi(L) \mathbf{z}_{t-1}$.

${ }^{13}$ Outros trabalhos no Brasil também utilizaram apenas uma defasagem, como Mendonça, Medrano e Sachsida (2009) e Gobetti, Orair e Siqueira (2016).

${ }^{14}$ As outras estratégias de identificação não podem ser usadas no Brasil. A abordagem narrativa, que usa notícias sobre gastos futuros, como por exemplo, gastos de defesa, referentes a guerras como choques exógenos. Não há períodos de guerra no Brasil no período analisado, além de não ser uma despesa elevada e que pouco varia ao longo do tempo. Outro exemplo que impede o uso desta abordagem é o crescimento vegetativo dos gastos com benefícios sociais, que ano após ano, cresce. A segunda abordagem, por meio dos erros de previsões, também não é possível utilizar, pois a série de projeção de despesas do governo, feita pelo mercado financeiro, através do Prisma Fiscal, foi criada em 2014.

${ }^{15}$ Esta forma de identificar o choque fiscal é equivalente a usar o resíduo da projeção do log dos gastos do governo contra as defasagens dos gastos, dos impostos e do produto. As inovações desta projeção são análogos
} 
O parâmetro $\beta_{h}$ na equação (1) dá a resposta da variável $\tilde{X}$ no período $t+h$ ao choque no período $t$. Desta maneira é possível construir as funções resposta ao impulso como uma sequência das estimativas de $\left\{\beta_{h}\right\}_{h=0}^{t}$, obtida à partir de uma série de regressões individuais para cada horizonte.

O método de projeção local adapta facilmente as estimações para permitir dependência de estado. Para tanto, deve ser estimado um conjunto de regressões para cada horizonte $h$ :

$$
\begin{aligned}
\tilde{X}_{\mathrm{t}+\mathrm{h}}= & I_{\mathrm{t}-1}\left[\alpha_{h}^{R}+\psi(L) \mathbf{z}_{t-1}+\beta_{h}^{R} \text { choque }_{t}\right] \\
& +\left(1-I_{\mathrm{t}-1}\right)\left[\alpha_{h}^{E}+\psi(L) \mathbf{z}_{t-1}+\beta_{h}^{E} \text { choque }_{t}\right]+\varepsilon_{t+h}
\end{aligned}
$$

o parâmetro I é uma variável dummy que indica o estado da economia quando o choque ocorre e toma valores iguais a 1 quando está em recessão. É permitido a todos os coeficientes do modelo variar de acordo com o estado da economia. Além do mais, as estimativas de $\tilde{X}_{t+h}$ diferem de acordo com o regime da economia, no momento em que acontece o choque fiscal. A complicação associada ao método de Projeção Local de Jordà decorre da presença de correlação serial nos termos do erro induzidas pela derivação sucessiva da variável dependente. Será utilizada a correção de Newey-West (1987) para os erros padrões para lidar com a autocorrelação dos erros ${ }^{16}$.

O método das projeções locais tem inúmeras vantagens. Em primeiro lugar, a dependência de estado é facilmente acomodada e não há necessidade de impor restrições dinâmicas nas funções resposta ao impulso (FRI) inerente ao VAR. Pelo fato de que a resposta de cada variável endógena é estimada separadamente, isto permite economizar o número de parâmetros a serem fixados simultaneamente e, portanto, aumenta o número de graus de liberdade ${ }^{17}$. Contrariamente ao modelo VAR, o qual requer diversas variáveis e defasagens para controlar os efeitos dos choques não exógenos, e por isso a perda significativa de graus de liberdade, o método de Jordà tem apenas uma perda de observação a cada horizonte $h$.

\footnotetext{
as que seriam produzidas por um SVAR, no qual os choques são identificados por meio da decomposição de Cholesky, com a variável gasto do governo ordenado em primeiro.

${ }^{16}$ Seguindo Auerbach e Gorodnichenko (2013), foi datado o período t-1, no subscrito de $I$, na equação (2), para evitar feedback da influência da política fiscal no estado econômico.

${ }^{17}$ Gobetti, Orair e Siqueira (2016) argumentam que a escassez de estudos sobre multiplicadores não lineares no Brasil se deve ao fato de haver pouca quantidade de dados, e os modelos não lineares exigem mais dos dados. Esta é uma das vantagens em utilizar o método de Projeção Local para a economia brasileira.
} 
Além disso, ao contrário do que ocorre nos modelos VAR, a defasagem das variáveis explicativas não são necessárias para caracterizar a dinâmica das variáveis dependentes, condicionadas ao choque ${ }^{18}$. Os parâmetros, $\beta_{h}$ e $\beta_{h}^{j}, j \in\{R, E\}$ descrevem o comportamento de uma variável no instante de tempo $t+h$, em resposta a um choque exógeno de política fiscal ocorrido no instante de tempo t. As respostas para cada uma das variáveis endógenas são estimadas separadamente, em relação às demais variáveis. A estrutura de defasagem $\psi(L) \mathbf{z}_{t-1}$ nas equações (1) e (2) não representam uma dinâmica interna do sistema ${ }^{19}$.

Em segundo lugar, as FRIs em um modelo VAR que dependa do estado, nitidamente não assumem mudança na variável de estado. Como por exemplo, o estado do ciclo de negócios pode permanecer em recessão mesmo após uma expansão fiscal. Esta conjectura é difícil de conciliar com um choque, o qual pode fazer com que o produto fique acima do seu nível potencial. O método de projeção local não restringe o estado da economia, isto quer dizer que o estado da economia não precisa ficar permanentemente rígido, dado que as FRIs estimam diretamente para cada horizonte, ao invés de obter recursivamente de um sistema estimado. Os coeficientes $\beta_{h}^{j}, j \in\{R, E\}$, computam diretamente os efeitos médios de um choque fiscal sobre o horizonte $h$, quando o estado do ciclo econômico é $j$.

Por fim, uma das limitações do modelo VAR é que ao computar as FRIs os multiplicadores fiscais não são revelados diretamente. Ainda que os trabalhos empíricos usem em geral as variáveis em logaritmos (log do produto real, logo dos gastos do governo, log dos impostos), as funções resposta ao impulso fornecem elasticidades que precisam ser convertidas em equivalentes monetários. Para que seja possível converter estas mudanças percentuais em equivalentes em reais (R\$), as FRIs são modificadas, pela média amostral da razão entre o PIB e a despesa. Ramey e Zubairy (2017) mostram que essa forma de proceder enviesa para cima o tamanho dos multiplicadores fiscais quando $\mathrm{Y} / \mathrm{G}$ é mais alto. Para permitir que os multiplicadores sejam consistentes com a variabilidade em $Y / G$ ao longo do tempo, seguiremos os artigos de Hall (2009), Barro e Redlick (2011) e Owyang, Ramey e Zubairy $(2013)^{20}$. As variáveis dependentes $\tilde{X}_{t}$ são definidas da seguinte forma:

\footnotetext{
${ }^{18}$ Nos modelos VAR, a função de resposta ao impulso que descrevem a dinâmica de uma variável seguida de um choque é uma combinação de parâmetros estimados das defasagens endógenas e dos parâmetros da matriz de resíduos, VAR-COV.

${ }^{19}$ A estrutura de defasagem não é de fato indexada por $h \mathrm{e}$, portanto, não se move com o horizonte de estimação do impacto do choque que ocorre no instante de tempo t, sobre o produto, por exemplo, no período $h$ à frente.

${ }^{20}$ Ramey e Zubairy (2017) usam a transformação de Gordonn e Krenn (2010). Ao invés de usar o logaritmo das variáveis, estas são divididas pela tendência do produto real obtida através da estimação de um polinômio. Como todas as variáveis passam a ser medidas nas mesmas unidades os multiplicadores podem ser estimados diretamente
} 


$$
\tilde{X}_{t+h}=\frac{X_{t+h}-X_{t-1}}{Y_{t-1}} \approx\left(\ln \left(X_{t+h}\right)-\ln \left(X_{t-1}\right)\right) \frac{X_{t-1}}{Y_{t-1}}
$$

onde $\left(\ln \left(X_{t+h}\right)-\ln \left(X_{t-1}\right)\right)$ corresponde à mudança acumulada entre os instantes $t$ - 1 e $t+h$ e $Y_{t-1}$ é o produto real antes do impacto do choque no período $t$. Os multiplicadores fiscais são derivados diretamente das estimativas $\operatorname{dos} \beta_{h}, \beta_{h}^{j}, j \in\{R, E\}$, para os valores reais do PIB, gastos do governo, receitas, consumo, investimento, exportações e importações, usando as equações (1) e (2). Agora, com a vantagem de estarem expressos nas mesmas unidades.

O multiplicador para cada horizonte $h$ é definido como a soma do produto dado o choque fiscal durante o período de tempo. No espírito de Mountford e Uhlig (2009) e Ramey e Zubairy $(2017)^{21}$, os multiplicadores dinâmicos são computados como a razão da integral da resposta da variável de interesse pela integral da variável fiscal, $M_{h}=\sum_{j=0}^{h} \beta_{Y, j} / \sum_{j=0}^{h} \beta_{G, j}$.

Desta forma, os multiplicadores fiscais reproduzem o ganho acumulado da variável de interesse, $\widetilde{X}$, referente ao gasto acumulado em um dado intervalo, oferecendo uma informação mais completa do ponto de vista do policymaker. Deste modo, os multiplicadores podem ser estimados convenientemente usando a seguinte regressão de variável instrumental:

$$
\sum_{i=0}^{h} \tilde{X}_{t+i}=\gamma_{h}+\phi_{h}(L) z_{t-1}+M_{h} \sum_{\mathrm{i}=0}^{\mathrm{h}} \frac{\mathrm{G}_{t+i}-\mathrm{G}_{t-1}}{\mathrm{Y}_{t-1}}+\omega_{t+h}, \text { para } \mathrm{h}=0,1,2, \ldots
$$

onde o choque $e_{t}$ atua como um instrumento para $\sum_{\mathrm{i}=0}^{\mathrm{h}} \frac{\mathrm{G}_{t+i}-\mathrm{G}_{t-1}}{\mathrm{Y}_{t-1}}$ do instante t até $t+h$. O termo $\sum_{i=0}^{h} \tilde{X}_{t+i}$ é a soma da variável de interesse do instante $t$ até $t+h^{22}$. Esta forma de estimar o multiplicador dinâmico $M_{h}$, é similar ao resultado do seguinte método por três passos: (i) estimar a equação (1) para o produto (e para as demais variáveis das contas nacionais e impostos) para cada horizonte até $h$ e somar os $\beta_{h}$; (ii) estimar a equação (1) para a variável gasto do governo para cada horizonte até $h$ e somar os $\beta_{h}$; (iii) calcular os multiplicadores como a resposta de (i) dividido por (ii) ${ }^{23}$. O procedimento que envolve somente um passo, estimar pela equação (4), possui algumas vantagens. Em primeiro lugar, o erro padrão do multiplicador é estimado diretamente. Em segundo, tanto o choque quanto a

\footnotetext{
${ }^{21}$ Ramey e Zubairy (2017) argumentam que muitos artigos calculam erroneamente os multiplicadores. Para Blanchard e Perotti (2002), por exemplo, o multiplicador é dado pela razão entre o pico da resposta do produto e o choque inicial do gasto do governo. Para Auerbach e Gorodninchenko (2012) e Auerbach e Gorodninchenko (2013) o multiplicador é a resposta média do produto ao choque inicial nos gastos do governo.

${ }^{22} \mathrm{O}$ uso de variável instrumental, como proxy para identificar o SVAR foi inicialmente proposto por Stock e Watson (2008). Para mais informação ler Ramey (2016).

${ }^{23}$ Os resultados por este método serão idênticos somente se todas as regressões forem estimadas sobre a mesma amostra, isto quer dizer que as regressões para os horizontes $0,1,2, \ldots$ devem excluir a $h$ última observação.
} 
variável de gasto do governo podem ter erro de mensuração, contanto que seus erros sejam não correlacionados. Em terceiro, pode haver mais de um instrumento por variável endógena se instrumentos adicionais estiverem disponíveis.

Quando há dependência de estado as estimativas usando-se somente um passo podem ser obtidas a partir da estimação da seguinte equação:

$$
\begin{aligned}
\sum_{i=0}^{h} \tilde{X}_{t+i}= & I_{\mathrm{t}-1}\left[\gamma_{h}^{R}+\psi(L) \mathbf{z}_{t-1}+M_{h}^{R} \sum_{\mathrm{i}=0}^{\mathrm{h}} \frac{\mathrm{G}_{t+i}-\mathrm{G}_{t-1}}{\mathrm{Y}_{\mathrm{t}-1}}\right]+\left(1-I_{\mathrm{t}-1}\right)\left[\gamma_{h}^{E}+\psi(L) \mathbf{z}_{t-1}+\right. \\
& \left.M_{h}^{E} \sum_{\mathrm{i}=0}^{\mathrm{h}} \frac{\mathrm{G}_{t+i}-\mathrm{G}_{t-1}}{\mathrm{Y}_{t-1}}\right]+\omega_{t+h}
\end{aligned}
$$

usando $I_{t-1}$ choque $_{t}$ e $\left(1-I_{t-1}\right)$ choque $_{t}$ como instrumentos para a interação dos choques fiscais cumulativos com os dois indicadores de estado. Os multiplicadores do modelo, a depender do estado, $M_{h}^{R}$ e $M_{h}^{E}$ são idênticos quando estimados e calculados usando o método de três passos, desde que mantenha a amostra constante ${ }^{24}$.

${ }^{24}$ Para aplicação da metodologia de projeções locais em política monetária, ler Tenreyro e Thwaites (2016). 


\section{Descrição da Base de Dados}

Para estimar os multiplicadores serão utilizados dados trimestrais para o Brasil do primeiro trimestre de 1999(1999T1) até o segundo trimestre de 2016(2016T2). É feita a opção por dados trimestrais ao invés de dados anuais porque os agentes podem reagir rapidamente a notícias sobre gastos do governo ou impostos e também, o estado da economia pode mudar inesperadamente.

A variável fiscal utilizada no trabalho para indicar o componente de receita será a carga tributária líquida, que foi construída a partir dos dados das três esferas do governo e encontra-se disponível nos artigos de Santos, Macedo e Silva e Ribeiro (2010) e Santos et al. (2014). A escolha desta variável fiscal seguiu os trabalhos de Mendonça, Medrano e Sachsida (2009), Pires (2014) e Castelo-Branco, Lima e Paula (2015) ${ }^{25}$.

Santos, Macedo e Silva e Ribeiro (2010) estimam a carga tributária líquida trimestral para o período de 1995 até 2009, enquanto que Santos et al. (2014) aperfeiçoam e expandem o trabalho anterior até 2012. A carga tributária líquida é definida como a diferença entre a carga tributária bruta (composta pelo valor de todos os impostos, taxas e contribuições arrecadas pelo governo - incluindo o FGTS e os tributos pagos pelas empresas estatais) e as transferências de previdência e assistência social às famílias e às instituições privadas sem fins lucrativos, o que inclui os saques do FGTS feitos pelos trabalhadores, bem como os subsídios ao setor privado ${ }^{26}$.

A variável gasto do governo utilizada no trabalho é representada pela despesa primária do governo central. A despesa primária é formada por despesas com pessoal e encargos, benefícios sociais (Previdência, LOAS/RMV, Abono e Seguro Desemprego e Bolsa Família), subsídios, custeio e capital (investimento e demais) ${ }^{27}$.

\footnotetext{
${ }^{25}$ Os trabalhos de Blanchard e Perotti (2002), Fatás e Mihov (2001) e Mountford e Uhlig (2005) também utilizam este mesmo conjunto de variáveis.

${ }^{26} \mathrm{O}$ trabalho de Santos, Macedo e Silva e Ribeiro (2010) é uma continuação de um trabalho anterior do IPEA, que começou a estimar a série trimestral da carga tributária líquida, a partir de 1995. Enquanto que Santos et al. (2014) complementam o trabalho de 2010 e ampliam a série até o ano de 2012. O IPEA ficou sendo o órgão responsável por estimar esta série de carga tributária até dezembro de 2015. Enquanto que o Tesouro Nacional passou a estimar esta mesma série a partir de 2010. No período em que ambas as instituições estimavam esta variável, os valores são muito próximos, de tal forma que se optou por utilizar entre 1999 e 2009 os valores estimados pelo IPEA, e a partir de 2010 foram usados os dados provenientes do Tesouro Nacional.

${ }^{27}$ Agradeço a gentileza de Sérgio Gobetti e Rodrigo Orair, ambos os pesquisadores do IPEA, por me disponibilizarem estas séries. Certamente deve ter sido um enorme trabalho construí-las e estou muito agradecido por terem me disponibilizado tais dados.
} 
O gasto primário sofreu inúmeros ajustes, ao limpar o que ficou conhecida como “contabilidade criativa" e as chamadas "pedaladas fiscais" ${ }^{28}$. Além disso, alguns outros ajustes adicionais foram feitos. Os gastos implícitos do BNDES, os quais estão fora do resultado primário das estatísticas oficiais, foram incorporados a conta Subsídios. Ainda foi adicionada a conta Subsídios, os gastos com Minha Casa e Minha Vida, que oficialmente entra na conta de Investimentos e também os gastos do CDE (Conta de Desenvolvimento Energético (subsídio)) ${ }^{29}$.

Por fim, as séries de produto, consumo, investimento, exportação e importação são obtidas das contas nacionais.

Todas as séries foram convertidas para milhões de reais do segundo trimestre de 2016 pelo IPCA e depois dessazonalizadas pelo método X-12 ARIMA $^{30}$.

Foram utilizadas como variáveis threshold, ou seja, variáveis para diferenciar os períodos de expansão e contração da economia, as variáveis comumente utilizadas na literatura: o hiato do produto, o nível de utilização da capacidade, a taxa de desemprego e a taxa crescimento do PIB.

A estimativa do PIB potencial é obtida através do Filtro Hodrick-Prescott (HP) $(\lambda=1600)$. Para evitar o problema de distorção de final de amostra, na estimação do filtro HP, a série de PIB é prolongada utilizando as projeções do PIB para os próximos seis trimestres, a partir dos dados do Relatório Focus, divulgado logo após a publicação do PIB do segundo trimestre de 2016, pelo IBGE. Esta nova série construída é então dessazonalizada pelo método X-12 ARIMA. O hiato do produto é obtido calculando a diferença entre o produto real atual e o produto real potencial (todas em logaritmo) ${ }^{31}$.

A série de nível de utilização da capacidade instalada (NUCI), a qual mede a variação mensal foi construída pela CNI (Confederação Nacional da Indústria) e obtida pelo IPEAdata.

A taxa de desemprego é extraída da Pesquisa Mensal de Emprego (PME) do IBGE, entre março de 2002 e fevereiro de 2016. O IBGE tem uma PME antiga, que vai de 1980 até fevereiro de 2002. Assim, de março de 2002 até fevereiro de 2016 é utilizada a PME

\footnotetext{
${ }^{28}$ Gobetti e Orair (2017) incorporaram ao resultado primário o efeito das chamadas "pedaladas fiscais", quando os passivos dos bancos públicos foram quitados em atendimento às determinações do Tribunal de Contas da União. Esse ajuste foi realizado por meio das estimativas do próprio Banco Central, explicitadas no quadro 44 da Nota de Política Fiscal de março de 2016.

${ }^{29}$ Para mais informações sobre os ajustes da variável despesa do Governo, ver em Gobetti e Orair (2017).

${ }^{30} \mathrm{As}$ séries fiscais foram deflacionadas pelo IPCA, pois o deflator implícito do PIB apresenta elevada volatilidade.

${ }^{31}$ Mesma metodologia utilizada pelo Monitor Fiscal, elaborado pela Secretaria do Tesouro Nacional.
} 
divulgada pelo IBGE, encadeando-se a ela os dados para o período de janeiro de 1999 até fevereiro de 2002 por meio de suas taxas de variação. Para os meses seguintes, de março de 2016 a junho de 2016, é feita uma interpolação linear.

Como a taxa de desemprego e o nível de capacidade ociosa são séries mensais, ambas foram dessazonalizadas pelo X-12 ARIMA e então foi calculada a média dos respectivos trimestres de cada uma, para obtenção dos dados trimestrais.

A taxa de crescimento do PIB real é dada $100 x\left(\ln \left(P I B_{t}\right)-\ln \left(P I B_{t-1}\right)\right)$. 


\section{Resultados da Estimação}

\subsection{Definindo os Estados de Slack}

$\mathrm{Na}$ tradição keynesiana, a política fiscal poderia ser mais efetiva em estimular o produto em períodos de recessão, devido à falta de recursos na economia, do que em períodos normais. Sob esta hipótese, as estimativas dos multiplicadores fiscais existentes na literatura estariam sobre-estimando os multiplicadores em recessão, pois eles correspondem à média dos multiplicadores nas expansões e contrações econômicas.

O entendimento keynesiano de que os multiplicadores fiscais são apropriados em uma economia com considerável subutilização dos recursos implica que o produto não é mais determinado pela oferta, passando a ser determinado pela demanda. São várias as medidas para o chamado slack (i.e. recessão da economia), tais como o hiato do produto, a capacidade utilizada, a taxa de desemprego ou até mesmo a taxa de crescimento. De acordo com os indicadores de ciclos de negócios, uma recessão típica é caracterizada por períodos nos quais o hiato do produto é negativo, o nível de utilização da capacidade instalada e a taxa de crescimento do PIB são baixos e a taxa de desemprego é alta.

Com o objetivo de encontrar o limiar (threshold) que define os períodos nos quais a economia encontra-se em recessão, será utilizada a metodologia proposta por Ramey e Zubairy (2015). Para calcular o valor do threshold, foi construído um grid search em que pelo menos $30 \%$ das observações ficasse em cada um dos regimes. Neste teste é comparada a log verossimilhança da especificação de Jordà, no horizonte $h=0$, com apenas uma defasagem do log do PIB, do log da carga tributária líquida e do log dos gastos do governo, somente para a equação do produto, associado à equação (2) ${ }^{32}$.

O valor do limiar escolhido por meio deste grid search é aquele que maximiza a verossimilhança do modelo base. Na Tabela 3, são apresentados os valores dos thresholds e também a duração em trimestres de cada regime, além da datação dos ciclos oficiais para o Brasil, feito pelo Comitê de Datação de Ciclos - CODACE.

A datação dos ciclos para o Brasil feita pelo Comitê de Datação de Ciclos - CODACE. Mais especificamente, são adotados os períodos e a duração em trimestres das recessões e expansões divulgados no cronograma trimestral do ciclo de negócios de 04/08/2015. Como

\footnotetext{
32 No artigo de Baum e Koester (2011), o grid search também foi dividido para que ao menos $30 \%$ das observações ficassem em recessão e em expansão. Já Soave (2015), construiu o grid com pelo menos 35\% das observações ficassem em cada um dos regimes.
} 
não houve mudança na datação feita pelo CODACE desde então, considera-se que até o segundo trimestre de 2016, fim da amostra aqui analisada, a economia continua em recessão.

Tabela 3 - Estimação dos Thresholds e Máxima

Verossimilhança

\begin{tabular}{ccccc}
\hline \hline & Threshold & Recessão & Expansão & $\begin{array}{c}\text { Máxima } \\
\text { Verossimilhança }\end{array}$ \\
\hline Hiato & $-0,46$ & 26 & 44 & 194,30 \\
\hline NUCI & 80,95 & 25 & 45 & 199,56 \\
\hline $\begin{array}{c}\text { Taxa de } \\
\text { Desemprego }\end{array}$ & 9,10 & 35 & 35 & 197,42 \\
\hline $\begin{array}{c}\text { Taxa de } \\
\text { Crescimento } \\
\text { do PIB (em \%) }\end{array}$ & 0,66 & 28 & 42 & 202,19 \\
\hline CODACE & - & 17 & 53 & - \\
\hline \hline
\end{tabular}

Fonte: Cálculo do Autor.

A Figura 1 mostra as variáveis thresholds. A área sombreada corresponde aos períodos de recessão, de acordo com o valor do limiar encontrado. É possível observar que a maioria das variáveis thresholds indica períodos ruins em trimestres idênticos. Por exemplo, o ano de 2001, caracterizado pela crise energética; o ano de 2009, marcado pela crise financeira internacional e a grave crise econômica pela qual passa o Brasil nos anos mais recentes. Vale destacar também o comportamento da taxa de desemprego, que apresenta queda durante praticamente todo o período da série e a partir de 2014 inicia um aumento, divergindo do comportamento das demais variáveis que oscilam bastante durante todo o período. Além do mais, esta variável aponta recessão entre os anos de 1999 e terceiro trimestre de 2007, e a partir daí indica apenas períodos de expansão. 
Figura 1 - Variáveis Threshold
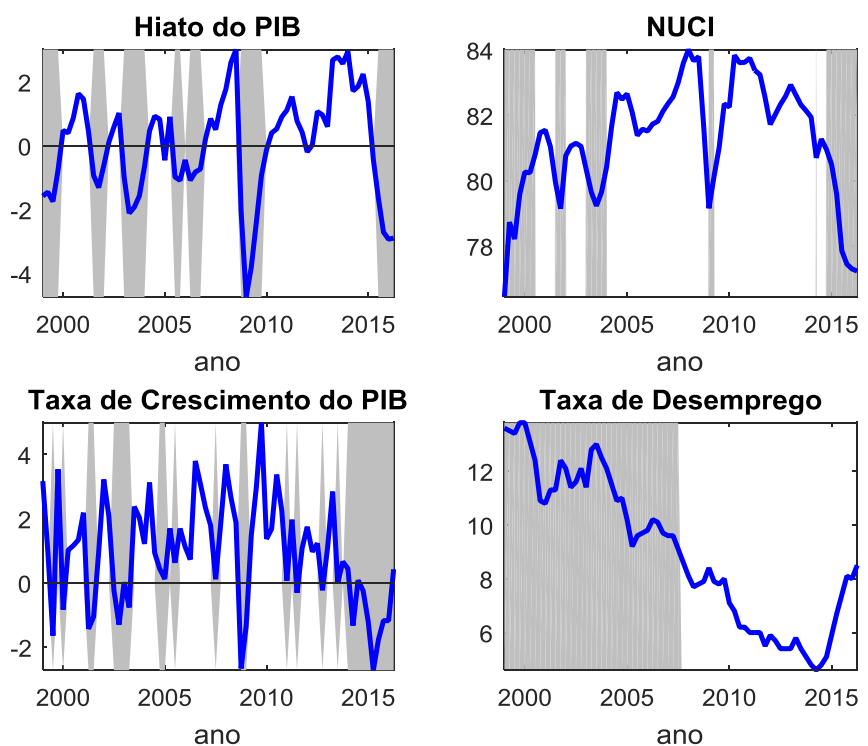

Fonte: Elaboração Própria.

Como discutido no Capítulo 3, os multiplicadores estimados neste trabalho são resultados de regressões por variáveis instrumentais. Uma indagação relevante que surge é se o instrumento utilizado, neste caso, o gasto do governo, é um instrumento relevante. A utilização do método de Projeção Local de Jordà implica correlação serial nos termos do erro, o que impede o uso da regra de bolso de uma estatística $\mathrm{F}$ inferior a 10 como indicativa de instrumento fraco (Staiger e Stock (1997)).

Deste modo, seguiu-se Ramey e Zubairy (2017) e utilizam-se as estatísticas F efetiva, e os limiares de Olea e Pflueger (2013), para averiguar a relevância do instrumento. Olea e Pflueger (2013) mostram que os thresholds podem ser distintos e algumas vezes maiores quando os erros são serialmente correlacionados.

A Figura 2 mostra a diferença entre as estatísticas $\mathrm{F}$ efetivas do primeiro estágio (regressão da soma do gasto real do governo de $t$ a $t+h$ nos choque em $t$, produto defasado, impostos defasados e despesas do governo defasados) e os thresholds de Olea e Pflueger (2013). Quando esta diferença é positiva, significa que a estatística F é maior do que o threshold, indicando que o instrumento é forte. 
Figura 2 - Teste de Relevância de Instrumento entre os Estados de Slack
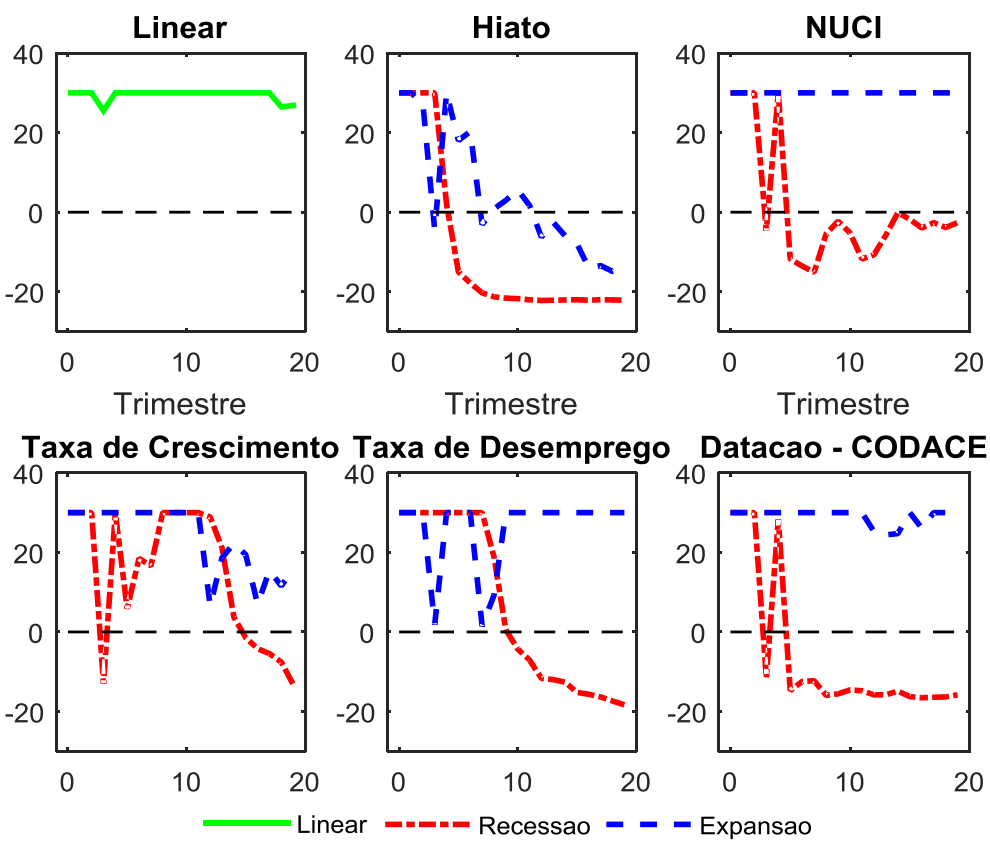

Nota: O gráfico reporta as diferenças entre as estatísticas efetivas F e o threshold de Olea e Pflueger (2013) para testar se o instrumento do primeiro estágio é fraco para as equações (4) e (5). O threshold é 23,1 para um instrumento para o valor crítico de 5\%, para testar a hipótese nula que o viés de mínimos quadrados dois estágios excede $10 \%$ do viés dos mínimos quadrados ordinários. Todas as estatísticas são robustas a heterocedasticidade e correlação serial.

A partir da Figura 2 é possível inferir que:

1) Para o modelo linear o choque B-P é relevante durante todos os trimestres porque a diferença entre estatística F e o limiar de Olea e Pflueger (2013) é sempre positiva.

2) Quando a variável limiar é o hiato do produto o instrumento não é relevante em expansão no quarto e no oitavo trimestre e a partir do décimo terceiro trimestre, enquanto em recessão o instrumento é relevante até o quinto trimestre ${ }^{33}$.

3) Quando a variável limiar é o NUCI o instrumento em expansão é relevante durante todo o período, enquanto em recessão o instrumento é relevante nos três primeiros trimestres e no quinto.

4) Quando a variável limiar é a taxa de crescimento do produto o instrumento em expansão é relevante durante todo o período, enquanto em recessão o instrumento não é relevante no quarto trimestre e a partir do décimo sexto trimestre.

\footnotetext{
${ }^{33}$ Este resultado é similar ao encontrado por Ramey e Zubairy (2017) quando o choque é identificado seguindo B-P. Elas afirmam que o choque B-P é identificado como parte do gasto corrente não explicado pelas outras defasagens das variáveis de controle. Por isso o seu desempenho é melhor no curto prazo.
} 
5) Quando o limiar é a taxa de desemprego o instrumento em expansão é relevante durante todo o período, enquanto que em recessão o instrumento é relevante até o décimo trimestre.

6) Quando a variável limiar é a datação do CODACE o instrumento em expansão é relevante durante todo o período, enquanto que em recessão o instrumento é relevante até o terceiro trimestre.

\subsection{Resultados das Estimativas}

A Tabela 4 apresenta os resultados do modelo linear, após um choque de despesa primária de $1 \%$ do PIB. O cálculo dos multiplicadores de impacto, de um ano e de dois anos, são feitos através do $M_{h}$, da equação $(4)^{34}$.

É possível notar que o multiplicador cresce bastante ao longo do horizonte de tempo, sendo igual a 0,5242 no impacto e igual a 2,228 e 2,5823, um ano e dois anos após o choque, respectivamente, indicando forte efeito das despesas primárias sobre o PIB. Os valores dos multiplicadores encontrados aqui são maiores do que os da literatura nacional, conforme apresentado na Tabela 1.

Tabela 4 - Multiplicadores do Modelo Linear

\begin{tabular}{lc}
\hline \hline Multiplicador de Impacto & 0,5242 \\
& $(0,3332)$ \\
\hline Multiplicador de 4 trimestres & $2,2280 * * *$ \\
& $(0,5844)$ \\
\hline Multiplicador de 8 trimestres & $2,5823 * * *$ \\
& $(0,4339)$ \\
\hline \hline Fonte: Cálculo do Autor. \\
Os erros padrões estão entre parênteses. \\
$(* * *)$ significativo a 1\%; $(* *)$ significativo a \\
$5 \% ;(*)$ significativo a 10\%.
\end{tabular}

${ }^{34}$ Para calcular as estimativas dos multiplicadores foram utilizados os softwares STATA e MATLAB. 
A Figura 3 apresenta as funções resposta ao impulso do produto e da despesa primária a um choque B-P no caso linear. As faixas com $95 \%$ de intervalo de confiança são baseadas nos erros padrões de Newey-West, que levam em conta as correlações seriais. Pode ser observado o comportamento de crescimento do produto, que uma apresenta queda, após 15 trimestres, mas que logo em seguida volta a crescer. No caso da despesa primária, há um aumento após o choque, seguido de uma queda até 10 trimestres e em seguida, volta a aumentar.

Figura 3 - Função Resposta ao Impulso do Modelo Linear: Despesa Primária e PIB
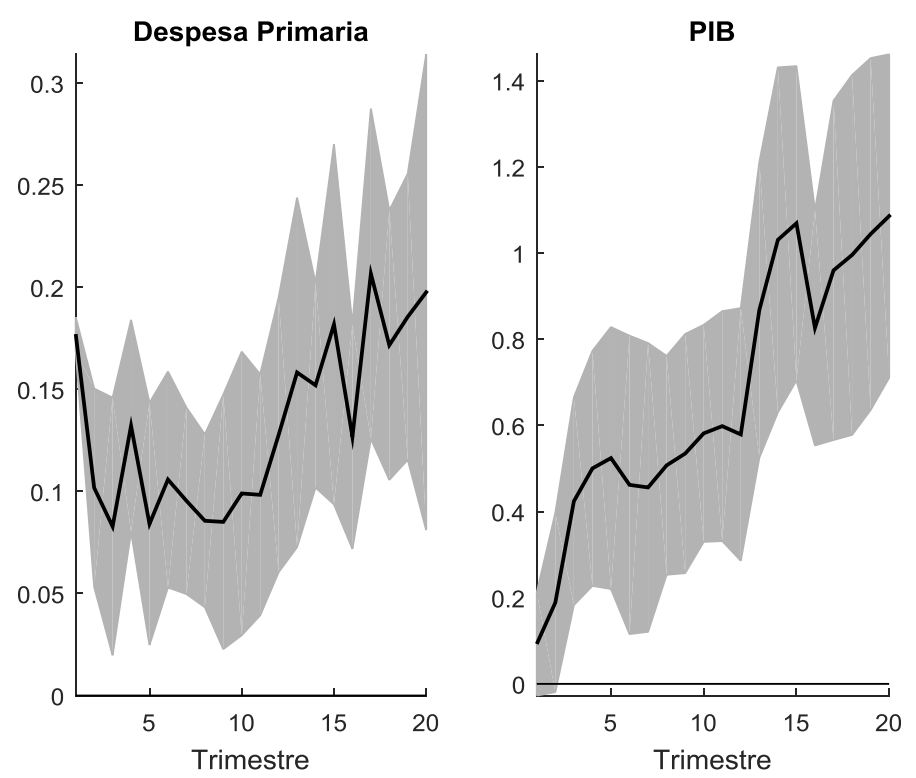

Fonte: Elaboração Própria.

Nota: Resposta da despesa primária e do PIB a um choque de gastos primários de $1 \%$ do PIB. As áreas sombreadas correspondem ao intervalo de confiança de $95 \%$.

Os multiplicadores do modelo não linear são dados pelos parâmetros $M_{h}^{R}$ e $M_{h}^{E}$ na equação (5), para períodos de recessão e de expansão, respectivamente e estão apresentados na Tabela 5. As estimativas mostram que os multiplicadores cumulativos são maiores quando a economia está em contração do que quando em expansão, para um e dois anos após o choque fiscal, independente da variável threshold utilizada. E na maior parte dos casos, os multiplicadores são significantes ao nível de $1 \%$ e maiores do que um ${ }^{35}$.

Estes resultados, em especial os multiplicadores de quatro e oito trimestres, corroboram as evidências encontradas na literatura de que os multiplicadores do produto

\footnotetext{
${ }^{35}$ No caso dos multiplicadores de impacto, o mesmo ocorre apenas quando a variável limiar é a taxa de desemprego.
} 
diferem de acordo com o regime econômico e são maiores em recessão, como os encontrados por: Baum e Koester (2011), Auerbach e Gorodnichenko (2012 e 2013), Fazzari, Morley e Panovska (2015) e Cos e Moral-Benito (2016) e Gobetti, Orair e Siqueira (2016) ${ }^{36}$.

Tabela 5 - Multiplicadores do Modelo Não Linear

\begin{tabular}{|c|c|c|c|c|}
\hline & & $\begin{array}{l}\text { Multiplicador } \\
\text { de Impacto }\end{array}$ & $\begin{array}{l}\text { Multiplicador } \\
4 \text { trimestres }\end{array}$ & $\begin{array}{l}\text { Multiplicador } \\
8 \text { trimestres }\end{array}$ \\
\hline \multirow{4}{*}{ Hiato } & Recessão & 0,3076 & $3,1711 * * *$ & $2,9105 * * *$ \\
\hline & & $(0,8178)$ & $(0,4587)$ & $(0,5206)$ \\
\hline & Expansão & 0,4293 & $1,3034 * *$ & 0,2079 \\
\hline & & $(0,3707)$ & $(0,5365)$ & $(1,6722)$ \\
\hline \multirow{2}{*}{$\begin{array}{c}\text { P-valor para diferença } \\
\text { entre estados }\end{array}$} & $\mathrm{HAC}$ & 0,9046 & 0,0014 & 0,1224 \\
\hline & AR & 0,0000 & 0,1687 & 0,1794 \\
\hline \multirow{4}{*}{ NUCI } & Recessão & $0,6130 * * *$ & $4,2722 * * *$ & $2,7254 * * *$ \\
\hline & & $(0,1934)$ & $(0,3696)$ & $(0,9135)$ \\
\hline & Expansão & $0,7939 *$ & $1,3847 * * *$ & $2,8145 * * *$ \\
\hline & & $(0,3910)$ & $(0,3514)$ & $(0,3381)$ \\
\hline \multirow{2}{*}{$\begin{array}{c}\text { P-valor para diferença } \\
\text { entre estados }\end{array}$} & HAC & 0,7007 & 0,0000 & 0,9320 \\
\hline & AR & 0,0000 & 0,0913 & 0,9295 \\
\hline \multirow{4}{*}{$\begin{array}{c}\text { Taxa de } \\
\text { Desemprego }\end{array}$} & Recessão & $2,0581 * * *$ & $3,0429 * * *$ & $3,1089 * * *$ \\
\hline & & $(0,1479)$ & $(0,2961)$ & $(0,3991)$ \\
\hline & Expansão & $-0,1102$ & $1,2165^{*}$ & 0,7941 \\
\hline & & $(0,2035)$ & $(0,6610)$ & $(1,3068)$ \\
\hline \multirow{2}{*}{$\begin{array}{c}\text { P-valor para diferença } \\
\text { entre estados }\end{array}$} & $\mathrm{HAC}$ & 0,0000 & 0,0248 & 0,0756 \\
\hline & AR & 0,0000 & 0,1472 & 0,1286 \\
\hline \multirow{4}{*}{$\begin{array}{c}\text { Taxa de Crescimento } \\
\text { do PIB }\end{array}$} & Recessão & 0,2727 & $2,5927 * * *$ & $2,8057 * * *$ \\
\hline & & $(0,2838)$ & $(0,6809)$ & $(0,6769)$ \\
\hline & Expansão & $0,9836 * *$ & 1,1849 & $2,8031 * * *$ \\
\hline & & $(0,4857)$ & $(0,8168)$ & $(0,6169)$ \\
\hline \multirow{2}{*}{$\begin{array}{l}\text { P-valor para diferença } \\
\text { entre estados }\end{array}$} & $\mathrm{HAC}$ & 0,2164 & 0,2564 & 0,9977 \\
\hline & $\mathrm{AR}$ & 0,0000 & 0,2686 & 0,9977 \\
\hline \multirow{4}{*}{ CODACE } & Recessão & 0,3940 & $4,2421 * * *$ & $4,6079 * * *$ \\
\hline & & $(0,2457)$ & $(0,3042)$ & $(0,2046)$ \\
\hline & Expansão & $0,9799 * *$ & $1,5591 * * *$ & $2,8632 * * *$ \\
\hline & & $(0,4059)$ & $(0,5975)$ & $(0,3338)$ \\
\hline \multirow{2}{*}{$\begin{array}{c}\text { P-valor para diferença } \\
\text { entre estados }\end{array}$} & $\mathrm{HAC}$ & 0,2056 & 0,0002 & 0,0003 \\
\hline & AR & 0,0000 & 0,0414 & 0,0925 \\
\hline
\end{tabular}

Fonte: Cálculo do Autor.

Os erros padrões estão entre parênteses. (***) significativo a 1\%; (**) significativo a 5\%; (*) significativo a $10 \%$.

Para verificar se as estimativas dos multiplicadores em recessão e em expansão são iguais para o mesmo período, isto é, $M_{h}^{R}=M_{h}^{E}$, são utilizados os p-valores baseados nos erros padrão consistentes com heterocedasticidade e autocorrelação (HAC) e no teste $t$ de Anderson

\footnotetext{
${ }^{36}$ Estes autores encontram multiplicadores maiores do que um, em recessão e menores em expansão.
} 
e Rubin - AR (1949). O primeiro é válido para instrumentos fortes ${ }^{37}$, enquanto o segundo é robusto a instrumentos fracos, embora tenha baixo poder. Nos trimestres em que o instrumento é relevante, a estatística HAC é utilizada, enquanto que nos trimestres em que o instrumento não é relevante, a estatística AR deve ser usada ${ }^{38}$.

A Tabela 6 abaixo resume os resultados dos testes HAC e AR. Na tabela, o NÃO indica não haver diferença entre os regimes para o multiplicador, ou seja, $M_{h}^{R}=M_{h}^{E}$, enquanto que o SIM sugere haver diferença. A maioria dos testes indicou não haver diferença entre os multiplicadores nos períodos de recessão e de expansão.

Tabela 6 - Teste para Verificação de Diferença entre os Regimes dos Multiplicadores

\begin{tabular}{|c|c|c|c|c|c|c|c|}
\hline \multirow{2}{*}{ Limiar } & \multirow{2}{*}{$\begin{array}{c}\text { Teste de } \\
\text { Instrumento }\end{array}$} & \multicolumn{3}{|c|}{ Expansão } & \multicolumn{3}{|c|}{ Recessão } \\
\hline & & Impacto & 4 trimestres & 8 trimestres & Impacto & 4 trimestres & 8 trimestres \\
\hline \multirow{2}{*}{ Hiato } & HAC & NÃO & & & NÃO & SIM & \\
\hline & $\mathrm{AR}$ & & NÃO & NÃO & & & NÃO \\
\hline \multirow{2}{*}{ NUCI } & HAC & NÃO & SIM & NÃO & NÃO & & \\
\hline & $\mathrm{AR}$ & & & & & SIM & NÃO \\
\hline Taxa de & HAC & SIM & SIM & SIM & SIM & SIM & SIM \\
\hline Desemprego & $\mathrm{AR}$ & & & & & & \\
\hline \multirow{2}{*}{$\begin{array}{c}\text { Taxa de Crescimento } \\
\text { do PIB }\end{array}$} & HAC & NÃO & NÃO & NÃO & NÃO & & NÃO \\
\hline & AR & & & & & NÃO & \\
\hline \multirow{2}{*}{ CODACE } & HAC & NÃO & SIM & SIM & NÃO & & \\
\hline & AR & & & & & SIM & SIM \\
\hline
\end{tabular}

Fonte: Elaborado pelo Autor.

A Figura 4, Figura 5, Figura 6, Figura 7 e Figura 8 exibem as funções resposta ao impulso do PIB e da despesa primária a um choque fiscal, no caso de haver dois regimes econômicos ${ }^{39}$. Para cada uma das figuras foi utilizadas as variáveis limiares: hiato, NUCI, taxa de crescimento do PIB, taxa de desemprego e datação da CODACE. A coluna da esquerda está presente às respostas da despesa primária e do produto, respectivamente, para o caso não linear. As linhas azuis tracejadas são as respostas nos períodos de recessão, ao passo que as linhas vermelhas com círculos correspondem às respostas nos períodos de expansão. As faixas com $95 \%$ de intervalo de confiança estão presentes. A coluna da direita compara as funções de impulso respostas entre o modelo não linear e o linear.

\footnotetext{
37 A estatística AR é um teste de menor poder, e pode ser usado para verificar diferenças nos multiplicadores.

${ }^{38} \mathrm{Na}$ seção 5.1, foram feitos os testes para definir quais trimestres o instrumento é relevante, para cada regime econômico.

${ }^{39}$ No Apêndice há um teste de robustez em que o threshold utilizado é o hiato do PIB, do trabalho de SouzaJúnior (2017). O autor estima o PIB potencial por meio de uma função de produção. Os resultados não foram alterados com este limiar.
} 
As funções de impulso resposta, quando a variável limiar é o nível de utilização da capacidade instalada e a datação da CODACE apresentam trajetória ascendente tanto do PIB, quanto da despesa, com o regime de recessão quase que exclusivamente acima do de expansão.

Da mesma forma, quando a variável threshold é a taxa de crescimento do PIB, o produto apresenta este comportamento de crescimento, enquanto que a despesa, para alguns trimestres, o regime de expansão supera o regime de recessão. Já para o hiato do produto e para a taxa de desemprego, tanto o PIB quanto a despesa primária se movimentam de maneira oscilatória durante o período, com trimestres em que o efeito do choque de gastos é maior em contração, e em outros, com efeitos maiores em expansão.

Figura 4 - Função Resposta ao Impulso do Modelo Não Linear: Threshold Hiato
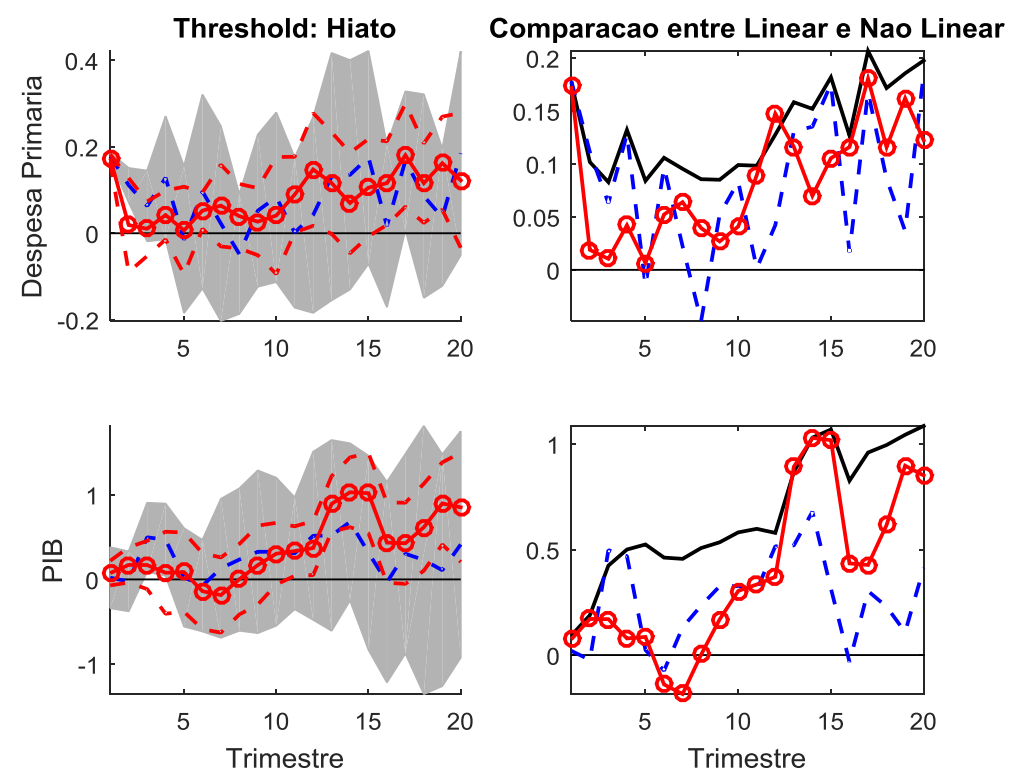

Fonte: Elaboração Própria.

Nota: Respostas do modelo não linear da despesa primária e do PIB a um choque de gastos primários de $1 \%$ do PIB. As áreas sombreadas correspondem ao intervalo de confiança de $95 \%$. 
Figura 5 - Função Resposta ao Impulso do Modelo Não Linear: Threshold NUCI
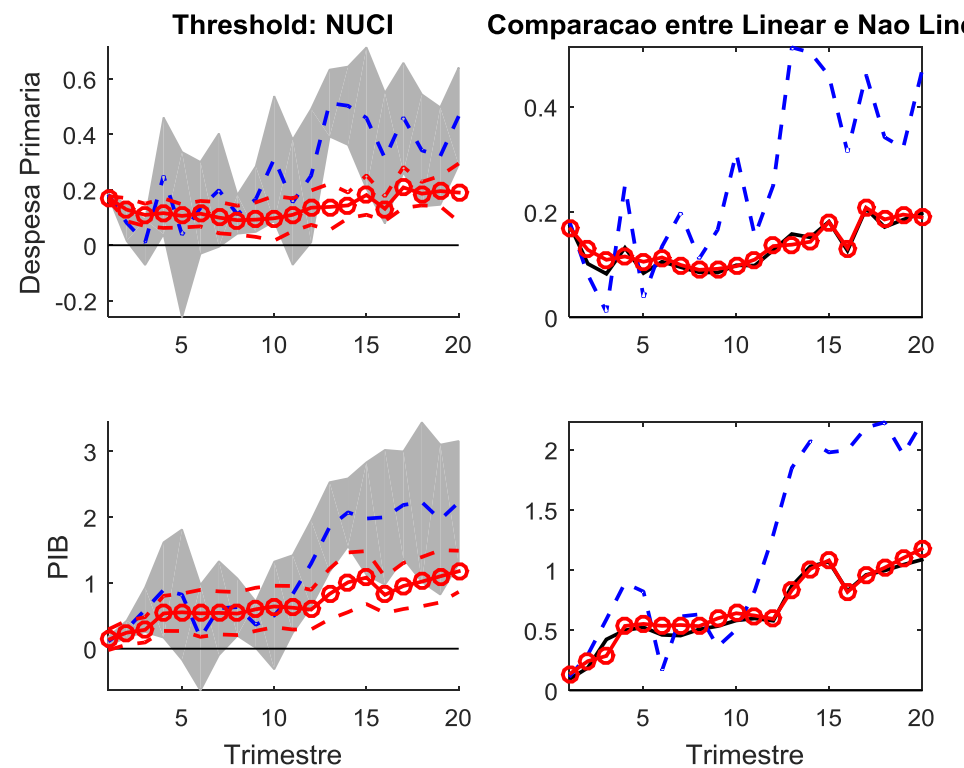

Fonte: Elaboração Própria.

Nota: Respostas do modelo não linear da despesa primária e do PIB a um choque de gastos primários de $1 \%$ do PIB. As áreas sombreadas correspondem ao intervalo de confiança de $95 \%$.

Figura 6 - Função Resposta ao Impulso do Modelo Não Linear: Threshold Taxa de Crescimento do PIB
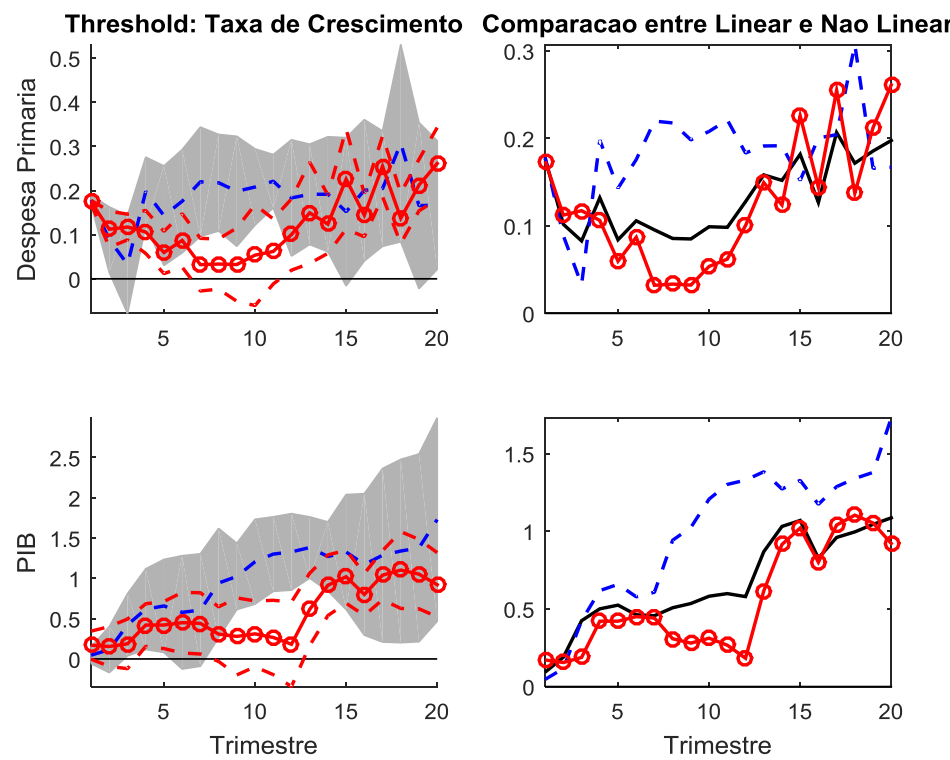

Fonte: Elaboração Própria.

Nota: Respostas do modelo não linear da despesa primária e do PIB a um choque de gastos primários de $1 \%$ do PIB. As áreas sombreadas correspondem ao intervalo de confiança de $95 \%$. 
Figura 7 - Função Resposta ao Impulso do Modelo Não Linear: Threshold Taxa de Desemprego
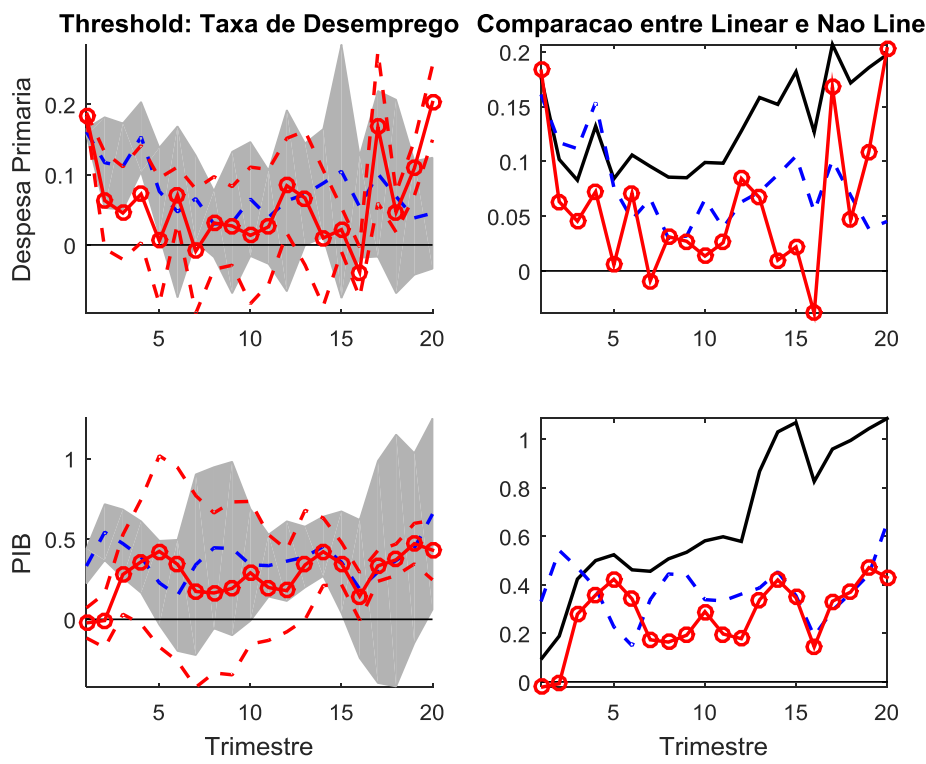

Fonte: Elaboração Própria.

Nota: Respostas do modelo não linear da despesa primária e do PIB a um choque de gastos primários de $1 \%$ do PIB. As áreas sombreadas correspondem ao intervalo de confiança de $95 \%$.

Figura 8 - Função Resposta ao Impulso do Modelo Não Linear: Threshold Datação da

\section{CODACE}
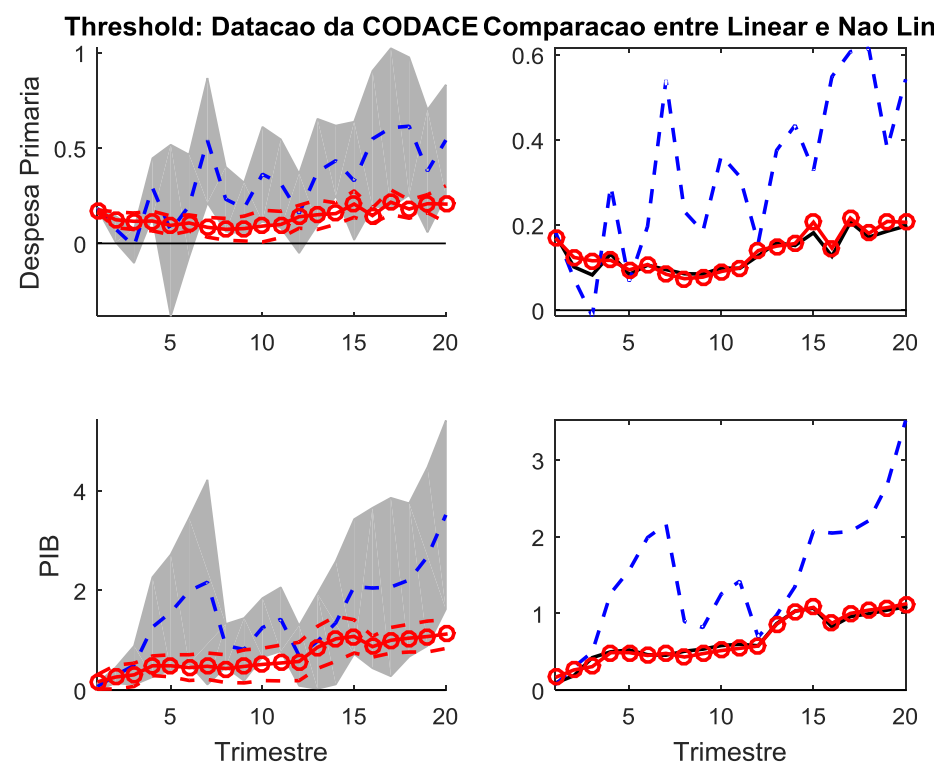

Fonte: Elaboração Própria.

Nota: Respostas do modelo não linear da despesa primária e do PIB a um choque de gastos primários de $1 \%$ do PIB. As áreas sombreadas correspondem ao intervalo de confiança de $95 \%$. 


\subsection{Testes de Robustez ${ }^{40}$}

Esta seção trata dos testes de robustez, para explorar a sensibilidade dos resultados do modelo base. A Tabela 7 exibe os resultados para o caso linear. E para a condição do modelo não linear, a Tabela 8 , Tabela 9 e Tabela 10 apresentam os multiplicadores de impacto, de 4 e de 8 trimestres, respectivamente.

A primeira mudança na especificação é a inclusão de uma tendência linear, nas equações (1) e (2), pois as séries de tempo podem ser sensíveis à presença de tendências. A única mudança no caso linear foi o multiplicador de impacto aumentando de 0,5242 para 0,8104 e tornando-se significativo. No contexto não linear, as variações mais significativas ocorreram no limiar hiato do produto, onde multiplicador de oito trimestres, no regime de expansão, passou de 0,2079 para -0,2243 e o de impacto, em recessão, que mudou de 0,3076 para 0,8312; para a taxa de desemprego, em expansão, o multiplicador de impacto aumentou de -0,1102 para 0,0565. Nos demais não ocorreu nenhuma mudança considerável. Os multiplicadores em contração permanecem maiores do que os de expansão.

Nas estimativas anteriores as variações percentuais das despesas do governo foram convertidas em variações em reais $(\mathrm{R} \$)$ usando-se o valor da razão gasto do governo-produto (G/Y) em cada momento do tempo ao invés de usar as médias amostrais. A ciclicalidade do produto, contudo, pode enviesar as estimativas dos multiplicadores. ${ }^{41}$ Assim, como segunda mudança adota-se a transformação sugerida por Miyamoto, Nguyen e Sergeyev (2017) similar, por sua vez, à proposta por Gordon e Krenn (2010) em que as despesas primárias e o produto são divididos pelo produto potencial: $\frac{\mathrm{Y}_{\mathrm{t}+\mathrm{h}}-\mathrm{Y}_{\mathrm{t}-1}}{\overline{\mathrm{Y}}_{\mathrm{t}-1}}$ e $\frac{\mathrm{G}_{\mathrm{t}+\mathrm{h}}-\mathrm{G}_{\mathrm{t}-1}}{\overline{\mathrm{Y}}_{\mathrm{t}-1}}$, onde $\bar{Y}$ é o produto potencial calculado usando-se o Filtro Hodrick-Prescott. Os resultados desta robustez estão em linha com os do modelo base: multiplicadores maiores em recessão do que em expansão.

O terceiro teste de robustez segue Auerbach e Gorodnichenko (2012) (AG). Para computar os multiplicadores fiscais não lineares, é utilizada uma função de transição em que a variável dummy $I_{t-1}$ na equação (2) é substituída pela função $F\left(z_{t}\right)=\frac{\exp \left(-\gamma z_{t}\right)}{1+\exp \left(-\gamma z_{t}\right)}$. Essa função é monotonicamente crescente em $z_{t}$, onde $F$ é uma função de transição contínua limitada entre zero e um, e $z_{t}$ é a variável de transição ${ }^{42}$. O parâmetro de inclinação $\gamma$ determina a suavidade da mudança entre zero (expansão extrema) e um (recessão extrema), e

\footnotetext{
${ }^{40}$ Os resultados detalhados dos testes de robustez são apresentados no Apêndice.

${ }^{41} \mathrm{O}$ problema emerge da equação (3), em que $\frac{\mathrm{Y}_{\mathrm{t}+\mathrm{h}}-\mathrm{Y}_{\mathrm{t}-1}}{\mathrm{Y}_{\mathrm{t}-1}} \mathrm{e} \frac{\mathrm{G}_{\mathrm{t}+\mathrm{h}}-\mathrm{G}_{\mathrm{t}-1}}{\mathrm{Y}_{\mathrm{t}-1}}$ estão correlacionados, pois $Y_{t-1}$ aparece no denominador e $G / Y$ varia ao longo do ciclo econômico.

${ }^{42}$ A variável $z_{t}$ é um índice que indica as fases do ciclo econômico, assumindo valores positivos nos períodos de expansão e negativos em recessão. Essa variável é normalizada para ter variância unitária.
} 
a identificação de restrição é que $\gamma>0$. Se $\gamma \rightarrow \infty$. Com isso a equação (2) torna-se um modelo de regressão de mudança de dois regimes ${ }^{43}$.

Auerbach e Gorodnichenko (2012) usam a média móvel de 7 trimestres da taxa de crescimento real do PIB para expressar a dicotomia entre recessão/expansão, indicada pela variável $z_{t}$. Aqui, seguiu-se Cos e Moral-Benito (2016) que também propuseram outras medidas para avaliar os regimes econômicos. Desta forma, além da taxa de crescimento, serão usadas as outras medidas de slack, o hiato do produto, a capacidade utilizada e a taxa de desemprego $^{44}$. A Figura 9 mostra as funções $F\left(z_{t}\right)$ para economia brasileira, para toda amostra utilizada, com a datação dos ciclos econômicos em barras cinza.

Em comparação com o modelo base, nos casos do hiato do produto e do NUCI, os multiplicadores de recessão ainda permanecem maiores do que os de expansão em todos os períodos. Os multiplicadores estimados são maiores do que dois, para quatro e oito trimestres após o choque fiscal e maiores do que 0,5 , no caso do multiplicador de impacto. No caso da taxa de desemprego, as variações mais expressivas ocorrem nos multiplicadores de impacto que passam de -0,1102 para 1,2644. O que mais chama atenção na Tabela 8 e na Tabela 10 é o fato de os multiplicadores estimados em recessão serem menores do que os de expansão quando a variável limiar é a taxa de desemprego e a taxa de crescimento do PIB. Este resultado diverge das evidências encontradas na literatura internacional, que tem encontrado, na maioria dos casos, multiplicadores maiores em regime de recessão.

\footnotetext{
${ }^{43}$ Seguimos aqui o trabalho de Gobetti, Orair e Siqueira (2016) e definimos que a economia brasileira está em recessão caso $F\left(z_{t}\right)>0,8$. Este critério é baseado na datação dos ciclos econômicos, de acordo com a CODACE.

${ }^{44}$ A variável de transição, $\gamma$, para média móvel de 7 trimestres da taxa de crescimento, foi calibrada igual a 4,4280 para garantir que o critério $p\left(F\left(z_{t}\right)>0,8\right)=0,2$ seja respeitado. Para o hiato do produto, o $\gamma=1,9527$, para taxa de desemprego $\gamma=1,3830$ e para o nuci $\gamma=2,4214$.
} 
Figura 9 - Teste de Robustez: Threshold Smooth Transition
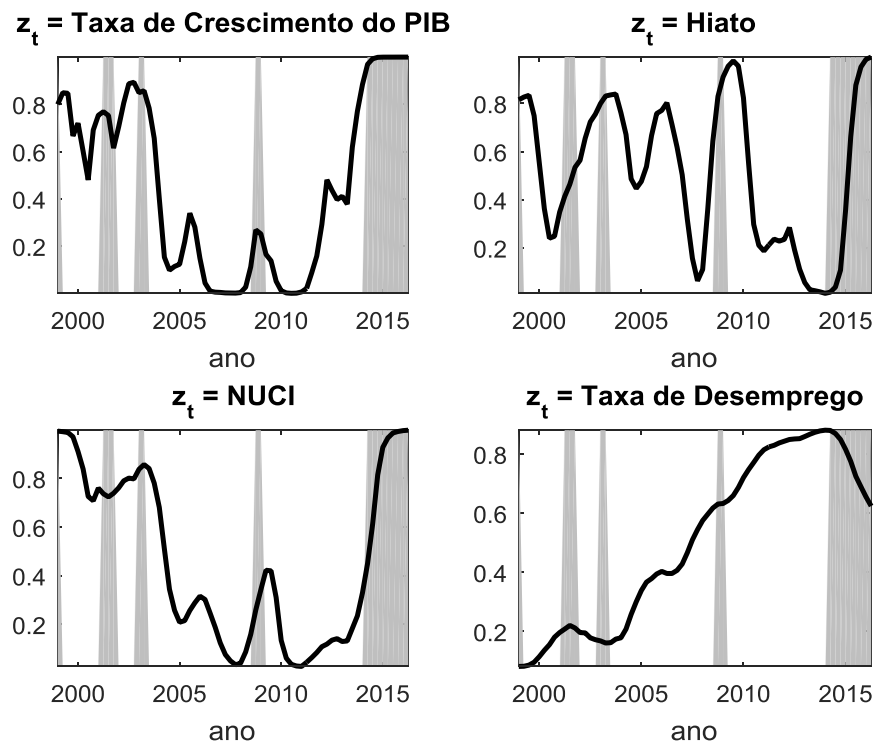

Fonte: Elaboração Própria.

Nota: Função $F\left(z_{t}\right)$ para economia brasileira. A linha sólida mostra a função de transição. As áreas sombreadas mostram os períodos de recessão, datados pelo CODACE.

Finalmente, o quarto teste de robustez exclui os últimos trimestres da amostra (a partir do segundo trimestre de 2014), período em que começou a grave crise econômica do país.

Para o modelo linear, apenas o multiplicador de oito trimestres não teve mudança significativa. No contexto não linear, os multiplicadores de impacto, sob o regime de recessão, apresentaram grandes mudanças, exceto para o limiar taxa de desemprego. Os multiplicadores de oito trimestres, para o hiato e para taxa de desemprego, em expansão, e o de recessão para o último, também tiveram alterações consideráveis. Para os demais, não ocorreu nenhuma modificação considerável, em comparação com o modelo base.

Em resumo, todos os testes de robustez confirmam que os multiplicadores em regime de recessão são maiores do que os multiplicadores em regime de expansão. Os testes HAC e AR sugerem que não há diferença entre multiplicadores nos períodos de recessão e de expansão. 
Tabela 7 - Multiplicadores do Modelo Linear - Testes de Robustez

\begin{tabular}{|c|c|c|c|}
\hline & Tendência & $\begin{array}{c}\text { PIB } \\
\text { Potencial }\end{array}$ & $\begin{array}{l}\text { Período } \\
\text { Truncado }\end{array}$ \\
\hline Multiplicador de Impacto & $\begin{array}{c}0,8104 * * * \\
(0,2058)\end{array}$ & $\begin{array}{c}0,5220 \\
(0,3246)\end{array}$ & $\begin{array}{c}0,8815 \\
(0,5590) \\
\end{array}$ \\
\hline Multiplicador de 4 trimestre & $\begin{array}{c}2,3193 * * * \\
(0,5004)\end{array}$ & $\begin{array}{c}2,1859 * * * \\
(0,5890)\end{array}$ & $\begin{array}{l}1,4322 * \\
(0,7565)\end{array}$ \\
\hline Multiplicador de 8 trimestre & $\begin{array}{c}2,8224 * * * \\
(0,4777)\end{array}$ & $\begin{array}{c}2,5188 * * * \\
(0,4467)\end{array}$ & $\begin{array}{c}2,7448 * * * \\
(0,2741)\end{array}$ \\
\hline
\end{tabular}

Fonte: Cálculo do Autor

Os erros padrões estão entre parênteses. (***) significativo a $1 \%$;

$(* *)$ significativo a $5 \% ;(*)$ significativo a $10 \%$.

Tabela 8 - Multiplicadores de Impacto do Modelo Não Linear - Testes de Robustez

\begin{tabular}{|c|c|c|c|c|c|}
\hline & & Tendência & PIB Potencial & $\begin{array}{l}\text { Smooth } \\
\text { Transition }\end{array}$ & $\begin{array}{l}\text { Período } \\
\text { Truncado }\end{array}$ \\
\hline \multirow{4}{*}{ Hiato } & Recessão & $0,8312^{*}$ & 0,3323 & $1,1204 * *$ & $1,9889 * * *$ \\
\hline & & $(0,5164)$ & $(0,8234)$ & $(0,4701)$ & $(0,5092)$ \\
\hline & Expansão & 0,4420 & 0,4203 & 0,9014 & 0,4890 \\
\hline & & $(0,3202)$ & $(0,3760)$ & $(0,7221)$ & $(0,6061)$ \\
\hline \multirow{2}{*}{$\begin{array}{l}\text { P-valor para diferença } \\
\text { entre estados }\end{array}$} & HAC & 0,4814 & 0,9318 & 0,4246 & 0,0613 \\
\hline & $\mathrm{AR}$ & 0,0000 & 0,0000 & 0,0000 & 0,0000 \\
\hline \multirow{4}{*}{ NUCI } & Recessão & $0,6116^{* * *}$ & $0,6261 * * *$ & $0,8813^{* *}$ & 2,0585 \\
\hline & & $(0,1318)$ & $(0,1939)$ & $(0,4211)$ & $(1,2930)$ \\
\hline & Expansão & $0,7849 * *$ & $0,7751^{*}$ & 0,8605 & $0,7332^{*}$ \\
\hline & & $(0,3917)$ & $(0,3894)$ & $(0,7771)$ & $(0,4921)$ \\
\hline \multirow{2}{*}{$\begin{array}{l}\text { P-valor para diferença } \\
\text { entre estados }\end{array}$} & HAC & 0,6753 & 0,7434 & 0,8630 & 0,3173 \\
\hline & $\mathrm{AR}$ & 0,0000 & 0,0000 & 0,0000 & 0,0000 \\
\hline \multirow{4}{*}{$\begin{array}{c}\text { Taxa de } \\
\text { Desemprego }\end{array}$} & Recessão & 2,1726 *** & $2,0434 * * *$ & 0,1812 & $2,0581 * * *$ \\
\hline & & $(0,1870)$ & $(0,1487)$ & $(0,3898)$ & $(0,2219)$ \\
\hline & Expansão & 0,0565 & $-0,1186$ & $1,2644 *$ & $-0,1653$ \\
\hline & & $(0,3244)$ & $(0,2118)$ & $(0,7928)$ & $(0,9265)$ \\
\hline \multirow{2}{*}{$\begin{array}{l}\text { P-valor para diferença } \\
\text { entre estados }\end{array}$} & HAC & 0,0000 & 0,0000 & 0,0684 & 0,0209 \\
\hline & $\mathrm{AR}$ & 0,0000 & 0,0000 & 0,0000 & 0,0000 \\
\hline \multirow{4}{*}{$\begin{array}{c}\text { Taxa de Crescimento } \\
\text { do PIB }\end{array}$} & Recessão & 0,3461 & 0,2781 & 0,4652 & $1,1884 * * *$ \\
\hline & & $(0,2123)$ & $(0,2837)$ & $(0,3301)$ & $(0,4075)$ \\
\hline & Expansão & $1,0742 * *$ & $0,9538 * *$ & 0,5835 & $0,9836^{* *}$ \\
\hline & & $(0,4670)$ & $(0,4721)$ & $(0,7601)$ & $(0,4866)$ \\
\hline \multirow{2}{*}{$\begin{array}{l}\text { P-valor para diferença } \\
\text { entre estados }\end{array}$} & HAC & 0,1872 & 0,2279 & 0,9187 & 0,7404 \\
\hline & $\mathrm{AR}$ & 0,0000 & 0,0000 & 0,0000 & 0,0000 \\
\hline \multirow{4}{*}{ CODACE } & Recessão & $0,3871 * *$ & 0,4034 & & $3,6363 * * *$ \\
\hline & & $(0,1909)$ & $(0,2477)$ & & $(1,1698)$ \\
\hline & Expansão & $1,0046^{* *}$ & $0,958^{* *}$ & & $0,9585 * *$ \\
\hline & & $(0,3996)$ & $(0,4063)$ & & $(0,4433)$ \\
\hline \multirow{2}{*}{$\begin{array}{l}\text { P-valor para diferença } \\
\text { entre estados }\end{array}$} & HAC & 0,1794 & 0,2198 & & 0,0058 \\
\hline & $\mathrm{AR}$ & 0,0000 & 0,0000 & & 0,0000 \\
\hline
\end{tabular}

Fonte: Cálculo do Autor. 
Os erros padrões estão entre parênteses. (***) significativo a 1\%; (**) significativo a 5\%; (*) significativo a $10 \%$.

Tabela 9 - Multiplicadores de 4 trimestres do Modelo Não Linear - Testes de Robustez

\begin{tabular}{|c|c|c|c|c|c|}
\hline & & Tendência & PIB Potencial & $\begin{array}{l}\text { Smooth } \\
\text { Transition }\end{array}$ & $\begin{array}{l}\text { Período } \\
\text { Truncado }\end{array}$ \\
\hline \multirow{4}{*}{ Hiato } & Recessão & $3,5618 * * *$ & $3,1603 * * *$ & $4,7571 * * *$ & $3,1711 * * *$ \\
\hline & & $(0,5828)$ & $(0,4531)$ & $(0,6021)$ & $(0,9415)$ \\
\hline & Expansão & $1,3310 * * *$ & $1,2679 * *$ & $3,2296 * * *$ & $1,1979 * *$ \\
\hline & & $(0,5144)$ & $(0,5393)$ & $(1,2492)$ & $(0,5945)$ \\
\hline \multirow{2}{*}{$\begin{array}{c}\text { P-valor para diferença } \\
\text { entre estados }\end{array}$} & $\mathrm{HAC}$ & 0,0003 & 0,0012 & 0,0012 & 0,0115 \\
\hline & AR & 0,1349 & 0,1615 & 0,0985 & 0,1770 \\
\hline \multirow{4}{*}{ NUCI } & Recessão & $4,3159 * * *$ & $4,2204 * * *$ & $3,7659 * * *$ & $3,4509 * * *$ \\
\hline & & $(0,3444)$ & $(0,3601)$ & $(0,7475)$ & $(0,8748)$ \\
\hline & Expansão & $1,397 * * *$ & $1,3517 * * *$ & $2,1254 * * *$ & $1,2341 * *$ \\
\hline & & $(0,4220)$ & $(0,3629)$ & $(0,6825)$ & $(0,5670)$ \\
\hline \multirow{2}{*}{$\begin{array}{c}\text { P-valor para diferença } \\
\text { entre estados }\end{array}$} & HAC & 0,0000 & 0,0000 & 0,1159 & 0,0034 \\
\hline & AR & 0,0806 & 0,0897 & 0,2423 & 0,3106 \\
\hline \multirow{4}{*}{$\begin{array}{c}\text { Taxa de } \\
\text { Desemprego }\end{array}$} & Recessão & $3,3499 * * *$ & $3,0183 * * *$ & $2,0492 *$ & $3,0429 * * *$ \\
\hline & & $(0,6365)$ & $(0,2950)$ & $(1,0792)$ & $(0,2910)$ \\
\hline & Expansão & $1,1000^{*}$ & $1,1558 *$ & $2,7541 * * *$ & $-0,0760$ \\
\hline & & $(0,5788)$ & $(0,6532)$ & $(0,8924)$ & $(1,4548)$ \\
\hline \multirow{2}{*}{$\begin{array}{c}\text { P-valor para diferença } \\
\text { entre estados }\end{array}$} & HAC & 0,0249 & 0,0208 & 0,1941 & 0,0339 \\
\hline & AR & 0,1336 & 0,1430 & 0,3762 & 0,1357 \\
\hline \multirow{4}{*}{$\begin{array}{c}\text { Taxa de Crescimento } \\
\text { do PIB }\end{array}$} & Recessão & $2,5939 * * *$ & $2,5574 * * *$ & $2,6194 * * *$ & $2,2672 * * *$ \\
\hline & & $(0,6809)$ & $(0,6963)$ & $(0,6173)$ & $(0,3521)$ \\
\hline & Expansão & 1,2697 & 1,1309 & $1,4028^{*}$ & $1,1998 *$ \\
\hline & & $(0,7797)$ & $(0,8095)$ & $(0,7650)$ & $(0,7078)$ \\
\hline \multirow{2}{*}{$\begin{array}{c}\text { P-valor para diferença } \\
\text { entre estados }\end{array}$} & HAC & 0,3715 & 0,2478 & 0,1550 & 0,1982 \\
\hline & AR & 0,4231 & 0,2540 & 0,3241 & 0,2644 \\
\hline \multirow{4}{*}{ CODACE } & Recessão & $4,8086 * * *$ & $4,2102 * * *$ & & $4,3562 * * *$ \\
\hline & & $(0,4644)$ & $(0,3073)$ & & $(0,9532)$ \\
\hline & Expansão & $1,6018 * * *$ & $1,5213^{*}$ & & $1,5140 * * *$ \\
\hline & & $(0,5170)$ & $(0,5887)$ & & $(0,5431)$ \\
\hline \multirow{2}{*}{$\begin{array}{c}\text { P-valor para diferença } \\
\text { entre estados }\end{array}$} & HAC & 0,0000 & 0,0002 & & 0,0000 \\
\hline & AR & 0,0826 & 0,0438 & & 0,2576 \\
\hline
\end{tabular}

Fonte: Cálculo do Autor.

Os erros padrões estão entre parênteses. (***) significativo a 1\%; (**) significativo a 5\%; (*) significativo a $10 \%$. 
Tabela 10 - Multiplicadores de 8 trimestres do Modelo Não Linear - Testes de Robustez

\begin{tabular}{|c|c|c|c|c|c|}
\hline & & Tendência & PIB Potencial & $\begin{array}{c}\text { Smooth } \\
\text { Transition }\end{array}$ & $\begin{array}{l}\text { Período } \\
\text { Truncado }\end{array}$ \\
\hline \multirow{4}{*}{ Hiato } & Recessão & $2,9725 * * *$ & $2,8904 * * *$ & $3,3291 * * *$ & $2,9105 * * *$ \\
\hline & & $(0,9284)$ & $(0,5383)$ & $(0,9185)$ & $(0,5206)$ \\
\hline & Expansão & $-0,2243$ & 0,1437 & 2,8785 & $2,1041 * * *$ \\
\hline & & $(1,8486)$ & $(1,7076)$ & $(2,0822)$ & $(0,5188)$ \\
\hline \multirow{2}{*}{$\begin{array}{l}\text { P-valor para diferença } \\
\text { entre estados }\end{array}$} & HAC & 0,1174 & 0,1332 & 0,1056 & 0,2236 \\
\hline & $\mathrm{AR}$ & 0,1517 & 0,1709 & 0,0957 & 0,3941 \\
\hline \multirow{4}{*}{ NUCI } & Recessão & 0,4063 & $2,7382 * * *$ & $5,8955 * * *$ & $2,7480 * * *$ \\
\hline & & $(1,4855)$ & $(0,8979)$ & $(1,5929)$ & $(0,4916)$ \\
\hline & Expansão & $2,5337 * * *$ & $2,7689 * * *$ & $5,2566 * * *$ & $2,7467 * * *$ \\
\hline & & $(0,4805)$ & $(0,3430)$ & $(0,4466)$ & $(0,3395)$ \\
\hline \multirow{2}{*}{$\begin{array}{l}\text { P-valor para diferença } \\
\text { entre estados }\end{array}$} & HAC & 0,9881 & 0,9761 & 0,8076 & 0,9984 \\
\hline & $\mathrm{AR}$ & 0,9881 & 0,9757 & 0,8228 & 0,9984 \\
\hline \multirow{4}{*}{$\begin{array}{c}\text { Taxa de } \\
\text { Desemprego }\end{array}$} & Recessão & $3,3075^{* * *}$ & $3,0515^{* * *}$ & 1,8478 & $3,1089 * * *$ \\
\hline & & $(0,7251)$ & $(0,3998)$ & $(2,0194)$ & $(0,3991)$ \\
\hline & Expansão & 0,3460 & 0,6420 & 2,8750 & $2,3106 * * *$ \\
\hline & & $(1,5218)$ & $(1,3454)$ & $(1,1950)$ & $(0,6853)$ \\
\hline \multirow{2}{*}{$\begin{array}{l}\text { P-valor para diferença } \\
\text { entre estados }\end{array}$} & HAC & 0,0603 & 0,0729 & 0,1278 & 0,3698 \\
\hline & $\mathrm{AR}$ & 0,1139 & 0,1252 & 0,2052 & 0,4564 \\
\hline \multirow{4}{*}{$\begin{array}{c}\text { Taxa de Crescimento } \\
\text { do PIB }\end{array}$} & Recessão & $2,4279 * * *$ & $2,7651 * * *$ & $2,8227^{*}$ & $2,6247 * * *$ \\
\hline & & $(0,7917)$ & $(0,6809)$ & $(1,6050)$ & $(0,1519)$ \\
\hline & Expansão & $2,4880^{* * *}$ & $2,7195^{* * *}$ & $4,1890 * * *$ & $3,1852 * * *$ \\
\hline & & $(0,8473)$ & $(0,6449)$ & $(0,4609)$ & $(0,4875)$ \\
\hline \multirow{2}{*}{$\begin{array}{l}\text { P-valor para diferença } \\
\text { entre estados }\end{array}$} & HAC & 0,9201 & 0,9624 & 0,0153 & 0,3028 \\
\hline & $\mathrm{AR}$ & 0,9215 & 0,9622 & 0,0969 & 0,3901 \\
\hline \multirow{4}{*}{ CODACE } & Recessão & $3,8762 * * *$ & $4,6293 * * *$ & & $3,8402 * * *$ \\
\hline & & $(1,1956)$ & $(0,1976)$ & & $(0,7848)$ \\
\hline & Expansão & $2,9545^{* * *}$ & $2,8116^{* * *}$ & & $2,9048 * * *$ \\
\hline & & $(0,5635)$ & $(0,3504)$ & & $(0,2468)$ \\
\hline \multirow{2}{*}{$\begin{array}{l}\text { P-valor para diferença } \\
\text { entre estados }\end{array}$} & HAC & 0,0000 & 0,0001 & & 0,2871 \\
\hline & $\mathrm{AR}$ & 0,1129 & 0,0893 & & 0,5366 \\
\hline
\end{tabular}

Fonte: Cálculo do Autor.

Os erros padrões estão entre parênteses. (***) significativo a 1\%; $(* *)$ significativo a $5 \% ;(*)$ significativo a $10 \%$.

\subsection{Teste de Robustez deflacionando pelo Deflator do PIB ${ }^{45}$}

A diferença sistemática entre o IPCA e o deflator do PIB é um tema considerável na conjuntura econômica brasileira, embora seja bastante técnico, traz implicações bastante relevantes para política econômica. Segundo Schymura (2017) entre os anos de 1996 e 2015, a inflação medida pelo IPCA, ficou em média, 1,4 ponto percentual (p.p.) menor, do que a

\footnotetext{
${ }^{45}$ As funções de respostas ao impulso são apresentadas no Apêndice.
} 
medição feita pelo deflator do PIB, a cada ano ${ }^{46}$. Além disso, há também uma enorme diferença entre o IPCA e o deflator do consumo do PIB.

Por diversos motivos, entender a divergência entre as trajetórias do IPCA e dos deflatores do PIB é essencial, em especial, quais as suas implicações relacionadas às questões fiscais. Primeiramente, caso esta disposição se mantiver para o futuro, será verificado um cenário menos desfavorável para a trajetória da dívida pública em porcentagem do PIB, isto porque o IPCA é a referência para projeção da elevação das despesas primárias do governo central, enquanto o deflator do PIB é usado para inflar grande parte das atividades econômicas que integram a base tributária.

Em segundo lugar, caso o IPCA estiver de fato distorcendo a inflação para baixo, isto implica que o juro real no Brasil é menor do que se supunha. Por fim, se o deflator estiver superestimado, a taxa de crescimento do PIB nominal foi maior.

Gobetti e Orair (2017) comparam as taxas de crescimento real das despesas do governo central, entre 1997 e 2015, utilizando tanto o IPCA, quanto o deflator do PIB, para deflacionar a série ${ }^{47}$. Os autores encontram que a taxa de crescimento da despesa ao ano, quando deflacionada pelo IPCA, foi de 5,7\% e quando o deflator do PIB é utilizado para deflacionar, a taxa de crescimento foi de $4,3 \%$.

Diante desta divergência entre IPCA e deflator do PIB e suas implicações sobre a política fiscal, esta seção refaz os exercícios de cálculo dos multiplicadores, mas agora usando o deflator do PIB para deflacionar as séries. O mesmo conjunto de dados foi usado e para calcular os multiplicadores fiscais não lineares foi utilizada a função de transição conforme Auerbach e Gorodnichenko (2012), apresentada na seção anterior.

Em primeiro, os resultados no contexto linear, estão presentes na Tabela 11. Em comparação com os resultados do modelo base, da seção 5.2, os multiplicadores de gastos do governo são menores, em todos os horizontes estimados, além de permanecerem significativos, um e dois anos após o choque fiscal.

No caso não linear, os multiplicadores em recessão econômica continuam sendo maiores do que os de expansão, exceto para a variável de transição taxa de desemprego, conforme a Tabela 12. Os testes HAC e AR ainda sugerem que não há diferença entre multiplicadores nos períodos de recessão e de expansão.

\footnotetext{
${ }^{46} \mathrm{O}$ mesmo autor também compara estas duas medidas de inflação, no mesmo período, entre os países desenvolvidos e os nossos pares. Nas economias avançadas, os índices de preços ao consumidor (IPC), ficaram em média, 0,3 p.p. acima do apresentado pelos deflatores do PIB. Já nos países com características similares a nossa, os deflatores do PIB foram maiores do que o IPC, em média, 0,5 p.p.

${ }^{47}$ Entre 1997 e 2015, a variação anual do IPCA foi de 6,4\%, enquanto o deflator do PIB foi de 7,9\%.
} 
Tabela 11 - Multiplicadores do

Modelo Linear - Teste de

Robustez, deflacionado pelo

Deflator do PIB

\begin{tabular}{lc}
\hline \hline Multiplicador de Impacto & 0,2719 \\
& $(0,2248)$ \\
\hline Multiplicador de 4 trimestre & $1,5762 * * *$ \\
& $(0,4142)$ \\
\hline Multiplicador de 8 trimestre & $2,0735^{* * *}$ \\
& $(0,5292)$ \\
\hline \hline
\end{tabular}

Fonte: Cálculo do Autor

Tabela 12 - Multiplicadores do Modelo Não Linear- Testes de Robustez, deflacionado pelo Deflator do PIB

\begin{tabular}{|c|c|c|c|c|}
\hline & & $\begin{array}{l}\text { Multiplicador } \\
\text { de Impacto }\end{array}$ & $\begin{array}{l}\text { Multiplicador } \\
4 \text { trimestre }\end{array}$ & $\begin{array}{l}\text { Multiplicador } \\
8 \text { trimestre }\end{array}$ \\
\hline \multirow{4}{*}{ Hiato } & Recessão & 0,6556 & $3,9424 * * *$ & $2,9570 * * *$ \\
\hline & & $(0,4019)$ & $(0,6236)$ & $(0,7910)$ \\
\hline & Expansão & 0,4914 & $1,9254 * *$ & 2,2228 \\
\hline & & $(0,3715)$ & $(0,7938)$ & $(1,9493)$ \\
\hline \multirow{2}{*}{$\begin{array}{c}\text { P-valor para diferença } \\
\text { entre estados }\end{array}$} & $\mathrm{HAC}$ & 0,4211 & 0,0004 & 0,2506 \\
\hline & AR & 0,0000 & 0,0873 & 0,1975 \\
\hline \multirow{4}{*}{ NUCI } & Recessão & 0,4934 & $2,3707 * * *$ & $4,5906 * *$ \\
\hline & & $(0,3005)$ & $(0,8926)$ & $(1,9983)$ \\
\hline & Expansão & 0,5605 & $1,4310 * * *$ & 3,9835 *** \\
\hline & & $(0,3595)$ & $(0,4277)$ & $(0,5242)$ \\
\hline \multirow{2}{*}{$\begin{array}{c}\text { P-valor para diferença } \\
\text { entre estados }\end{array}$} & $\mathrm{HAC}$ & 0,9971 & 0,4055 & 0,5817 \\
\hline & AR & 0,0000 & 0,474 & 0,6407 \\
\hline \multirow{4}{*}{$\begin{array}{c}\text { Taxa de } \\
\text { Desemprego }\end{array}$} & Recessão & $-0,0490$ & $1,6371^{*}$ & 1,8957 \\
\hline & & $(0,2186)$ & $(0,9123)$ & $(2,0236)$ \\
\hline & Expansão & 0,7199 & $2,4258 * * *$ & $3,3841 * * *$ \\
\hline & & $(0,7025)$ & $(0,7304)$ & $(0,9675)$ \\
\hline \multirow{2}{*}{$\begin{array}{l}\text { P-valor para diferença } \\
\text { entre estados }\end{array}$} & $\mathrm{HAC}$ & 0,0463 & 0,2694 & 0,0433 \\
\hline & $\mathrm{AR}$ & 0,0000 & 0,4099 & 0,1618 \\
\hline \multirow{4}{*}{$\begin{array}{c}\text { Taxa de Crescimento } \\
\text { do PIB }\end{array}$} & Recessão & 0,3078 & $2,9940 * * *$ & $3,8446 * * *$ \\
\hline & & $(0,2527)$ & $(0,6449)$ & $(0,8224)$ \\
\hline & Expansão & $0,7310 *$ & $1,4703 * *$ & $3,8523 * * *$ \\
\hline & & $(0,3738)$ & $(0,6273)$ & $(0,3072)$ \\
\hline \multirow{2}{*}{$\begin{array}{l}\text { P-valor para diferença } \\
\text { entre estados }\end{array}$} & HAC & 0,3284 & 0,0972 & 0,2744 \\
\hline & AR & 0,0000 & 0,2840 & 0,2243 \\
\hline
\end{tabular}

Fonte: Cálculo do Autor

O segundo teste de robustez, utilizando ainda o deflator do PIB para deflacionar a série, foi substituir a variável carga tributária líquida, pela carga tributária bruta. Novamente, foram estimados os multiplicadores, tanto no caso linear, quanto no caso não linear, usando a função de transição. A Tabela 13 e Tabela 14 mostram os resultados. 
Para o caso linear, novamente os multiplicadores são menores do que os apresentados no modelo base da seção 5.2. O multiplicador de impacto é um pouco menos que a metade do multiplicador do modelo base e permanecem significativos os multiplicadores de quatro e oito trimestres.

No caso não linear, a maior parte dos multiplicadores são maiores em recessão econômica do que em expansão e são significativos. O que chamou atenção foram os multiplicadores de oito trimestres, para as variáveis de transição NUCI, taxa de desemprego e taxa de crescimento, que em expansão econômica são maiores do que em contração.

Tabela 13 - Multiplicadores do

Modelo Linear - Teste de Robustez

Carga Tributária Bruta

\begin{tabular}{lc}
\hline \hline Multiplicador de Impacto & 0,2573 \\
& $(0,2713)$ \\
\hline Multiplicador de 4 trimestre & $1,6105^{* * *}$ \\
& $(0,4072)$ \\
\hline Multiplicador de 8 trimestre & $2,0620^{* * *}$ \\
& $(0,5687)$ \\
\hline \hline
\end{tabular}

Fonte: Cálculo do Autor

Tabela 14 - Multiplicadores do Modelo Não Linear- Testes de Robustez Carga Tributária Bruta

\begin{tabular}{|c|c|c|c|c|}
\hline & & $\begin{array}{l}\text { Multiplicador } \\
\text { de Impacto }\end{array}$ & $\begin{array}{l}\text { Multiplicador } \\
4 \text { trimestre }\end{array}$ & $\begin{array}{l}\text { Multiplicador } \\
8 \text { trimestre }\end{array}$ \\
\hline \multirow{4}{*}{ Hiato } & Recessão & 0,6822 & $3,6490 * * *$ & $2,7335 * * *$ \\
\hline & & $(0,4886)$ & $(0,5930)$ & $(0,8114)$ \\
\hline & Expansão & 0,5411 & 1,4294 & 1,2690 \\
\hline & & $(0,5502)$ & $(0,7212)$ & $(1,9201)$ \\
\hline \multirow{2}{*}{$\begin{array}{c}\text { P-valor para diferença } \\
\text { entre estados }\end{array}$} & $\mathrm{HAC}$ & 0,5480 & 0,0000 & 0,1382 \\
\hline & AR & 0,0000 & 0,0835 & 0,1247 \\
\hline \multirow{4}{*}{ NUCI } & Recessão & $0,6242 *$ & $1,7648^{*}$ & $3,7940^{*}$ \\
\hline & & $(0,3736)$ & $(0,9243)$ & $(1,9947)$ \\
\hline & Expansão & $0,4999 *$ & $1,4623 * * *$ & $4,4231 * * *$ \\
\hline & & $(0,2715)$ & $(0,4528)$ & $(0,3939)$ \\
\hline \multirow{2}{*}{$\begin{array}{c}\text { P-valor para diferença } \\
\text { entre estados }\end{array}$} & $\mathrm{HAC}$ & 0,8821 & 0,9711 & 0,0484 \\
\hline & $\mathrm{AR}$ & 0,0000 & 0,9712 & 0,3369 \\
\hline \multirow{4}{*}{$\begin{array}{c}\text { Taxa de } \\
\text { Desemprego }\end{array}$} & Recessão & 0,5611 & 1,6438 & 2,2388 \\
\hline & & $(0,6664)$ & $(0,7809)$ & $(1,7808)$ \\
\hline & Expansão & $-0,0352$ & $2,0592 * * *$ & $3,1644 * * *$ \\
\hline & & $(0,2309)$ & $(0,7848)$ & $(1,0300)$ \\
\hline \multirow{2}{*}{$\begin{array}{l}\text { P-valor para diferença } \\
\text { entre estados }\end{array}$} & HAC & 0,1425 & 0,6420 & 0,0953 \\
\hline & AR & 0,0000 & 0,6955 & 0,2088 \\
\hline \multirow{4}{*}{$\begin{array}{c}\text { Taxa de Crescimento } \\
\text { do PIB }\end{array}$} & Recessão & 0,3282 & $2,8329 * * *$ & $3,6009 * * *$ \\
\hline & & $(0,2861)$ & $(0,5896)$ & $(0,7242)$ \\
\hline & Expansão & $0,7717 * *$ & $1,5501 * *$ & $4,0444 * * *$ \\
\hline & & $(0,3640)$ & $(0,6110)$ & $(0,2946)$ \\
\hline
\end{tabular}




\begin{tabular}{ccccc} 
P-valor para diferença & HAC & 0,3570 & 0,1266 & 0,1151 \\
entre estados & AR & 0,0000 & 0,3156 & 0,1254 \\
\hline \hline
\end{tabular}

Fonte: Cálculo do Autor 


\section{Multiplicadores sobre as demais Variáveis}

Dados os resultados encontrados até aqui sobre os multiplicadores fiscais, este capítulo foi proposto para compreender sobre os mecanismos de transmissão envolvidos que poderiam explicar as conclusões empíricas. O objetivo não é desenvolver um modelo teórico que possa explicar os resultados encontrados. Mas sim, mostrar algumas das principais forças implícitas que poderiam ajudar a fundamentar os achados anteriores e apontar fatores que possam se adequar de base para pesquisas futuras nesta área.

\subsection{Carga Tributária Líquida}

Inicialmente foram estimadas as respostas da carga tributária líquida a um choque fiscal, quando não há distinção entre os regimes econômicos, e posteriormente, quando se faz a diferenciação entre os regimes de expansão e de recessão.

O multiplicador da carga tributária líquida pode ser estimado por variáveis instrumentais como descrito nas equações (4) e (5), sendo definido por $M_{h}^{T}=\frac{\sum_{s=1}^{h} \beta_{s}^{T}}{\sum_{s=1}^{h} \beta_{s}^{G}}$.

A Tabela 15 e Tabela 16apresentam os resultados dos multiplicadores da carga tributária, para o modelo linear e não linear, respectivamente. No caso linear, um choque de gastos do governo de $1 \%$ do produto produz efeito negativo sobre a carga tributária líquida sendo apenas significativo o multiplicador de impacto. Este resultado do modelo linear é semelhante ao encontrado por Mendonça, Medrano e Sachsida (2009), que também estimam efeitos negativos e muito pequenos do choque fiscal sobre a carga tributária.

No caso não linear, os multiplicadores são quase todos negativos, embora poucos sejam significantes. A Figura 10, Figura 11, Figura 12, Figura 13, Figura 14 e Figura 15 mostram as funções de impulso resposta da carga tributária líquida, após o choque de despesa primária. 


\begin{tabular}{lr} 
Tabela 15 - Multiplicadores da Carga \\
Tributária Líquida do Modelo Linear \\
\hline \hline Multiplicador de Impacto & $-0.5882^{* *}$ \\
& $(0,2632)$ \\
\hline Multiplicador de 4 trimestre & $-0,0310$ \\
& $(0,0769)$ \\
\hline Multiplicador de 8 trimestre & $-0,0480$ \\
& $(0,0580)$ \\
\hline \hline
\end{tabular}

Fonte: Cálculo do Autor.

Os erros padrões estão entre parênteses. (***) significativo a $1 \% ;(* *)$ significativo a $5 \%$;

$(*)$

Tabela 16 - Multiplicadores da Carga Tributária Líquida do Não Modelo Linear

\begin{tabular}{|c|c|c|c|c|}
\hline & & $\begin{array}{l}\text { Multiplicador } \\
\text { de Impacto }\end{array}$ & $\begin{array}{l}\text { Multiplicador } \\
4 \text { trimestre }\end{array}$ & $\begin{array}{l}\text { Multiplicador } \\
8 \text { trimestre }\end{array}$ \\
\hline \multirow{4}{*}{ Hiato } & Recessão & $-0,8591$ & $-0,0113^{*}$ & $-0,0096^{*}$ \\
\hline & & $(0,3044)$ & $(0,1219)$ & $(0,1017)$ \\
\hline & Expansão & $0,0569 * * *$ & $-0,0401$ & $-0,0094 *$ \\
\hline & & $(0,2234)$ & $(0,1253)$ & $(0,0916)$ \\
\hline \multirow{2}{*}{$\begin{array}{c}\text { P-valor para diferença } \\
\text { entre estados }\end{array}$} & HAC & 0,0070 & 0,8380 & 0,9987 \\
\hline & AR & 0,0000 & 0,8414 & 0,9987 \\
\hline \multirow{4}{*}{ NUCI } & Recessão & $-0,6682 * * *$ & 0,0325 & $0,0886 * * *$ \\
\hline & & $(0,1640)$ & $(0,0716)$ & $(0,0338)$ \\
\hline & Expansão & $-0,1795$ & $-0,0529$ & $-0,0354$ \\
\hline & & $(0,3928)$ & $(0,1147)$ & $(0,0711)$ \\
\hline \multirow{2}{*}{$\begin{array}{c}\text { P-valor para diferença } \\
\text { entre estados }\end{array}$} & $\mathrm{HAC}$ & 0,2424 & 0,4189 & 0,2090 \\
\hline & $\mathrm{AR}$ & 0,0000 & 0,4469 & 0,141 \\
\hline \multirow{4}{*}{$\begin{array}{c}\text { Taxa de } \\
\text { Desemprego }\end{array}$} & Recessão & 0,2206 & 0,0645 & 0,0397 \\
\hline & & $(0,3317)$ & $(0,0925)$ & $(0,0623)$ \\
\hline & Expansão & $-1,3576^{* * *}$ & $-0,3372 * * *$ & $-0,3342 * * *$ \\
\hline & & $(0,1783)$ & $(0,0842)$ & $(0,0802)$ \\
\hline \multirow{2}{*}{$\begin{array}{c}\text { P-valor para diferença } \\
\text { entre estados }\end{array}$} & HAC & 0,0000 & 0,0006 & 0,0008 \\
\hline & AR & 0,0000 & 0,1102 & 0,0434 \\
\hline \multirow{4}{*}{$\begin{array}{c}\text { Taxa de Crescimento } \\
\text { do PIB }\end{array}$} & Recessão & $-0,5462 *$ & 0,0244 & 0,0237 \\
\hline & & $(0,3195)$ & $(0,0674)$ & $(0,0384)$ \\
\hline & Expansão & $-0,6051^{*}$ & $-0,1539 *$ & $-0,1220$ \\
\hline & & $(0,1640)$ & $(0,0939)$ & $(0,0618)$ \\
\hline \multirow{2}{*}{$\begin{array}{l}\text { P-valor para diferença } \\
\text { entre estados }\end{array}$} & HAC & 0,2424 & 0,4189 & 0,2009 \\
\hline & AR & 0,0000 & 0,1657 & 0,1692 \\
\hline \multirow{4}{*}{ CODACE } & Recessão & $-0,6639 * * *$ & $-0,0007 * * *$ & 0,0557 \\
\hline & & $(0,1569)$ & $(0,0661)$ & $(0,0372)$ \\
\hline & Expansão & $-0,1697$ & $-0,0496$ & $-0,2924$ \\
\hline & & $(0,3444)$ & $(0,1019)$ & $(0,0614)$ \\
\hline $\mathrm{P}$-valor para diferença & $\mathrm{HAC}$ & 0,1984 & 0,6318 & 0,2198 \\
\hline
\end{tabular}




entre estados $\quad$ AR
Fonte: Cálculo do Autor.
Os erros padrões estão entre parênteses. $(* * *)$ significativo a $1 \% ;(* *)$ significativo a $5 \%$;
$(*)$ significativo a $10 \%$.

Figura 10 - Função Resposta ao Impulso do Modelo Linear: Carga Tributária Líquida

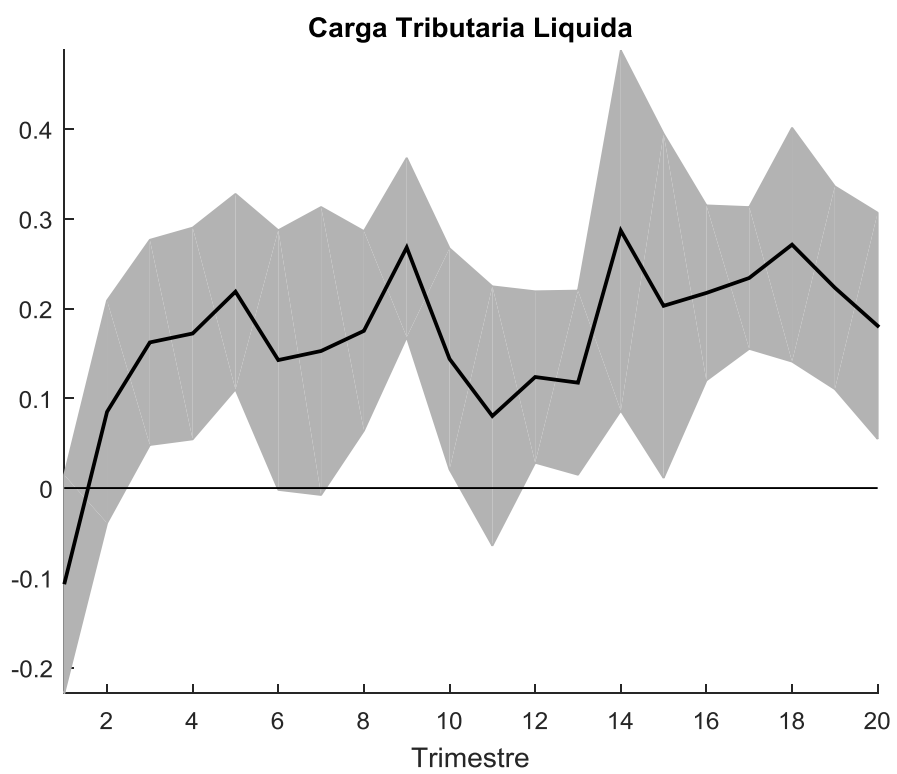

Fonte: Elaboração Própria.

Nota: Resposta da carga tributária líquida a um choque de gastos primários de $1 \%$ do PIB. As áreas sombreadas correspondem ao intervalo de confiança de $95 \%$.

Figura 11 - Função Resposta ao Impulso da Carga Tributária Líquida do Modelo Não Linear: Threshold Hiato
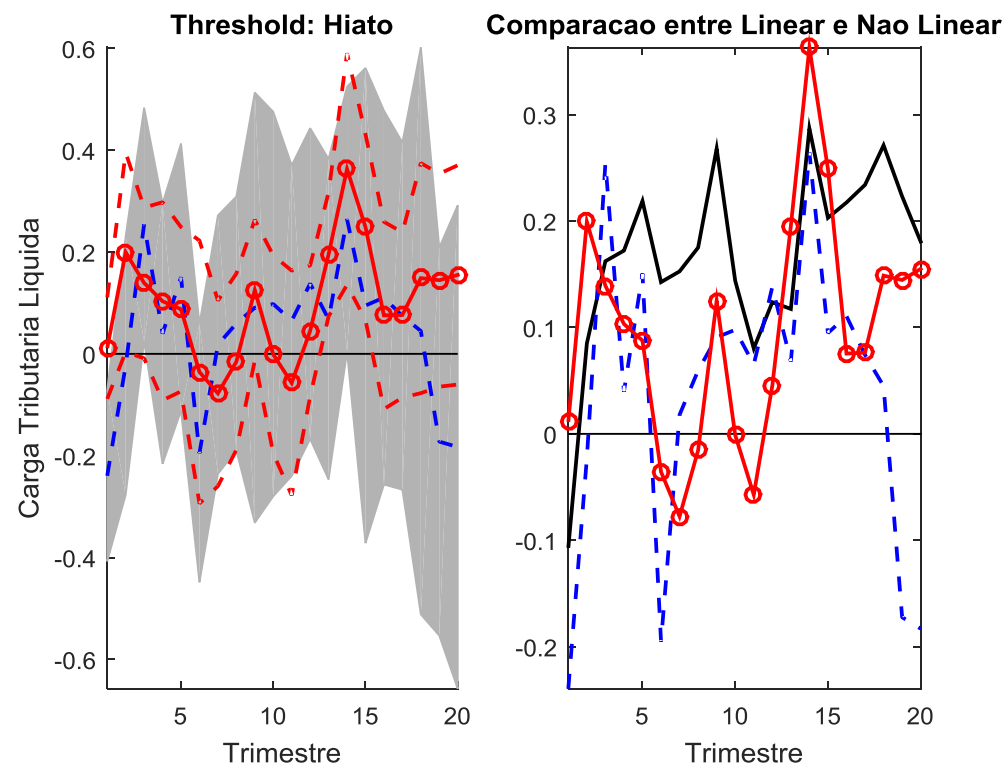

Fonte: Elaboração Própria.

Nota: Respostas do modelo não linear da carga tributária líquida a um choque de gastos primários de $1 \%$ do PIB. As áreas sombreadas correspondem ao intervalo de confiança de $95 \%$. 
Figura 12 - Função Resposta ao Impulso da Carga Tributária Líquida do Modelo Não Linear: Threshold NUCI
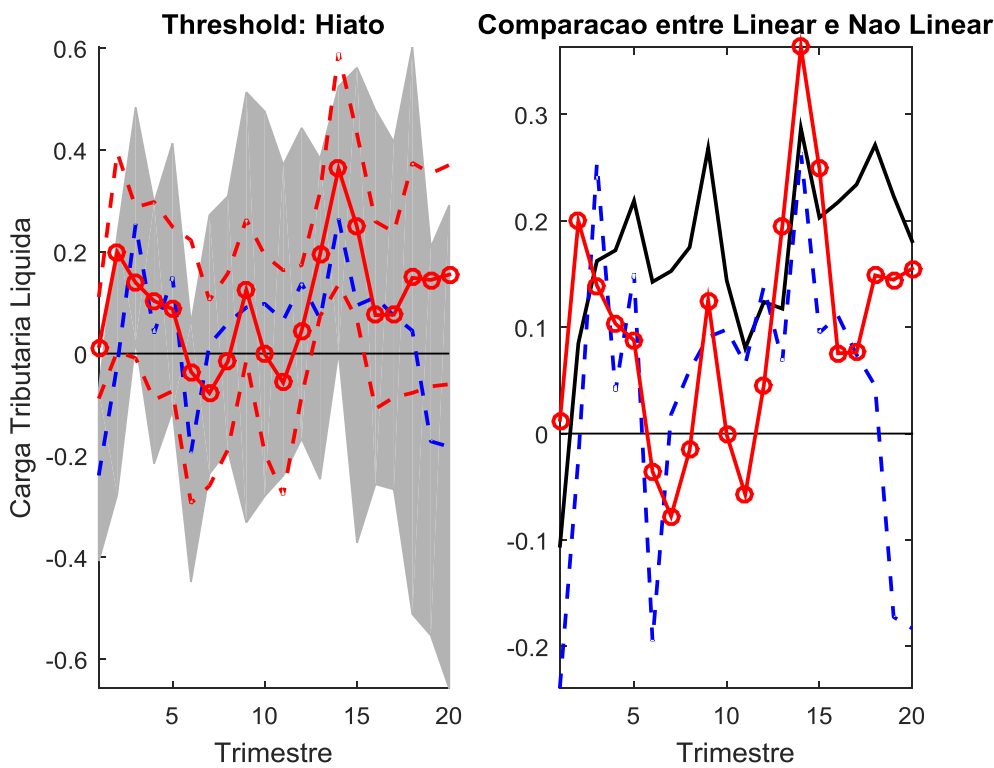

Fonte: Elaboração Própria.

Nota: Respostas do modelo não linear da carga tributária líquida a um choque de gastos primários de $1 \%$ do PIB. As áreas sombreadas correspondem ao intervalo de confiança de $95 \%$.

Figura 13 - Função Resposta ao Impulso da Carga Tributária Líquida do Modelo Não Linear: Threshold Taxa de Crescimento do PIB
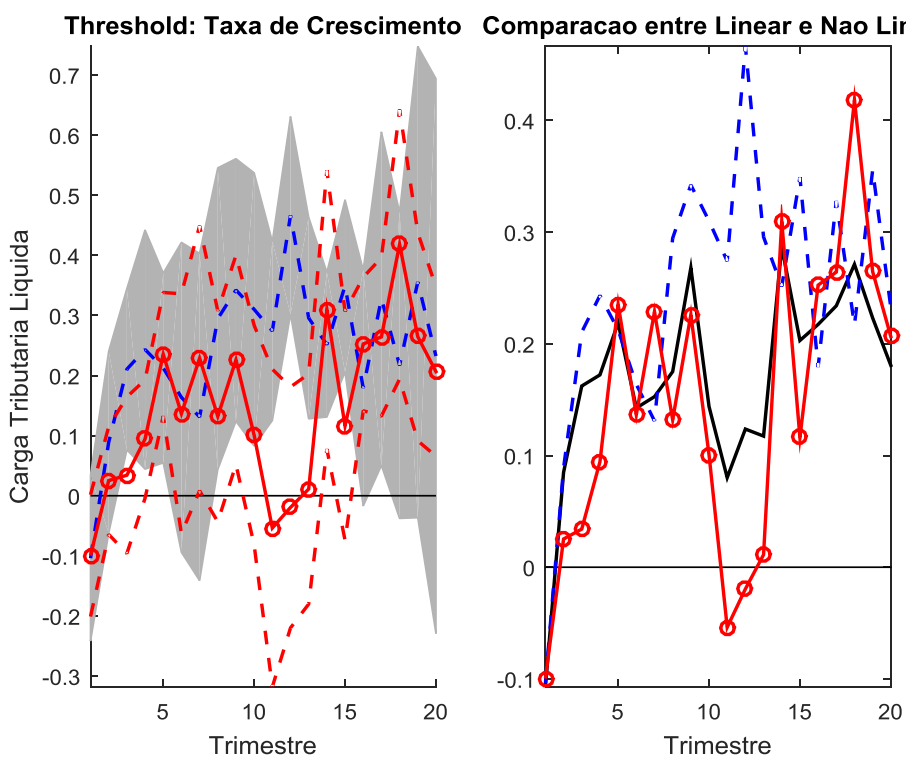

Fonte: Elaboração Própria.

Nota: Respostas do modelo não linear da carga tributária líquida a um choque de gastos primários de $1 \%$ do PIB. As áreas sombreadas correspondem ao intervalo de confiança de $95 \%$. 
Figura 14 - Função Resposta ao Impulso da Carga Tributária Líquida do Modelo Não Linear:

Threshold Taxa de Desemprego
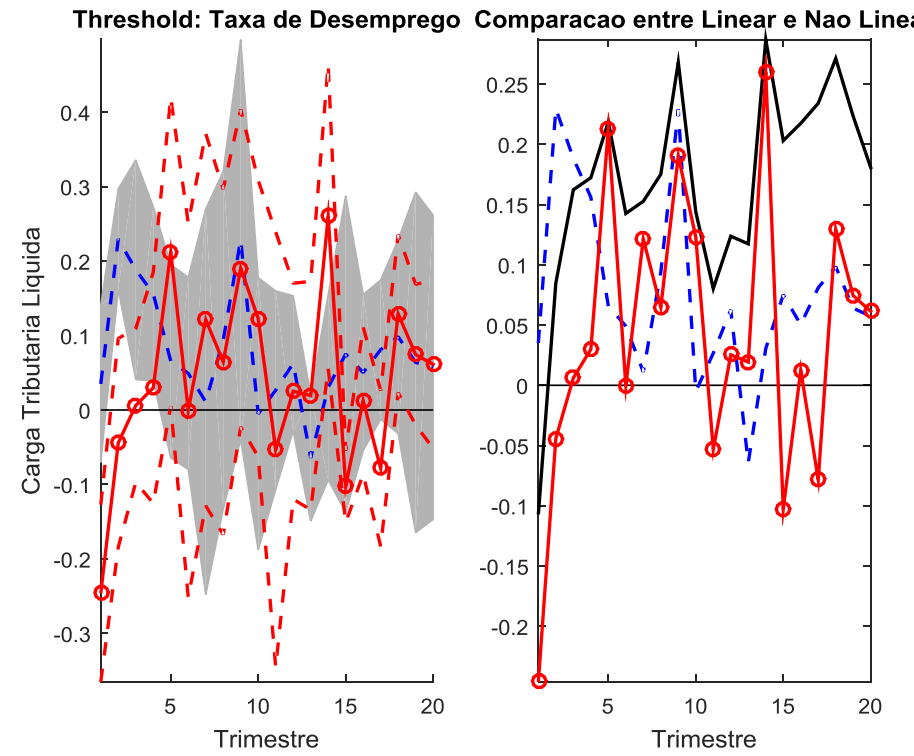

Fonte: Elaboração Própria.

Nota: Respostas do modelo não linear da carga tributária líquida a um choque de gastos primários de $1 \%$ do PIB. As áreas sombreadas correspondem ao intervalo de confiança de $95 \%$.

Figura 15 - Função Resposta ao Impulso da Carga Tributária Líquida do Modelo Não Linear: Threshold Datação da CODACE
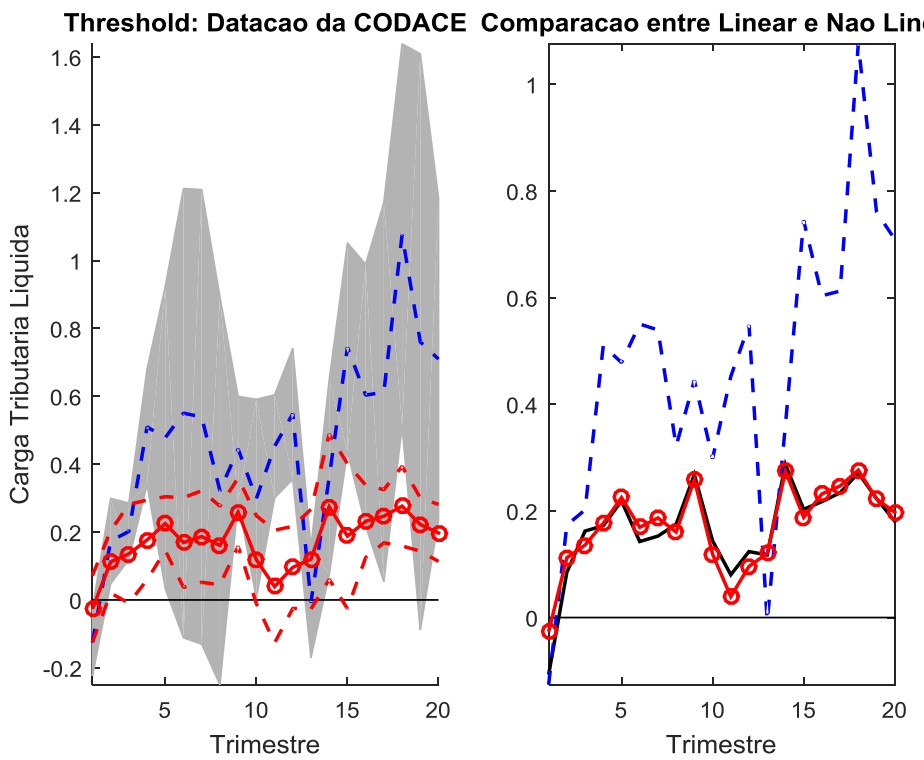

Fonte: Elaboração Própria.

Nota: Respostas do modelo não linear da carga tributária líquida a um choque de gastos primários de $1 \%$ do PIB. As áreas sombreadas correspondem ao intervalo de confiança de $95 \%$.

\subsection{Consumo Privado e Investimento}

Para avaliar os efeitos de um choque fiscal sobre o consumo privado, foi feita uma pequena alteração na especificação das equações (1) e (2), tendo sido incluída uma defasagem 
do consumo, além das defasagens das variáveis de controle padrão (produto, despesa primária e carga tributária líquida) ${ }^{48}$.

O multiplicador do consumo pode ser estimado por variáveis instrumentais, da mesma forma descrita nas equações (4) e (5), sendo definido por $M_{h}^{C}=\frac{\sum_{s=1}^{h} \beta_{s}^{C}}{\sum_{s=1}^{h} \beta_{s}^{G}}$.

As respostas ao impulso fiscal e o multiplicador do investimento foram definidos e estimados da mesma forma.

A Tabela 17 apresenta os resultados para o modelo linear e a Figura 16 mostra as funções de impulso resposta. O multiplicador do consumo aumenta com o passar dos trimestres, indicando um efeito positivo e crescente do choque fiscal. O multiplicador do investimento oscila ao longo dos trimestres, aumentando nos primeiros trimestres, chegando em 0,7896 um ano após o choque de gastos, e depois reduz para 0,6458, oito trimestres depois do choque fiscal ${ }^{49}$.

Tabela 17 - Multiplicadores do Consumo e do Investimento do Modelo Linear

\begin{tabular}{lcc}
\hline \hline & Consumo & Investimento \\
\hline Multiplicador de Impacto & 0,0620 & 0,0261 \\
& $(0,0825)$ & $(0,1903)$ \\
\hline Multiplicador de 4 trimestres & $0,7873 * * *$ & $0,7896 * * *$ \\
& $(0,1658)$ & $(0,2946)$ \\
\hline Multiplicador de 8 trimestres & $0,9750 * * *$ & $0,6458 *$ \\
& $(0,2284)$ & $(0,3366)$ \\
\hline \hline
\end{tabular}

Fonte: Cálculo do Autor.

Os erros padrões estão entre parênteses. (***) significativo a 1\%;

$(* *)$ significativo a $5 \% ;(*)$ significativo a $10 \%$.

\footnotetext{
${ }^{48}$ Esta abordagem foi feita por Miyamoto, Nguyen e Sergeyev (2017), ao estudar os efeitos dos demais componentes do PIB. Riera-Crichton, Vegh e Vuletin (2015) não alteram as especificações das equações (1) e (2) para calcular as respostas dos demais componentes da demanda agregada.

${ }^{49}$ A série de formação bruta de capital fixo, nas contas brasileiras, não distingue entre capital privado e capital público, de tal modo que nesta seção, não conseguiremos distinguir se os efeitos são sobre o investimento privado ou sobre o investimento público.
} 
Figura 16 - Função Resposta ao Impulso do Modelo Linear: Consumo Privado e Investimento
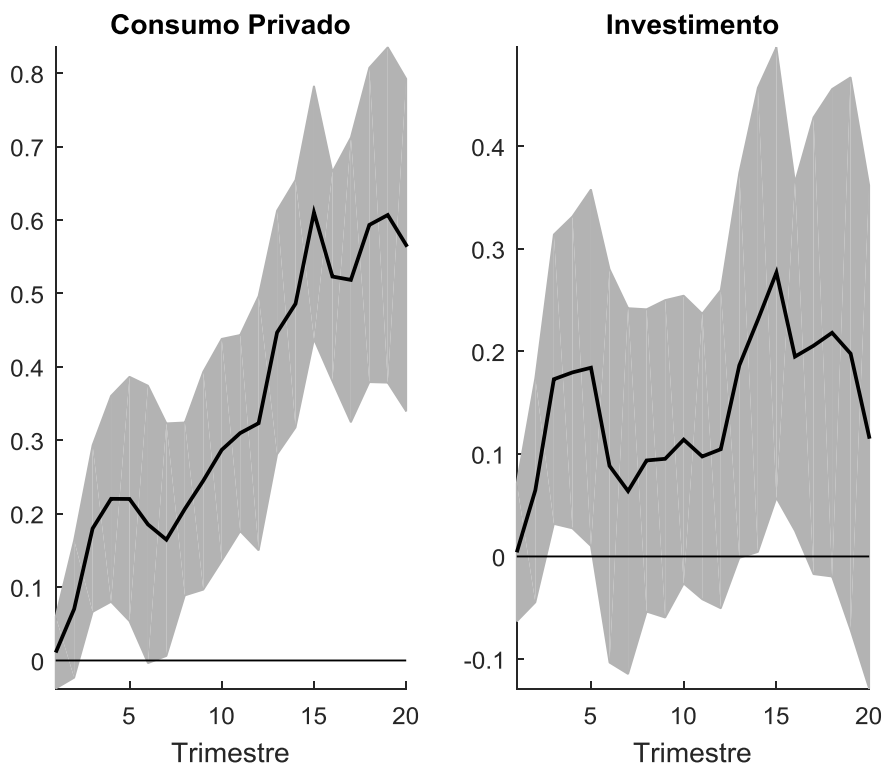

Fonte: Elaboração Própria.

Nota: Resposta do consumo privado a um choque de gastos primários de $1 \%$ do PIB. As áreas sombreadas correspondem ao intervalo de confiança de $95 \%$.

Os multiplicadores do modelo não linear para o consumo e para o investimento estão na Tabela 18 e Tabela 19, respectivamente. A Figura 17, Figura 18, Figura 19, Figura 20 e Figura 21 mostram as funções impulso resposta do consumo e do investimento para dependência de regime.

Para o consumo, os multiplicadores são maiores em recessão, exceto para o limiar taxa de desemprego, após um ano do choque de gastos. Para os limiares hiato e CODACE, os multiplicadores são maiores do que um e a maior parte é significativa, após um e dois anos do choque fiscal. Este resultado esta em linha com o encontrado por Tagkalakis (2008) para os países da OCDE, onde o consumo privado aumenta mais após um choque fiscal, nos períodos de contração econômica.

No caso do investimento, há multiplicadores maiores do que um, em recessão, quando os limiares são a taxa de crescimento e CODACE. Entretanto, alguns são negativos, quando o threshold é o hiato, o NUCI e a taxa de desemprego ${ }^{50}$.

\footnotetext{
${ }^{50}$ Riera-Crichton, Vegh e Vuletin (2015) não encontraram multiplicadores estatisticamente significativos do consumo e do investimento.
} 
Tabela 18 - Multiplicadores do Consumo do Não Modelo Linear

\begin{tabular}{|c|c|c|c|c|}
\hline & & $\begin{array}{l}\text { Multiplicador } \\
\text { de Impacto }\end{array}$ & $\begin{array}{l}\text { Multiplicador } \\
4 \text { trimestre }\end{array}$ & $\begin{array}{l}\text { Multiplicador } \\
8 \text { trimestre }\end{array}$ \\
\hline \multirow{4}{*}{ Hiato } & Recessão & 0,3387 & $1,4891 * * *$ & $1,7345 * * *$ \\
\hline & & $(0,4265)$ & $(0,2898)$ & $(0,6653)$ \\
\hline & Expansão & $-0,1863$ & 0,1276 & $-0,0969$ \\
\hline & & $(0,2410)$ & $(0,3816)$ & $(0,5382)$ \\
\hline \multirow{2}{*}{$\begin{array}{l}\text { P-valor para diferença } \\
\text { entre estados }\end{array}$} & HAC & 0,3797 & 0,0158 & 0,0574 \\
\hline & AR & 0,0000 & 0,1453 & 0,211 \\
\hline \multirow{4}{*}{ NUCI } & Recessão & $0,2612 * * *$ & $2,0482 * * *$ & 0,2093 \\
\hline & & $(0,0978)$ & $(0,7058)$ & $(1,0263)$ \\
\hline & Expansão & 0,0042 & $0,4377 * * *$ & $1,1417 * * *$ \\
\hline & & $(0,1351)$ & $(0,1023)$ & $(0,1338)$ \\
\hline \multirow{2}{*}{$\begin{array}{c}\text { P-valor para diferença } \\
\text { entre estados }\end{array}$} & HAC & 0,1455 & 0,0247 & 0,2786 \\
\hline & AR & 0,0000 & 0,1643 & 0,3074 \\
\hline \multirow{4}{*}{$\begin{array}{c}\text { Taxa de } \\
\text { Desemprego }\end{array}$} & Recessão & 0,4813 & $0,9699 * * *$ & $1,3933 * * *$ \\
\hline & & $(0,4012)$ & $(0,2503)$ & $(0,1894)$ \\
\hline & Expansão & $0,0974 * *$ & $1,0232 * * *$ & 0,4941 \\
\hline & & $(0,0498)$ & $(0,2313)$ & $(0,8537)$ \\
\hline \multirow{2}{*}{$\begin{array}{c}\text { P-valor para diferença } \\
\text { entre estados }\end{array}$} & HAC & 0,3429 & 0,8758 & 0,2668 \\
\hline & AR & 0,0000 & 0,8773 & 0,2548 \\
\hline \multirow{4}{*}{$\begin{array}{c}\text { Taxa de Crescimento } \\
\text { do PIB }\end{array}$} & Recessão & $-0,0758$ & $0,9885 * *$ & $1,5811 * * *$ \\
\hline & & $(0,1136)$ & $(0,4152)$ & $(0,4427)$ \\
\hline & Expansão & 0,2044 & 0,1842 & $0,5775 * *$ \\
\hline & & $(0,2523)$ & $(0,1953)$ & $(0,2700)$ \\
\hline \multirow{2}{*}{$\begin{array}{c}\text { P-valor para diferença } \\
\text { entre estados }\end{array}$} & HAC & 0,4128 & 0,1389 & 0,0808 \\
\hline & $\mathrm{AR}$ & 0,0000 & 0,2743 & 0,1387 \\
\hline \multirow{4}{*}{ CODACE } & Recessão & $0,1957 *$ & $3,0132 * * *$ & $5,1697 * * *$ \\
\hline & & $(0,1139)$ & $(0,3903)$ & $(1,7004)$ \\
\hline & Expansão & 0,0104 & $0,2942 * * *$ & $0,8976 * * *$ \\
\hline & & $(0,1592)$ & $(0,0981)$ & $(0,1987)$ \\
\hline \multirow{2}{*}{$\begin{array}{l}\text { P-valor para diferença } \\
\text { entre estados }\end{array}$} & HAC & 0,4491 & 0,0000 & 0,0134 \\
\hline & AR & 0,0000 & 0,1447 & 0,0699 \\
\hline
\end{tabular}

Fonte: Cálculo do Autor.

Os erros padrões estão entre parênteses. (***) significativo a 1\%; (**) significativo a 5\%;

(*) significativo a $10 \%$.

Tabela 19 - Multiplicadores do Investimento do Não Modelo Linear

\begin{tabular}{ccccc}
\hline \hline & & $\begin{array}{c}\text { Multiplicador } \\
\text { de Impacto }\end{array}$ & $\begin{array}{c}\text { Multiplicador } \\
4 \text { trimestre }\end{array}$ & $\begin{array}{c}\text { Multiplicador } \\
8 \text { trimestre }\end{array}$ \\
\hline \multirow{2}{*}{ Hiato } & Recessão & $-0,5956$ & 0,2450 & $-0,2278$ \\
& Expansão & $0,5007)$ & $(0,6924)$ & $(0,6564)$ \\
& & $(0,1763)$ & $0,6641 * *$ & $-0,1650$ \\
P-valor para diferença & HAC & 0,0922 & $0,2819)$ & $(1,0310)$ \\
entre estados & AR & 0,0000 & 0,6024 & 0,9556 \\
\hline \multirow{2}{*}{ NUCI } & Recessão & $-0,3723$ & $1,791 * * *$ & 0,9558 \\
\hline & & $(0,1799)$ & $(0,6642)$ & $(1,5444)$
\end{tabular}




\begin{tabular}{|c|c|c|c|c|}
\hline \multirow{3}{*}{$\begin{array}{c}\text { P-valor para diferença } \\
\text { entre estados }\end{array}$} & Expansão & $\begin{array}{c}0,1535 \\
(0,2391)\end{array}$ & $\begin{array}{c}0,4182 \\
(0,2846)\end{array}$ & $\begin{array}{c}0,9067 * * * \\
(0,2220)\end{array}$ \\
\hline & HAC & 0,5460 & 0,0902 & 0,1577 \\
\hline & $\mathrm{AR}$ & 0,0000 & 0,2730 & 0,1151 \\
\hline \multirow{4}{*}{$\begin{array}{c}\text { Taxa de } \\
\text { Desemprego }\end{array}$} & Recessão & 0,2396 & $0,8905^{* * *}$ & $0,9345 * * *$ \\
\hline & & $(0,2562)$ & $(0,2293)$ & $(0,3438)$ \\
\hline & Expansão & $-0,1068$ & 0,0115 & 0,0479 \\
\hline & & $(0,1114)$ & $(0,2173)$ & $(0,6308)$ \\
\hline \multirow{2}{*}{$\begin{array}{l}\text { P-valor para diferença } \\
\text { entre estados }\end{array}$} & HAC & 0,2012 & 0,0035 & 0,2197 \\
\hline & AR & 0,0000 & 0,1294 & 0,2395 \\
\hline \multirow{4}{*}{$\begin{array}{c}\text { Taxa de Crescimento } \\
\text { do PIB }\end{array}$} & Recessão & 0,0346 & $1,2226 * * *$ & $1,0381 * * *$ \\
\hline & & $(0,1010)$ & $(0,2693)$ & $(0,3468)$ \\
\hline & Expansão & 0,0002 & $-0,0192$ & 0,3619 \\
\hline & & $(0,2246)$ & $(0,3280)$ & $(0,3633)$ \\
\hline \multirow{2}{*}{$\begin{array}{l}\text { P-valor para diferença } \\
\text { entre estados }\end{array}$} & HAC & 0,8856 & 0,0081 & 0,1385 \\
\hline & $\mathrm{AR}$ & 0,0000 & 0,1127 & 0,2647 \\
\hline \multirow{4}{*}{ CODACE } & Recessão & 0,0491 & $1,9698^{* * *}$ & 0,0882 \\
\hline & & $(0,0460)$ & $(0,3824)$ & $(1,2311)$ \\
\hline & Expansão & 0,1396 & 0,3552 & $0,7219 * *$ \\
\hline & & $(0,2010)$ & $(0,2945)$ & $(0,3085)$ \\
\hline \multirow{2}{*}{$\begin{array}{l}\text { P-valor para diferença } \\
\text { entre estados }\end{array}$} & HAC & 0,6457 & 0,0043 & 0,6195 \\
\hline & $\mathrm{AR}$ & 0,0000 & 0,1288 & 0,6259 \\
\hline
\end{tabular}

Fonte: Cálculo do Autor.

Os erros padrões estão entre parênteses. (***) significativo a 1\%; (**) significativo a 5\%;

(*) significativo a $10 \%$.

Figura 17 - Função Resposta ao Impulso do Consumo Privado e do Investimento no Modelo Não Linear: Threshold Hiato
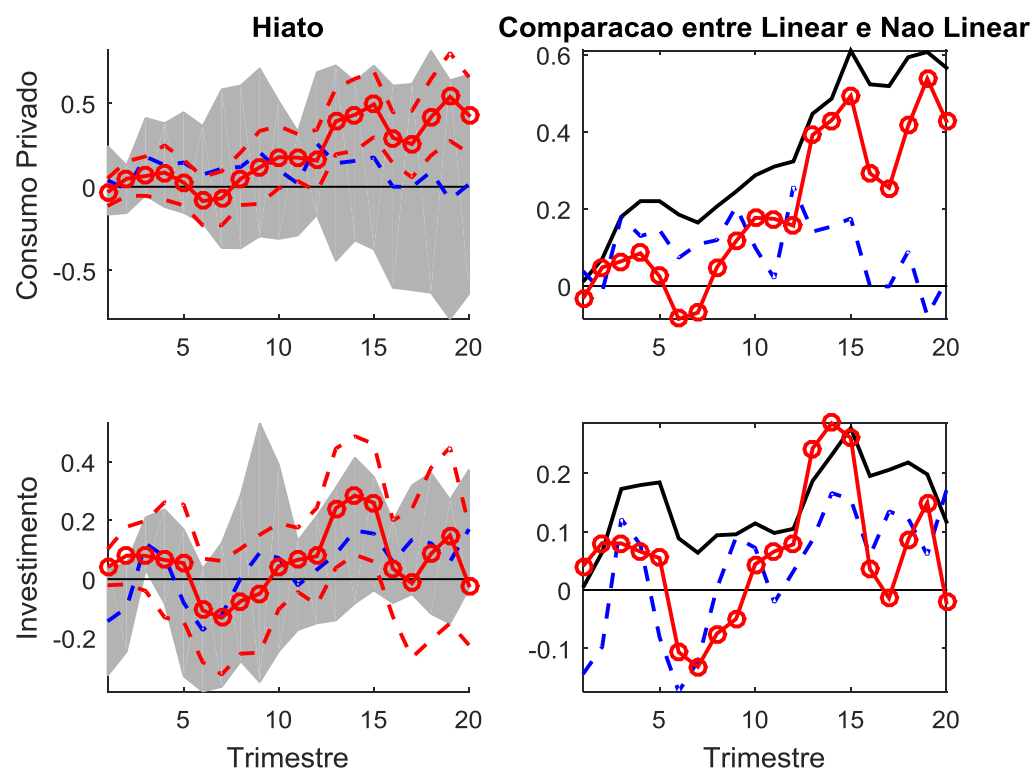

Fonte: Elaboração Própria.

Nota: Respostas do modelo não linear do consumo privado e do investimento a um choque de gastos primários de $1 \%$ do PIB. As áreas sombreadas correspondem ao intervalo de confiança de $95 \%$. 
Figura 18 - Função Resposta ao Impulso do Consumo Privado e do Investimento no Modelo Não Linear: Threshold NUCI
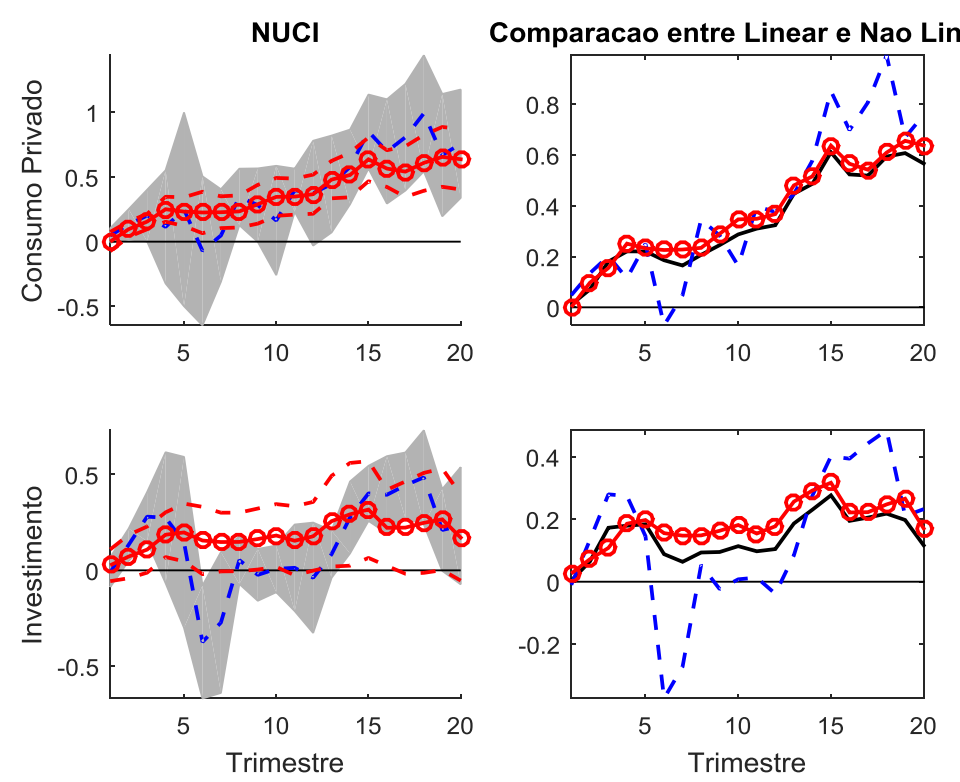

Fonte: Elaboração Própria.

Nota: Respostas do modelo não linear do consumo privado e do investimento a um choque de gastos primários de $1 \%$ do PIB. As áreas sombreadas correspondem ao intervalo de confiança de $95 \%$.

Figura 19 - Função Resposta ao Impulso do Consumo Privado e do Investimento no Modelo Não Linear: Threshold Taxa de Crescimento do PIB
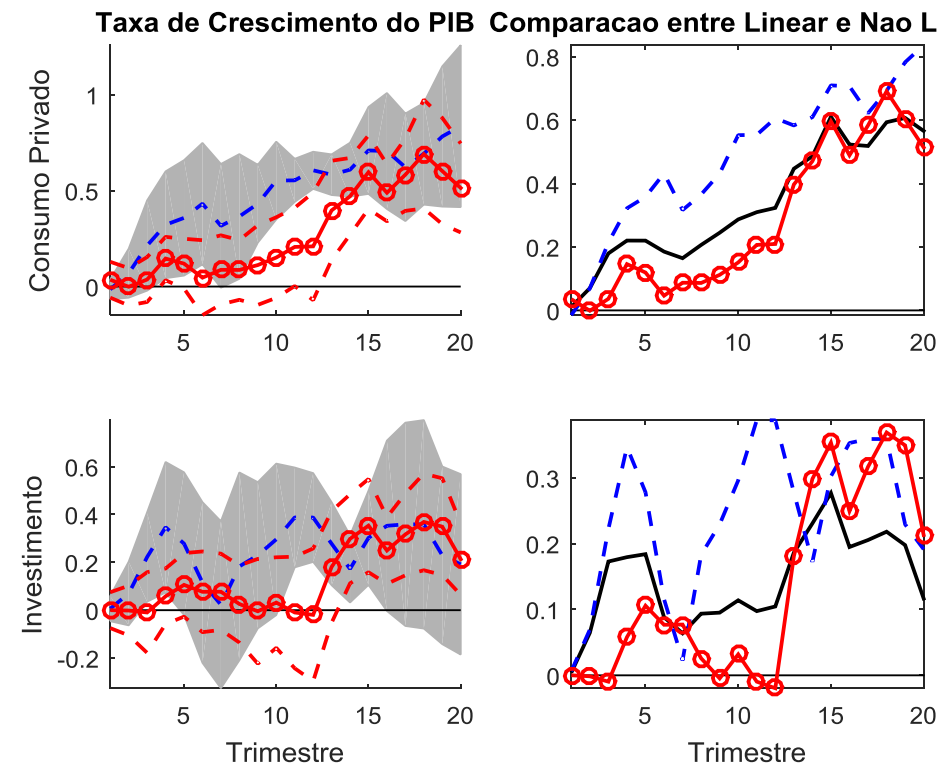

Fonte: Elaboração Própria.

Nota: Respostas do modelo não linear do consumo privado e do investimento a um choque de gastos primários de $1 \%$ do PIB. As áreas sombreadas correspondem ao intervalo de confiança de $95 \%$. 
Figura 20 - Função Resposta ao Impulso do Consumo Privado e do Investimento no Modelo Não Linear: Threshold Taxa de Desemprego
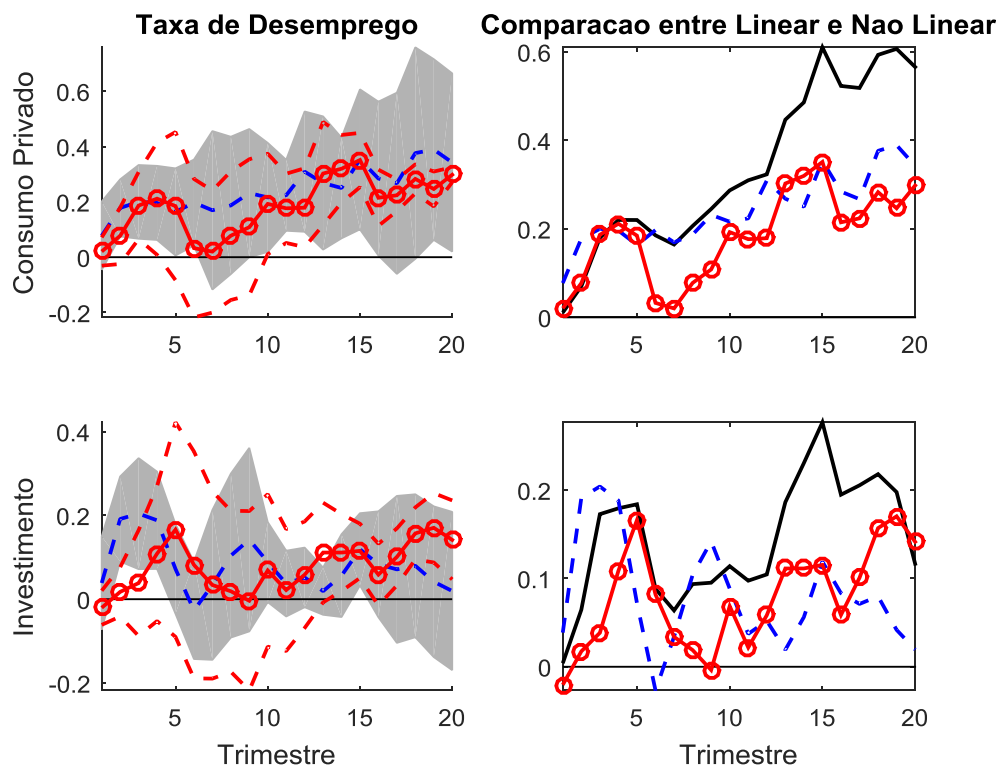

Fonte: Elaboração Própria.

Nota: Respostas do modelo não linear do consumo privado e do investimento a um choque de gastos primários de $1 \%$ do PIB. As áreas sombreadas correspondem ao intervalo de confiança de $95 \%$.

Figura 21 - Função Resposta ao Impulso do Consumo Privado e do Investimento no Modelo Não Linear: Threshold Datação da CODACE
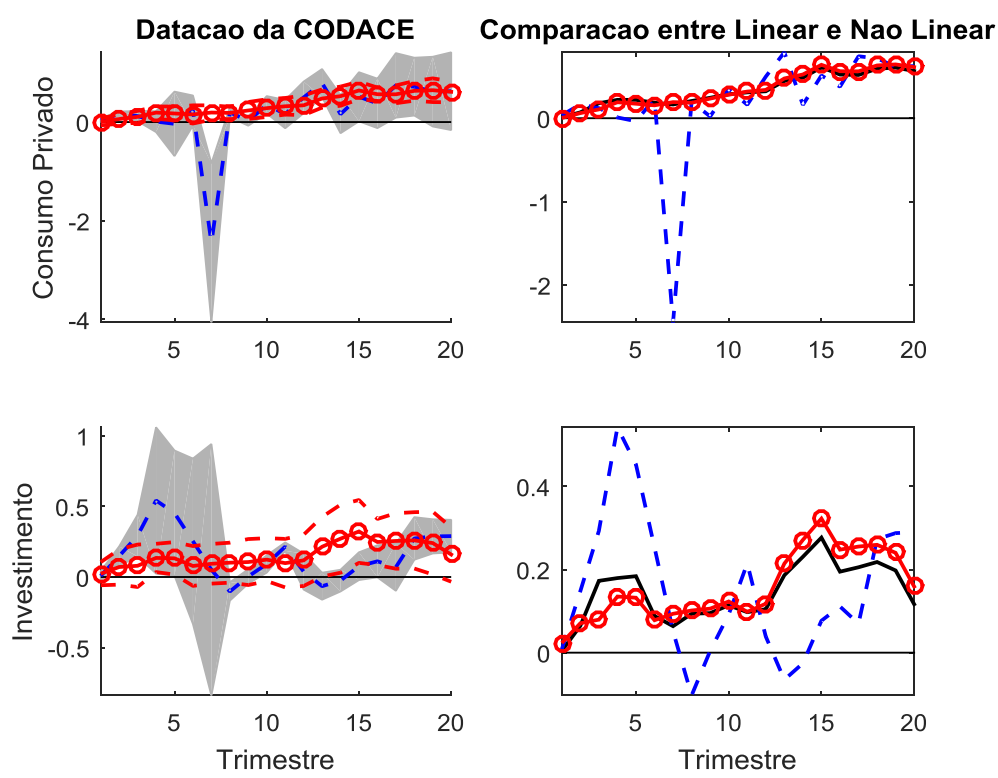

Fonte: Elaboração Própria.

Nota: Respostas do modelo não linear do consumo privado e do investimento a um choque de gastos primários de $1 \%$ do PIB. As áreas sombreadas correspondem ao intervalo de confiança de $95 \%$.

\subsection{Exportação e Importação}

Os multiplicadores para exportação e importação podem ser estimados por variáveis instrumentais, como descrito nas equações (4) e (5). 
Os resultados do modelo linear estão presentes na Tabela 20 e as funções de impulso resposta na Figura 22. Os multiplicadores de exportação são menores do que 0,5 e para importação, são negativos. Nenhum multiplicador é estatisticamente significante.

Tabela 20 - Multiplicadores da Exportação e da Importação do Modelo Linear

\begin{tabular}{lcc}
\hline \hline & Exportação & Importação \\
\hline Multiplicador de Impacto & 0,1946 & $-0,1288$ \\
& $(0,1686)$ & $(0,1147)$ \\
\hline Multiplicador de 4 trimestres & 0,1153 & $-0,2118$ \\
& $(0,4948)$ & $(0,3544)$ \\
\hline Multiplicador de 8 trimestres & 0,4340 & $-0,2008$ \\
& $(0,4590)$ & $(0,2358)$ \\
\hline \hline
\end{tabular}

Fonte: Cálculo do Autor.

Os erros padrões estão entre parênteses. (***) significativo a 1\%; (**) significativo a $5 \%$; (*) significativo a $10 \%$.

Figura 22 - Função Resposta ao Impulso do Modelo Linear: Exportação e Importação
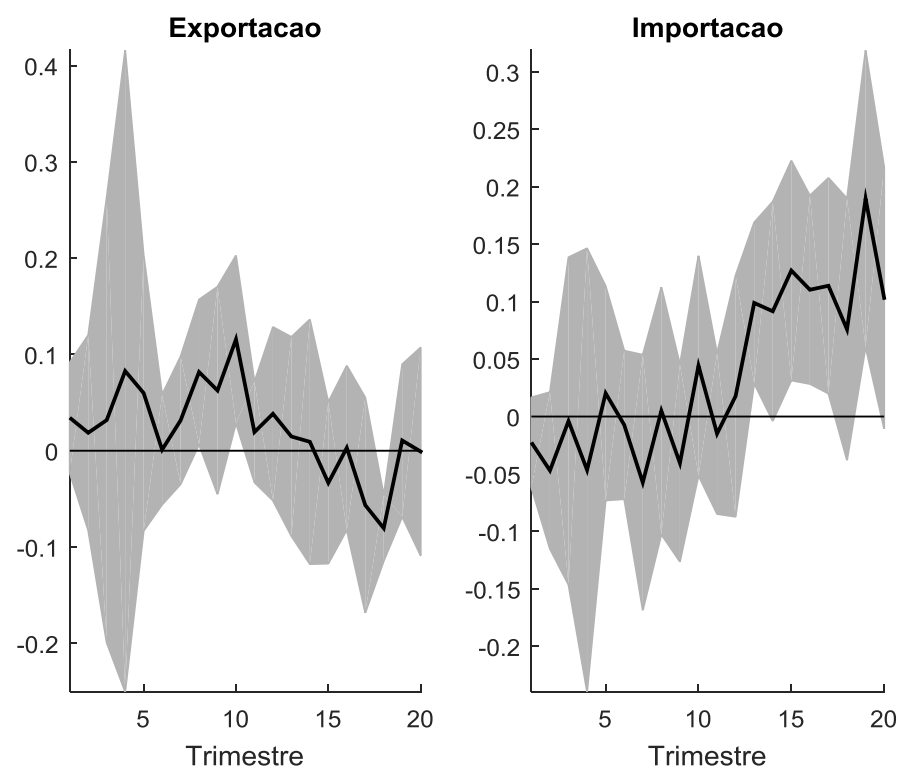

Fonte: Elaboração Própria.

Nota: Resposta da exportação e da importação a um choque de gastos primários de $1 \%$ do PIB. As áreas sombreadas correspondem ao intervalo de confiança de $95 \%$.

No contexto não linear, alguns os multiplicadores de exportação e de importação são negativos, tanto em contração quanto em expansão, e poucos são estatisticamente significativos. 
Tabela 21 - Multiplicadores da Exportação do Modelo Não Linear

\begin{tabular}{|c|c|c|c|c|}
\hline & & $\begin{array}{l}\text { Multiplicador } \\
\text { de Impacto }\end{array}$ & $\begin{array}{l}\text { Multiplicador } \\
4 \text { trimestre }\end{array}$ & $\begin{array}{l}\text { Multiplicador } \\
8 \text { trimestre }\end{array}$ \\
\hline \multirow{4}{*}{ Hiato } & Recessão & $1,3274 * *$ & $2,5042 * *$ & $2,8199 * *$ \\
\hline & & $(0,6136)$ & $(1,0329)$ & $(1,3231)$ \\
\hline & Expansão & 0,0448 & 0,0843 & $0,4117 * *$ \\
\hline & & $(0,2121)$ & $(0,5461)$ & $(0,1978)$ \\
\hline \multirow{2}{*}{$\begin{array}{c}\text { P-valor para diferença } \\
\text { entre estados }\end{array}$} & HAC & 0,0341 & 0,0683 & 0,0876 \\
\hline & AR & 0,0000 & 0,1729 & 0,1351 \\
\hline \multirow{4}{*}{ NUCI } & Recessão & 0,0124 & $-0,1548$ & 2,3713 \\
\hline & & $(0,2095)$ & $(0,8800)$ & $(2,4793)$ \\
\hline & Expansão & 0,1686 & 0,0322 & $-0,1146$ \\
\hline & & $(0,0280)$ & $(0,3407)$ & $(0,2599)$ \\
\hline \multirow{2}{*}{$\begin{array}{c}\text { P-valor para diferença } \\
\text { entre estados }\end{array}$} & HAC & 0,9605 & 0,7717 & 0,3275 \\
\hline & AR & 0,0000 & 0,785 & 0,2459 \\
\hline \multirow{4}{*}{$\begin{array}{c}\text { Taxa de } \\
\text { Desemprego }\end{array}$} & Recessão & 0,6832 & $1,3309 * * *$ & $1,4853 * * *$ \\
\hline & & $(0,4433)$ & $(0,4455)$ & $(0,4275)$ \\
\hline & Expansão & $-0,1508$ & $-1,2502^{*}$ & $-0,8642 *$ \\
\hline & & $(0,1504)$ & $(0,4827)$ & $(0,3349)$ \\
\hline \multirow{2}{*}{$\begin{array}{c}\text { P-valor para diferença } \\
\text { entre estados }\end{array}$} & HAC & 0,0904 & 0,0002 & 0,0000 \\
\hline & AR & 0,0000 & 0,0848 & 0,1100 \\
\hline \multirow{4}{*}{$\begin{array}{c}\text { Taxa de Crescimento } \\
\text { do PIB }\end{array}$} & Recessão & $-0,0212$ & $-0,5551 * *$ & 0,0812 \\
\hline & & $(0,1328)$ & $(0,6928)$ & $(0,3891)$ \\
\hline & Expansão & $0,7327 * *$ & $0,6286^{*}$ & $0,8202 *$ \\
\hline & & $(0,3212)$ & $(0,3224)$ & $(0,4684)$ \\
\hline \multirow{2}{*}{$\begin{array}{c}\text { P-valor para diferença } \\
\text { entre estados }\end{array}$} & HAC & 0,0164 & 0,0211 & 0,0312 \\
\hline & AR & 0,0000 & 0,0647 & 0,1260 \\
\hline \multirow{4}{*}{ CODACE } & Recessão & 0,0079 & $-1,2608^{*}$ & 2,1360 \\
\hline & & $(0,0782)$ & $(0,7241)$ & $(0,8946)$ \\
\hline & Expansão & $0,5144 * * *$ & $0,6133^{*}$ & $0,6145^{* *}$ \\
\hline & & $(0,1541)$ & $(0,3363)$ & $(0,2598)$ \\
\hline \multirow{2}{*}{$\begin{array}{l}\text { P-valor para diferença } \\
\text { entre estados }\end{array}$} & HAC & 0,0008 & 0,0000 & 0,9864 \\
\hline & AR & 0,0000 & 0,1223 & 0,9580 \\
\hline
\end{tabular}

Fonte: Cálculo do Autor.

Os erros padrões estão entre parênteses. (***) significativo a 1\%; (**) significativo a 5\%;

(*) significativo a $10 \%$.

Tabela 22 - Multiplicadores da Importação do Modelo Não Linear

\begin{tabular}{|c|c|c|c|c|}
\hline & & $\begin{array}{l}\text { Multiplicador } \\
\text { de Impacto }\end{array}$ & $\begin{array}{l}\text { Multiplicador } \\
4 \text { trimestre }\end{array}$ & $\begin{array}{c}\text { Multiplicador } \\
8 \text { trimestre }\end{array}$ \\
\hline \multirow{4}{*}{ Hiato } & Recessão & $0,7607 * * *$ & $0,5389 *$ & 0,1023 \\
\hline & \multirow{3}{*}{ Expansão } & $(0,2830)$ & $(0,2850)$ & $(0,4662)$ \\
\hline & & 0,0617 & 0,0685 & $-0,0859$ \\
\hline & & $(0,2109)$ & $(0,4413)$ & $(0,2784)$ \\
\hline
\end{tabular}




\begin{tabular}{|c|c|c|c|c|}
\hline \multirow{2}{*}{$\begin{array}{c}\text { P-valor para diferença } \\
\text { entre estados }\end{array}$} & $\mathrm{HAC}$ & 0,0008 & 0,2987 & 0,7279 \\
\hline & AR & 0,0000 & 0,3858 & 0,7589 \\
\hline \multirow{4}{*}{ NUCI } & Recessão & $-0,0715$ & $-0,2746$ & 0,2743 \\
\hline & & $(0,1132)$ & $(0,4762)$ & $(0,2402)$ \\
\hline & Expansão & $-0,2762$ & $-0,4011$ & $-0,3663 *$ \\
\hline & & $(0,2872)$ & $(0,3942)$ & $(0,2034)$ \\
\hline \multirow{2}{*}{$\begin{array}{c}\text { P-valor para diferença } \\
\text { entre estados }\end{array}$} & $\mathrm{HAC}$ & 0,5646 & 0,8007 & 0,0260 \\
\hline & AR & 0,0000 & 0,8037 & 0,2855 \\
\hline \multirow{4}{*}{$\begin{array}{c}\text { Taxa de } \\
\text { Desemprego }\end{array}$} & Recessão & $-0,1154$ & 0,3250 & $0,3304 * * *$ \\
\hline & & $(0,2987)$ & $(0,3062)$ & $(0,1133)$ \\
\hline & Expansão & $-0,1564$ & $-0,6313$ & $-0,7059 *$ \\
\hline & & $(0,1689)$ & $(0,5489)$ & $(0,3797)$ \\
\hline \multirow{2}{*}{$\begin{array}{c}\text { P-valor para diferença } \\
\text { entre estados }\end{array}$} & HAC & 0,9128 & 0,1523 & 0,0050 \\
\hline & AR & 0,0000 & 0,2095 & 0,1093 \\
\hline \multirow{4}{*}{$\begin{array}{c}\text { Taxa de Crescimento } \\
\text { do PIB }\end{array}$} & Recessão & $-0,4186$ & $-0,9332 * * *$ & $-0,5787 * * *$ \\
\hline & & $(0,2612)$ & $(0,3103)$ & $(0,1264)$ \\
\hline & Expansão & $0,5154 * * *$ & 0,2918 & 0,1177 \\
\hline & & $(0,1456)$ & $(0,2865)$ & $(0,2331)$ \\
\hline \multirow{2}{*}{$\begin{array}{c}\text { P-valor para diferença } \\
\text { entre estados }\end{array}$} & $\mathrm{HAC}$ & 0,0006 & 0,0000 & 0,0027 \\
\hline & AR & 0,0000 & 0,0804 & 0,0997 \\
\hline \multirow{4}{*}{ CODACE } & Recessão & $-0,2138$ & $-0,6458$ & $-0,2458$ \\
\hline & & $(0,1447)$ & $(0,7218)$ & $(0,5089)$ \\
\hline & Expansão & 0,2552 & 0,2116 & $-0,0857$ \\
\hline & & $(0,1946)$ & $(0,3189)$ & $(0,1285)$ \\
\hline \multirow{2}{*}{$\begin{array}{c}\text { P-valor para diferença } \\
\text { entre estados }\end{array}$} & HAC & 0,0627 & 0,1812 & 0,7414 \\
\hline & AR & 0,0000 & 0,2641 & 0,7338 \\
\hline
\end{tabular}

Fonte: Cálculo do Autor

Os erros padrões estão entre parênteses. (***) significativo a 1\%; (**) significativo a 5\%;

(*) significativo a $10 \%$. 
Figura 23 - Função Resposta ao Impulso da Exportação e da Importação no Modelo Não Linear: Threshold Hiato
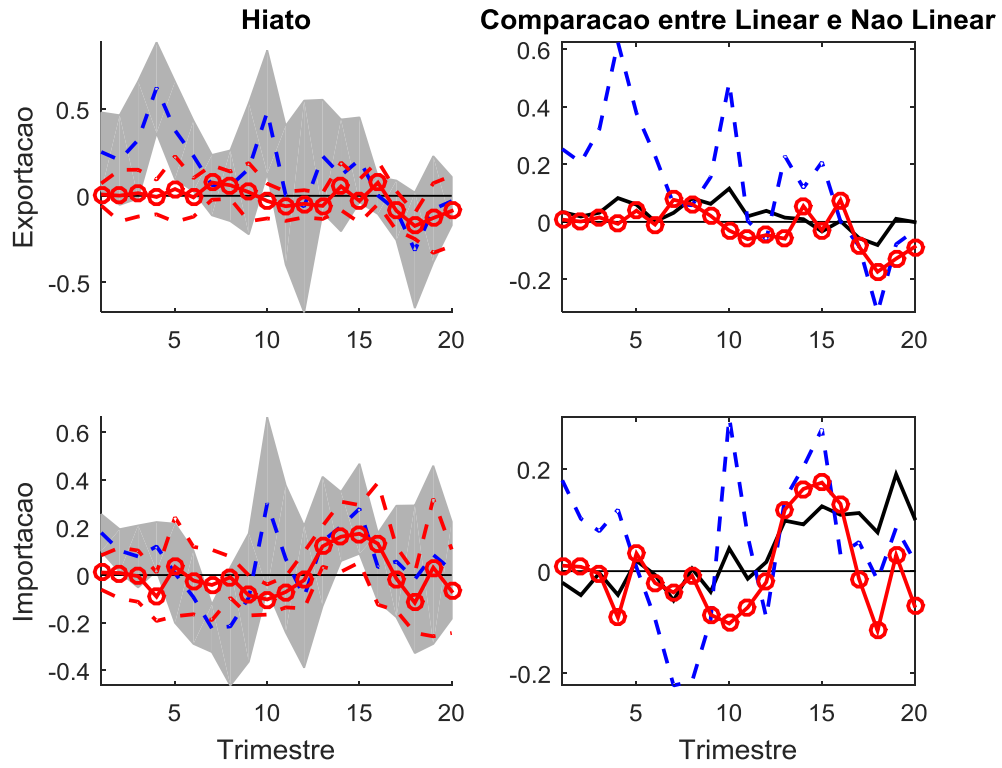

Fonte: Elaboração Própria.

Nota: Respostas do modelo não linear da exportação e da importação a um choque de gastos primários de $1 \%$ do PIB. As áreas sombreadas correspondem ao intervalo de confiança de $95 \%$.

Figura 24 - Função Resposta ao Impulso da Exportação e da Importação no Modelo Não Linear: Threshold NUCI
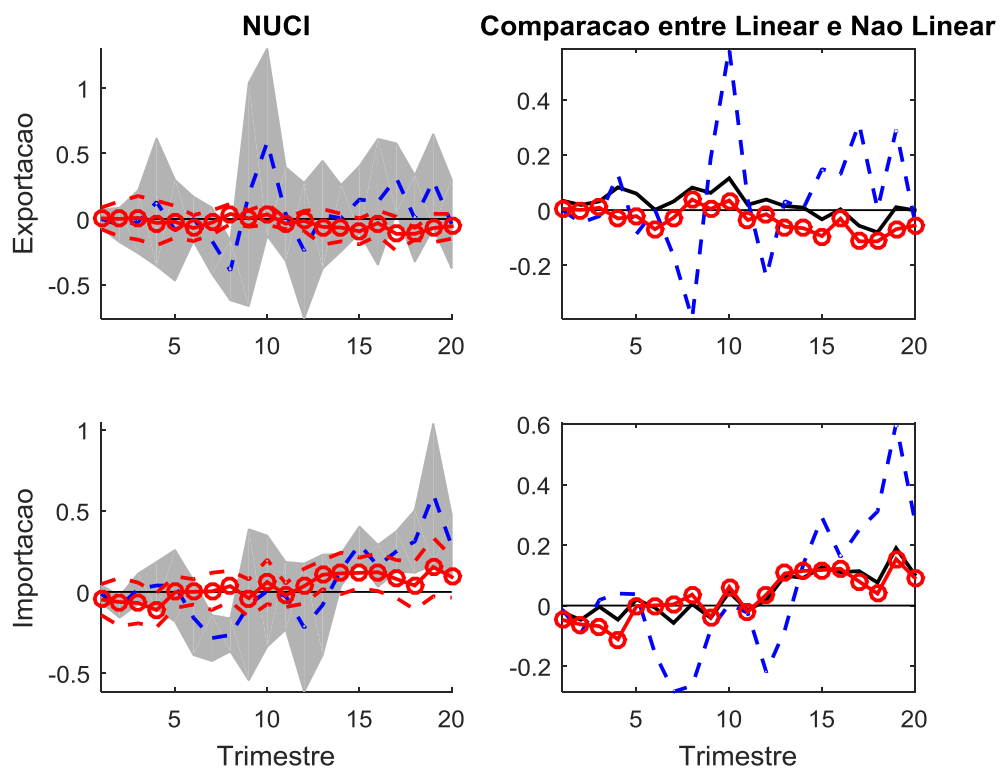

Fonte: Elaboração Própria.

Nota: Respostas do modelo não linear da exportação e da importação a um choque de gastos primários de $1 \%$ do PIB. As áreas sombreadas correspondem ao intervalo de confiança de $95 \%$. 
Figura 25 - Função Resposta ao Impulso da Exportação e da Importação no Modelo Não Linear: Threshold Taxa de Crescimento do PIB
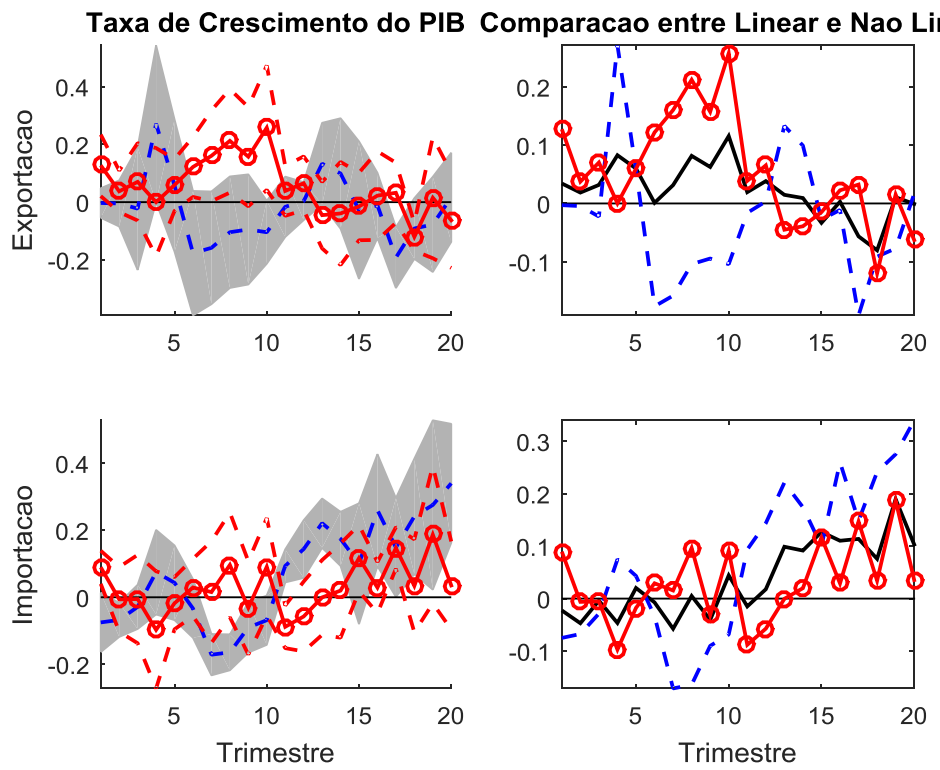

Fonte: Elaboração Própria.

Nota: Respostas do modelo não linear da exportação e da importação a um choque de gastos primários de $1 \%$ do PIB. As áreas sombreadas correspondem ao intervalo de confiança de $95 \%$.

Figura 26 - Função Resposta ao Impulso da Exportação e da Importação no Modelo Não Linear: Threshold Taxa de Desemprego

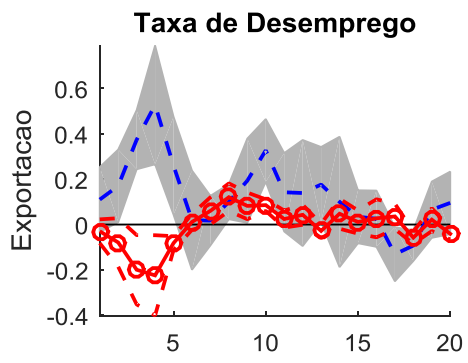

\section{Comparacao entre Linear e Nao Linear}
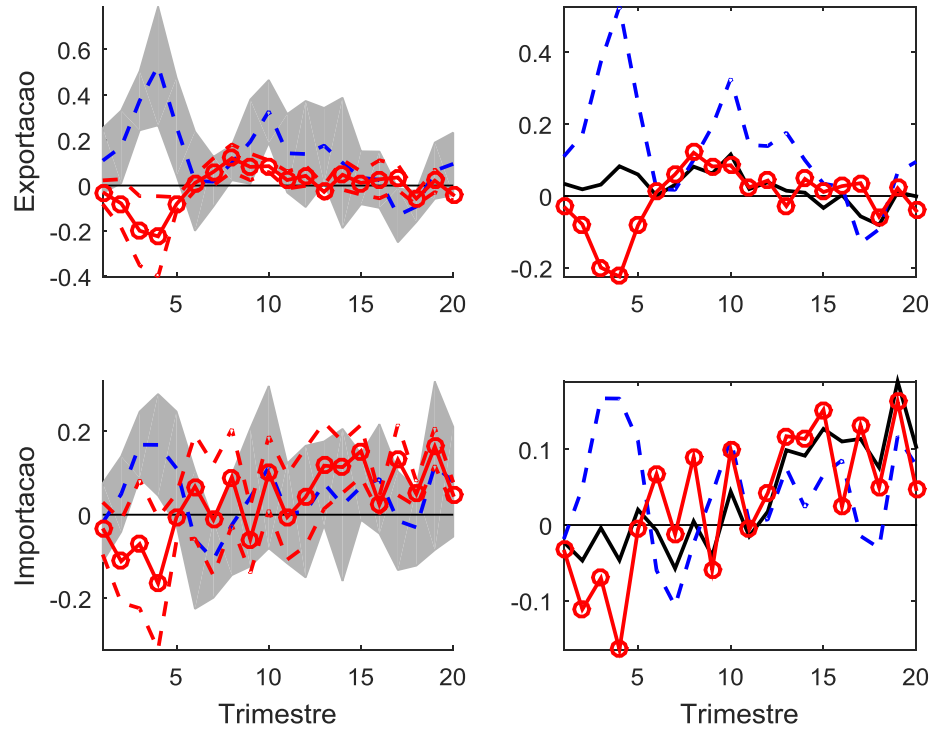

Fonte: Elaboração Própria.

Nota: Respostas do modelo não linear da exportação e da importação a um choque de gastos primários de $1 \%$ do PIB. As áreas sombreadas correspondem ao intervalo de confiança de $95 \%$. 
Figura 27 - Função Resposta ao Impulso da Exportação e da Importação no Modelo Não Linear: Threshold Datação da CODACE
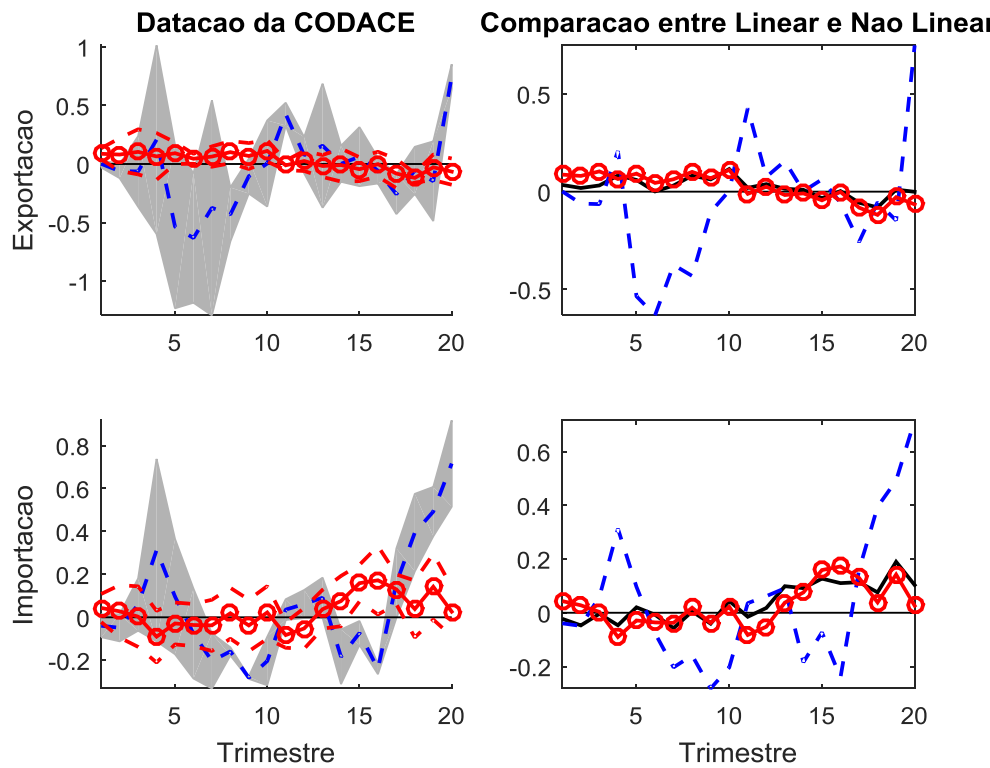

Fonte: Elaboração Própria.

Nota: Respostas do modelo não linear da exportação e da importação a um choque de gastos primários de $1 \%$ do PIB. As áreas sombreadas correspondem ao intervalo de confiança de $95 \%$. 


\section{Conclusão}

A crise financeira de 2008/2009 reforçou o interesse dos policy makers e da academia em compreender melhor o papel estabilizador da política fiscal, ou seja, sua capacidade de agir como um instrumento capaz de promover crescimento econômico e impedir o aumento do desemprego.

Nos últimos anos, a pesquisa empírica sobre os efeitos dos gastos do governo sobre o produto e seus componentes foi intensificada, sendo que trabalhos foram iniciados procurando verificar se essas respostas são não lineares, isto é, dependentes de várias circunstâncias, como, por exemplo, o ciclo econômico.

Os resultados empíricos sobre os efeitos da política fiscal sobre o crescimento econômico são muito controversos. Conforme mostrado no Capítulo 2, os estudos empíricos divergem em relação aos procedimentos de identificação do choque fiscal, à inclusão de variáveis, aos componentes estocásticos e determinísticos, aos períodos da amostra e ao número de defasagens. Além disso, os trabalhos se diferenciam com relação à despesa do governo utilizada (consumo do governo, investimento do governo, gasto com pensões, gasto com funcionalismo) e à forma de construir a série de receitas. Dos modelos lineares resultam, então, multiplicadores com diferentes magnitudes, revelando falta de qualquer consenso. No caso dos modelos não lineares, os resultados são mais convergentes indicando multiplicadores maiores nas recessões do que nas expansões.

O objetivo desta dissertação foi verificar os impactos dos choques fiscais sobre o produto brasileiro e em particular avaliar se os multiplicadores dos gastos do governo variam a depender do estado do ciclo de negócios. Foram desta forma, estimados os tamanhos dos multiplicadores de gastos do governo sob dois regimes econômicos (recessão/expansão).

Para averiguar se os multiplicadores são diferentes a depender do ciclo econômico, foram seguidos os procedimentos de Auerbach e Gorodnichenko (2013), Owyang, Ramey e Zubairy (2013) e Ramey e Zubairy (2017). Foi aplicado o método de projeção local de Jordà (2005), usando-se dados trimestrais para o período de 1999:1-2016:2. As variáveis de controle usadas foram o $\log$ do PIB real, da despesa primária real do governo geral e da carga tributária líquida real. A série de despesa primária do governo geral sofreu diversos ajustes para expurgar os efeitos das medidas não recorrentes (por exemplo, contabilidade criativa e pedaladas fiscais). 
Para definir os diferentes regimes, foram utilizadas diferentes variáveis: o hiato do produto, o nível de utilização da capacidade instalada, a taxa de crescimento do PIB, a taxa de desemprego e a datação oficial de ciclos no Brasil.

A estimação do modelo linear gerou multiplicadores maiores do que os encontrados na literatura nacional. A estimação do modelo não linear, por sua vez, resultou em multiplicadores de gastos do governo, após um e dois anos, maiores nos períodos de recessão econômica, seja qual for a variável escolhida para diferenciar os regimes. Porém, em alguns casos, ambos os multiplicadores são maiores do que um. Os testes não deram evidências para afirmar se há diferença dos multiplicadores ao longo dos regimes econômicos. Resultado similar foi encontrado para o Brasil por Grüdtner e Aragon (2017) e para os Estados Unidos por Ramey e Zubairy (2017).

Vários testes de robustez foram realizados: inclusão de uma tendência linear, uso da transformação com o PIB potencial, a medição de regime feita de maneira igual à Auerbach e Gorodnichenko (2012) e truncando a série até o primeiro trimestre de 2014. Os resultados dos testes de robustez indicam multiplicadores de gastos maiores nos períodos de recessão, todavia, não sugerem que estes sejam diferentes entre os ciclos de negócios.

A diferença sistemática entre o IPCA e o deflator do PIB e as suas trajetórias é relevante não apenas do ponto de fiscal, mas também sobre a compreensão da economia brasileira. Por isso, também foi verificado qual sensível é o multiplicador quando o deflator do PIB é utilizado para deflacionar as séries. Novamente, os resultados mostraram que os multiplicadores de gastos são maiores nos períodos de contração, embora mais uma vez sugerem não haver diferença entre os ciclos econômicos.

Para carga tributária líquida, os multiplicadores encontrados são predominantemente negativos, semelhante ao obtido anteriormente por Mendonça, Medrano e Sachsida (2009). Foram estimados ainda os multiplicadores dos gastos sobre os componentes do produto: consumo, investimento, exportação e importação.

O consumo privado aumenta mais nos períodos de recessão, resultado semelhante ao encontrado para os países da OCDE. No caso do investimento, há multiplicadores maiores do que um, em recessão, quando os limiares são a taxa de crescimento e CODACE. Entretanto, alguns multiplicadores são negativos, quando o threshold é o hiato, o NUCI e a taxa de desemprego. Tanto para exportação quanto para importação, os resultados são na maioria não significativos e para importação alguns multiplicadores são até mesmo negativos.

Um dos obstáculos encontrados na literatura empírica sobre multiplicadores fiscais no Brasil, conforme apontou Gobetti, Orair e Siqueira (2016), é a carência de séries estatísticas 
fiscais consideravelmente longas. Como observado por Ramey e Zubairy (2017) a existência de séries históricas é fundamental para a estimação dos multiplicadores: "To be informative, the identified changes in government spending must be exogenous and big enough to be able to extract their effects from the many other economic shocks hitting the economy. The challenge becomes even greater once one attempts to estimate state-dependent multipliers since informative estimates require that the states span a sufficient portion of the sample and that the exogenous changes in government spending be spread across the states". (p. 5). 


\section{Referências Bibliográficas}

AFONSO, António; BAXA, Jaromír; SLAVÍK, Michal. Fiscal developments and financial stress: a threshold VAR analysis. Working Paper Series 1319, European Central Bank, 2011.

ALESINA, A.; PEROTTI, R. Fiscal Adjustments in OECD Countries: Composition and Macroeconomic Effects. International Monetary Fund Staff Papers: Vol. 44 (2), pp. 210-248, 1997.

ANDERSON, T.W.; RUBIN, H. Estimation of the Parameters of a Single Equation in a Complete System of Stochastic Equation. Annuals of Mathematical Statistics 20, p. 46-63, 1949.

AUERBACH,A.J.;GORODNICHENKO,Y. Measuring the Output Responses to Fiscal Policy. American Economic Journal: Economic Policy, v. 4, n.2 , p. 1-27, 2012.

AUERBACH,A.J.;GORODNICHENKO,Y. Fiscal Multipliers in Recession and Expansion. Em "Fiscal Policy after the Financial Crisis", Alesina, A.; Giavazzi, F. (eds), University of Chicago Press, 2013.

BACHMANN, R.; SIMS, R. E. Confidence and the transmission of government spending shocks. Journal of Monetary Economics, v. 59, n. 3, p. 235-249, 2012.

BAUM, A.; KOESTER G.B. The impact of fiscal policy on economic activity over the business cycle: evidence from a threshold VAR analysis. Discussion paper series 1: Economic Studies No. 03/2011, Deutsche Bundesbank, 2011.

BAUM, A.; CHECHERITA-WESTPHAL, C.; ROTHER, P. Debt and growth: new evidence for the euro area. ECB working paper series 1450, European Central Bank, 2012.

BAUM, A.; POPLAWSKI-RIBEIRO, M.; WEBER, A. Fiscal multipliers and the state of the economy. Working Paper 12/286, IMF, 2012.

BARRO,R.J. Government Spending, Interest Rate, Prices and Budget Deficits in the United Kingdom, 1701-1918. Journal of Monetary Economics, v. 20, n. 2, p. 221-247, 1987.

BATINI, N.; CALlEGARI, G.; MELINA, G. Successful Austerity in the United States, Europe and Japan. Working paper 12/190, IMF, 2012.

BARRO, R. J.; REDLICK, C. J. Macroeconomic Effects from Government Purchases and Taxes. Quarterly Journal of Economics, v. 126, n.1, p. 51-102, 2011.

BAXTER, M.; KING, R. Fiscal Policy in General Equilibrium. American Economic Review 83(3), pp. 315-334, 1993.

BEETSMA, R. A Survey of the Effects of Discretionary Fiscal Policy. Working Paper, Universidade de Amsterdam, 2008.

BEETSMA, R.; GIULIODORI, M. The Effects of Government Purchases Shocks: Review and Estimates for the EU. Economic Journal, vol. 121(550), p. F4-F32, 2011. 
BELINGA, V.; NGOUANA, C. L. (Not) Dancing Together: Monetary Policy Stance and the Government Spending Multiplier. Working paper 12/286, IMF, 2015.

BERNSTEIN, J.; ROMER, C. The job impact of the American Recovery and Reinvestment Plan. Jan. 2009 Disponível em: <http://www.economy.com/markzandi/documents/The_Job_Impact_of_the_American_Recov ery_and_Reinvestment_Plan.pdf>. Acesso em: 10 abril 2016.

BIOLSI, C. Nonlinear Effects of Fiscal Policy over the Business Cycle. Journal of Dynamic \& Control, 78, p. 54-87, 2017.

BLANCHARD, Olivier; PEROTTI, Robert. An Empirical Characterization of the Dynamic Effects of Changes in Government Spending and Taxes on Output. The Quarterly Journal of Economics, 117, 1329-1368, 2002.

BLANCHARD, Olivier; LEIGH, D. Growth forecast errors and fiscal multipliers. American Economic Review Papers and Proceedings, v. 103, n. 3, p.117-120, 2013.

BURNSIDE, C.; EICHENBAUM, M.; FISHER, J.D.M. Fiscal Shocks and their Consequences. Journal of Economic Theory, v. 115, n.1, p. 89-117, 2004.

BURRIEL, P.; DE CASTRO, F.; GARROTE, D.; GORDO, E.; PAREDES, J.; PÉREZ, J.J. Fiscal Multipliers in the Euro Area. Revista de Economía y Estadística, v. 0, n. 2, p. 727, 2010.

CAGGIANO, G.; CASTELNUOVO E.; COLOMBO, V.; NODARI, G. Estimating Fiscal Multipliers: News From A Non-linear World. Economic Journal, v. 125, n. 584, p. 746 - 776, 2015.

CALDARA, D.; KAMPS, C. What are the effects of fiscal policy shocks? A VAR-based comparative analysis. BCE Working Paper, série n. 877, março, 2008.

CANOVA, F.; PAPPA, E. Price Differentials in Monetary Unions: The Role of Fiscal Shocks. The Economic Journal, v. 117, n. 520, p. 713-737, 2007.

de CASTRO. The macroeconomic effects of fiscal policy in Spain. Applied Economics, v. 38, p. 913-924, 2006.

de CASTRO, F.; de COS, P. H. The economic effects of fiscal policy: The case of Spain. Journal of Macroeconomics, v. 30, p. 1005-1028, 2008.

CASTELO-BRANCO, M.A.; LIMA, E.C. R.; LIMA, L.F. Mudanças de Regime e Multiplicadores Fiscais no Brasil entre 1999-2012: uma avaliação empírica. Anais XLIII Encontro Nacional de Economia da ANPEC. Florianópolis: Anpec, 2015.

CAVALCANTI, M. A.; SILVA, N. Dívida pública, política fiscal e nível de atividade: Uma abordagem VAR para o Brasil no período 1995-2008. Revista de Economia Aplicada, v. 14, n. 4, p.391-418. Set. 2010. 
CHRISTIANO, L.; EICHENBAUM, M. Current Real-Business-Cycle Theories and Aggregate Labor-Market Fluctuations. American Economic Review, v.82(3), p 430-450, 1992.

CHRISTIANO, L.; EICHENBAUM, M.; REBELO, S. When is the Government Spending Multiplier Large?. Journal of Political Economy, 119(1), pp. 78-121, 2011.

COGAN, J. et al. New Keynesian versus old Keynesian government spending multipliers. Journal of Economics Dynamics and Control, v. 34, n. 3, p. 281-295, mar. 2009.

COGAN, J.; TAYLOR, J. What the government purchases multiplier actually multiplied in the 2009 stimulus package. NBER Working Paper Series, n. 16505, p. 1-33, out. 2010.

COLOMBO, V. Three Essays of Macroeconometrics. Tese (Doutorado em Ciências Econômicas) - Università Degli Studi di Padova, 2012.

CORSETTI, G.; KUESTER, K.; MEIER, A.; MUllER, G. J. Debt Consolidation and Fiscal Stabilization of Deep Recessions. American Economic Review, v. 100, n.2, p. 41-45, 2010.

CORSETTI, G.; MEIER, A.; MILER, G. J. What Determines Government Spending Multipliers? Economic Policy, v. 27, n. 72, p. 521- 565, 2012.

COS, P. H.; MORAL-BENITO, E. Fiscal Multipliers in Turbulent Times: the case of Spain. Empirical Economics, v. 50, n. 4, p. 1589-1625, 2016.

COS, P. H,; WARMEDINGER, T.; WESTPHAL, C. C. Fiscal Multipliers and Beyond. Working Paper Series. European Central Bank, 2015.

COUNCIL OF ECONOMIC ADVISERS. The economic impact of the American Recovery and Reinvestment act of 2009. Executive Office of the President, First Quartely Report. Set. 2009.

ÇEBI, C.; OZDEMIR, K. A. Cyclical Variation of Fiscal Multiplier in Turkey. Working Paper, Central Bank of the Republic of Turkey, n. 16/19, p. 1-22, 2016.

EDELBERG, W.; EICHENBAUM, M.; FISHER, J.D. Understanding the Effects of a Shock to Government Purchases. Review of Economic Dynamic, v.2, n.1, p. 166-206, 1999.

ENDERS,Walter. Applied Econometrics Time Series. 3 ed. New Jersey: Willey, 2010.

FATÁS, A.;MIHOV,I. The effects of Fiscal Policy on Consumption and Employment: Theory and Evidence. CEPR, Working Paper 2760, 2001.

FAVERO, C.; GIAVAZZI, F. Debt and the Effects of Fiscal Policy. NBER Working Paper $12822,2007$.

FAVERO, C.; KARAMYSHEVA, M. What do We Know About Fiscal Multipliers? Centre for Economic Policy Research, Working Paper, n. 10986, 2015.

FAZZARI,S.M.;MORLEY,J.;PANOVSKA,I. State-dependent effects of fiscal policy. Studies in Nonlinear Dynamics and Econometrics, v. 19(3), p.285-315, 2015. 
FERRARESI, T.; ROVENTINI, A.; e FAGIOLO G. Fiscal policies and credit regimes: a TVAR approach. Journal of Applied Econometric, 30: 1047-1072 (2015), 2015.

GALÍ, J.; LÓPEZ-SALIDO, J. D.; VALLÉS, J. Understanding the Effects of Government Spending on Consumption. Journal of the European Economic Association 5(1), pp. 227-270, 2007.

GIAVAZZI, F.;PAGANO, M. Can Severe Fiscal Contractions Be Expansionary? Tales of Two Small European Countries. CEPR Discussion Papers, 1990.

GIAVAZZI, F.; JAPPELLI, T.;PAGANO, M. Searching for non-linear effects of fiscal policy: Evidence from industrial and developing countries. European Economic Review, Elsevier 44(7), pp. 1259-1289, 2000.

GIORDANO, R.; MOMIGLIANO, S.; NERI, S.; PEROTTI, R. The effects of fiscal policy in Italy Evidence from a VAR model. European Journal of Political Economy, vol. 23, p. 707733, 2007.

GOBETTI, S.W.; ORAIR, R.O. Resultado Primário e Contabilidade Criativa: Reconstruindo as Estatísticas Fiscais “Acima da Linha” do Governo Geral. Texto para Discussão, n. 2288, p. $1-58,2017$.

GOBETTI, S.W.; ORAIR, R.O.; SIQUEIRA, F.F. Política Fiscal e Ciclo Econômico: Uma Análise Baseada em Multiplicadores do Gasto Público. Brasília: XXI Prêmio do Tesouro Nacional. Secretária do Tesouro Nacional, 2016.

GORDON, R.J.; KRENN, R. The End of the Great Depression: VAR Insight on the Roles of Monetary and Fiscal Policy. NBER Working Paper, n. 16380, 2010.

GRÜDTNER, V.; ARAGON, E.K.S.B. Multiplicador dos Gastos do Governo em Períodos de Expansão e Recessão: Evidências Empíricas para o Brasil, Encontro Nacional de Economia da ANPEC do Sul, 2017.

HALL, R. By how much does GDP rise if the Government buys more output? Brooking Papers on Economic Activity, n. 2, 183-231, 2009.

HAMILTON, J. D. A New Approach to the Economic Analysis of Nonstationary Time Series and the Business Cycle. Econometrica, v. 57, p. 357 - 384, 1989.

HAMILTON, J. D. Time Series Analysis. Princeton: University Press, 1994.

HEMMING, R; KELL, M.; MAHFOUZ, S. The Effectiveness of Fiscal Policy in a Stimulating Economic Activity - A Review of the Literature. IMF Working Paper. 02/208, International Monetary Fund, 2002.

HEPPKE-FALK, K. H.; TENHOFEN, J.; WOLFF, G. B. The Macroeconomic Effects of Exogenous Fiscal Policy Shocks in Germany a Disaggregated SVAR Analysis. Discussion paper series 1: Economic Studies No. 41/2006, Deutsche Bundesbank, 2006.

HERBOUS, S. The Effects of Discretionary Fiscal Policy on Macroeconomic Aggregates: A Reappraisal. Journal of Economic Surveys, v. 25, n.4, p. 674-707, 2011. 
HOLLAND, M.; MARÇAL, E.; MENDONÇA, D. P. Is Fiscal Policy Effective in Brazil? An Empirical Analysis. Working Paper, janeiro, 2017.

ILZETZKI,E.;MENDOZA,E.G.;VEGH,C. How Big(small?) are the fiscal multipliers? Journal of Monetary Economics, v.60, n.2, p. 239-254, 2013.

JORDÀ, Oscar. Estimation and Inference of Impulse Responses by Local Projections. American Economic Review, v. 95, n. 1, p. 161-182, 2005.

KIRCHNER, M.; CIMADOMO, J.; HAUPTMEIER, S. Transmission of Government Spending Shocks in the Euro Area Time: Variation and Driving Forces. Working Paper Series. European Central Bank, 2010.

KOOP, Gary; PESARAN, M. Hashem; POTTER, Simon M. Impulse response analysis in nonlinear multivariate models. Journal of Econometrics, v. 74(1), p. 119-147, 1996.

LJUNGQVIST, Lars, SARGENT, Thomas. J. Recursive Macroeconomic Theory. 2 ed. The MIT Press, 2004.

MATHESON,T.;PEREIRA,J. Fiscal Multipliers for Brazil. IMF Working Paper. 16/79, International Monetary Fund, 2016.

MENDONÇA,M.J.;MEDRANO,L.A.;SACHSIDA,A. Avaliando os efeitos da política fiscal no Brasil Resultados de um procedimento de identificação agnóstica. Texto para discussão 1377, IPEA.2009.

MERTENS, K.; RAVN, M.O. Measuring the Impact of Fiscal Policy in the Face of Anticipation: A Structural VAR Approach. The Economic Journal, vol. 120(544), p. 393413, 2011.

MERTENS, K.;RAVN, M.O. A reconciliation of SVAR and Narrative Estimates of Tax Multipliers. Journal of Monetary Economics, v. 68, p. 1-19, 2014.

MITTNIK, Stefan; SEMMLER, Willi. Regime Dependence of the Fiscal Multiplier. Journal of Economic Behavior \& Organization, v.83, p.502-522, 2012.

MIYAMOTO, W.; NGUYEN, T. L.; SERGEYEV, D. Government Spending Multipliers under the Zero Lower Bound: Evidence from Japan. Working Paper, abril, 2017.

MONACELLI,T.;PEROTTI,R. Fiscal Policy, Wealth Effects and Markups. Working Paper no. 14584, NBER, Cambridge, MA, 2008.

MONOKROUSSOS, P.; THOMAKOS, D. Fiscal Multipliers in Deep Economic Recessions and the Case for a 2-year extension in Greece Austerity Programme. Economy \& Markets, VIII, n.4, 2012.

MOUNTFORD, A.; UHLIG,H. What are the Effects of Fiscal Policy Shocks? Journal of Applied Econometrics, v. 24, n.6, p. 960-992, 2009. 
OLEA, J. L. M.; PFLUGER, C. A Robust Test for Weak Instruments. Journal of Business \& Economic Statistics, v. 31(3), p. 358-369, 2013.

OWYANG, M. T.; RAMEY, V. A.; ZUBAURY, S. Are Government Spending Multipliers Greater During Periods of Slack? American Economic Review: Papers \& Proceedings, v. 103, p. $129-134,2013$.

PAPPA, Evi. The Effects Of Fiscal Shocks On Employment And The Real Wage. International Economic Review, vol. 50, n. 1, p. 217-244, 2009.

PARKER, J.A. On measuring the effects of fiscal policy in recessions. Journal of Economic Literature v. 49, no. 3, 703-18, 2011.

PEREIRA, M. C.; LOPES, A. S. Time-Varying Fiscal Policy in the U.S. Working Paper, n. 21/2010, Banco de Portugal, 2010.

PERES, M. A. F. Os Efeitos Dinâmicos da Política Fiscal sobre a Atividade Econômica: Um Estudo para o Caso Brasileiro. Brasília: XII Prêmio do Tesouro Nacional. Secretária do Tesouro Nacional, 2007.

PERES, M. A.; ELLERY, R. Efeitos Dinâmicos dos Choques Fiscais do Governo Central no PIB. Pesquisa e Planejamento Econômico, v. 39, n. 2, p.159-206, fev.2009.

PEROTTI, Roberto. Fiscal Policy in Good Times and Bad. Quarterly Journal of Economics, vol. 114, n. 4, p. 1399 - 1436, 1999.

PEROTTI, Roberto. Estimating the Effects of Fiscal Policy in OCDE Countries. Working Papers. IGIER (Innocenzo Gasparini Institute for Economic Research), Bocconi University, 2005.

PEROTTI, Roberto. Comparing Alternative Methodologies to Estimate the Effects of Fiscal Policy. Working Paper, Preliminar e Incompleto, 2007.

PIRES, M.C.C. Controvérsias recentes sobre multiplicadores fiscais, BID, Multiplicadores fiscais no Brasil. Brasília- DF, 2011.

PIRES, M.C.C. Política Fiscal e ciclos econômicos no Brasil. Economia Aplicada, v.18, n.1, p.69-90, jan./mar. 2014.

POIRIER, Renato. Fiscal Multipliers in Portugal Using a Threshold Approach. Lisboa:

NOVA - School of Business and Economics - Working Paper. 2014.

RAMEY, V. A.; SHAPIRO, M. D. Costly Capital Reallocation and the Effects of Government Spending. Carnegie-Rochester Conference Series on Public Policy, v. 48, n.1, p. 145-104, 1998.

RAMEY, V.A. Can government purchases stimulate the economy? Journal of Economic Literature v.49, no.3, p. 673-685, 2011,a. 
RAMEY, V. A. Identifying Government Spending Shocks It's All in the Timing. The Quarterly Journal of Economics, v. 126, n.1, p.1-50, 2011,b.

RAMEY, V. A. Macroeconomic Shocks and their Propagation. Handbook of Macroeconomics, editado H. Uhlig e J. Taylor, 2016

RAMEY, V.A.; ZUBAIRY, S. Are Government Spending Multipliers State Dependent? Evidence from Canadian Historical Data. Working Paper, National Bureau of Economic Research, dezembro, 2015.

RAMEY, V.A.; ZUBAIRY, S. Government Spending Multipliers in Good Times and in Bad: Evidence from 20th Century Historical Data. Journal of Political Economy, em breve 2017.

RAVNIK, R.; ZILIC, I. The Use of SVAR Analysis in Determining the Effects of Fiscal Shocks in Croatia. Financial Theory and Practice, vol. 35(11), p. 25-58, 2011.

RIERA-CRICHTON, D.; VEGH, C. A.; VULETIN, G. Procyclical and Countercyclical Fiscal Multipliers Evidence from OECD Countries. Journal of International Money and Finance, v. 52, p- 35 - 51, 2015.

ROMER, C. D.; ROMER, D.H. The Macroeconomic Effects of Tax Changes Estimates Based on a New Measure of Fiscal Shocks. American Economic Review, v. 100, n.3, p. 763-801, 2010.

SANTOS, C. H. M.; MACEDO E SILVA, A. C.; RIBEIRO, M. B. Uma metodologia de estimação da carga tributária líquida brasileira trimestral no período 1995-2009. Economia Contemporânea 14(2), 209-236, 2010.

SANTOS, C.H.M.; GOUVEA, R. R.; LEAL, E. M.; LEÃO, I. D. Estimativas Trimestrais das Transferências Públicas de Assistências e Previdência no Brasil (1995-2012). Economia Aplicada, v.18, n.3, p. 543-573, 2014.

SCHYMURA, L.G. Há relevantes questões em jogo na divergência entre o IPCA e o deflator do PIB. Carta do IBRE, vol. 71, $\mathrm{n}{ }^{\circ} 4,4$ de abril de 2017. Acesso: < http://portalibre.fgv.br/main.jsp?lumPageId=4028818B379EFC9401379FA912825D74\&cont entId=8A7C82C5593FD36B015B5D8C56A2554E>

SIQUEIRA, F. F. Política Fiscal e ciclo político no Brasil: uma análise empírica. Dissertação (Mestrado em Ciências Econômicas) - Faculdade de Economia, Administração e Contabilidade, Universidade de São Paulo, Outubro, 2015.

SOAVE, G. P. Choques Fiscais e Instabilidade Financeira no Brasil: uma abordagem TVAR. São Paulo: FEA-USP - Working Paper Series n. 2015-02. 2015.

SOUZA-JÚNIOR, J.R.C. Capacidade Produtiva Ociosa Atual e Projeção para o Produto Potencial 2017-2018. Carta de Conjuntura do IPEA, v.34, p. , 2017.

SPILIMBERGO, A.; SYMANSKI, S.; SCHINDLER, M. Fiscal multipliers, Technical report, IMF Staff Position Note, IMF, 2009. 
STAIGER,D.; STOCK, J.H. 1997. Instrumental variables regression with weak instruments. Econometrica 65(3): 557-586.

STOCK, J.H.;WATSON,M.W. NBER Summer Institute Minicourse 2008: What's New in Econometrics-Time Series, Lecture 7: Structural VARs," Cambridge, Mass.: National Institute for Economic Research.

SUMNER, S. Why the Fiscal Multipliers is Roughly Zero. Working Paper, Mercatus Center at George Mason University, p.1-4, 2013.

SUTHERLAND, A. Fiscal Crises and Aggregate Demand: Can High Public Debt Reverse the Effects of Fiscal Policy? Journal of Public Economics, v. 65, p. 147-162, 1997.

TAGKALAKIS, A. The effects of fiscal policy on consumption in recessions and expansions. Journal of Public Economics 92(5-6), 1486-1508, 2008.

TAYLOR, J. An empirical analysis of the revival of fiscal activism in the 2000's'. Journal of Economic Literature 49(3), 686-702, 2011.

TENREYRO, S.; THWAITES, G. Pushing on a String: US Monetary Policy is Less Powerful in Recessions. American Economic Journal: Macroeconomics, v.8(4), p. 43-74, 2016.

UHLIG,H. What are the Effects of Monetary Policy on Output Results from an Agnostic Identification Procedure. Journal of Monetary Economics, v. 52, n.2, p. 381-419, 2005.

WOODFORD, Michael. Simple Analytics of the Government Expenditure Multiplier. American Economic Journal: Macroeconomics, v.3(1), p. 1-35, 2011.

\section{Apêndices}

\section{A.1 - Hiato do Produto Potencial via Função de Produção}

Neste apêndice está presente o teste de robustez com o hiato do PIB obtido via estimação do PIB potencial, por meio de uma função de produção, conforme Souza-Júnior (2017). A estimação do threshold seguiu a mesma forma proposta na seção 5.1.

Tabela 23 - Estimação do Threshold e Máxima Verossimilhança

\begin{tabular}{ccccc}
\hline \hline & Threshold & Recessão & Expansão & $\begin{array}{c}\text { Máxima } \\
\text { Verossimilhança }\end{array}$ \\
\hline Hiato do PIB via Produto Potencial & $-1,42$ & 27 & 43 & 194,77 \\
\hline \hline
\end{tabular}

Fonte: Cálculo do Autor. 
Figura 28 - Variável Threshold

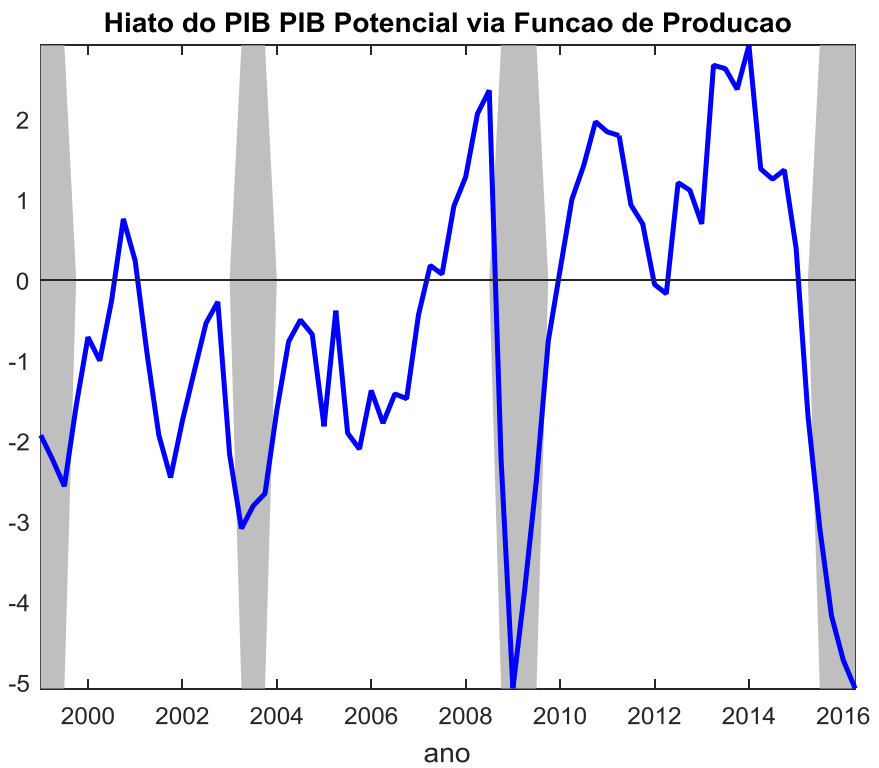

Fonte: Elaboração Própria.

Tabela 24 - Multiplicadores do Modelo Não Linear com Hiato via Função de Produção

\begin{tabular}{ccccc}
\hline \hline & & Multiplicador & Multiplicador & Multiplicador \\
& & de Impacto & 4 trimestres & 8 trimestres \\
\hline \multirow{3}{*}{ Hiato } & Recessão & 0,7022 & 4,3607 & 3,8356 \\
& & $(0,2173)$ & $(0,3543)$ & $(0,4785)$ \\
& Expansão & 0,3230 & 0,8372 & 1,6449 \\
P-valor para diferença & & $(0,4410)$ & $(0,4983)$ & $(1,1454)$ \\
entre estados & HAC & 0,4488 & 0,0000 & 0,0647 \\
\hline \hline
\end{tabular}

Fonte: Cálculo do Autor. 


\section{A.2 - Funções Resposta ao Impulso dos Testes de Robustez}

Figura 29 - Função Resposta ao Impulso do Modelo Linear com Tendência: Despesa Primária e PIB
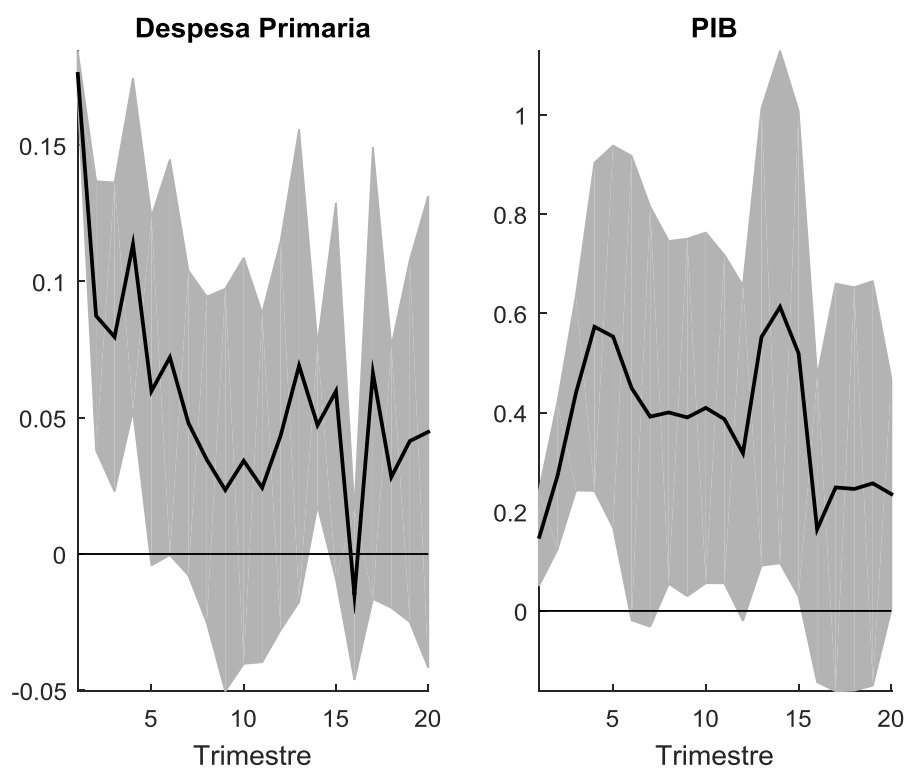

Fonte: Elaboração Própria.

Nota: Resposta da despesa primária e do PIB a um choque de gastos primários de $1 \%$ do PIB. As áreas sombreadas correspondem ao intervalo de confiança de $95 \%$.

Figura 30 - Função Resposta ao Impulso do Modelo Não Linear, com Tendência: Threshold Hiato

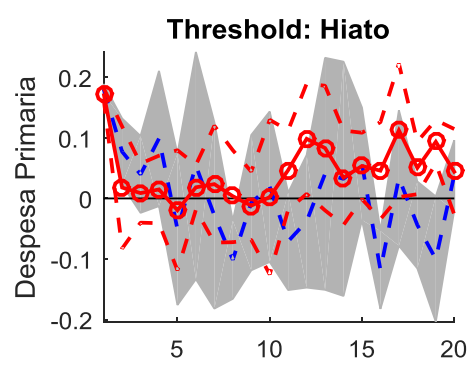

Comparacao entre Linear e Nao Linear
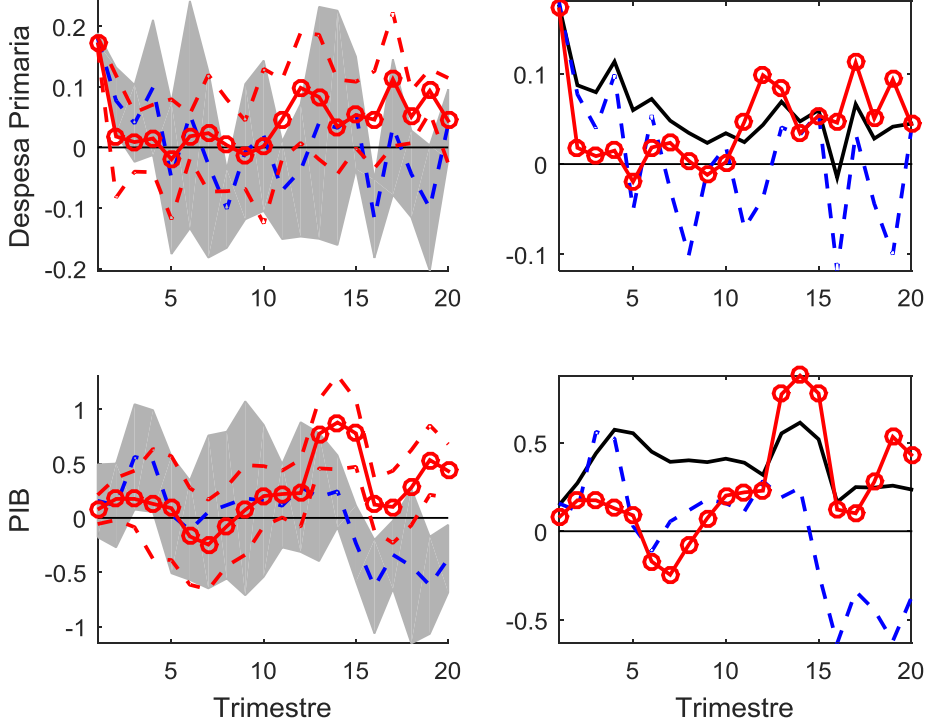

Fonte: Elaboração Própria.

Nota: Respostas do modelo não linear da despesa primária e do PIB a um choque de gastos primários de $1 \%$ do PIB. As áreas sombreadas correspondem ao intervalo de confiança de $95 \%$. 
Figura 31 - Função Resposta ao Impulso do Modelo Não Linear, com Tendência: Threshold NUCI
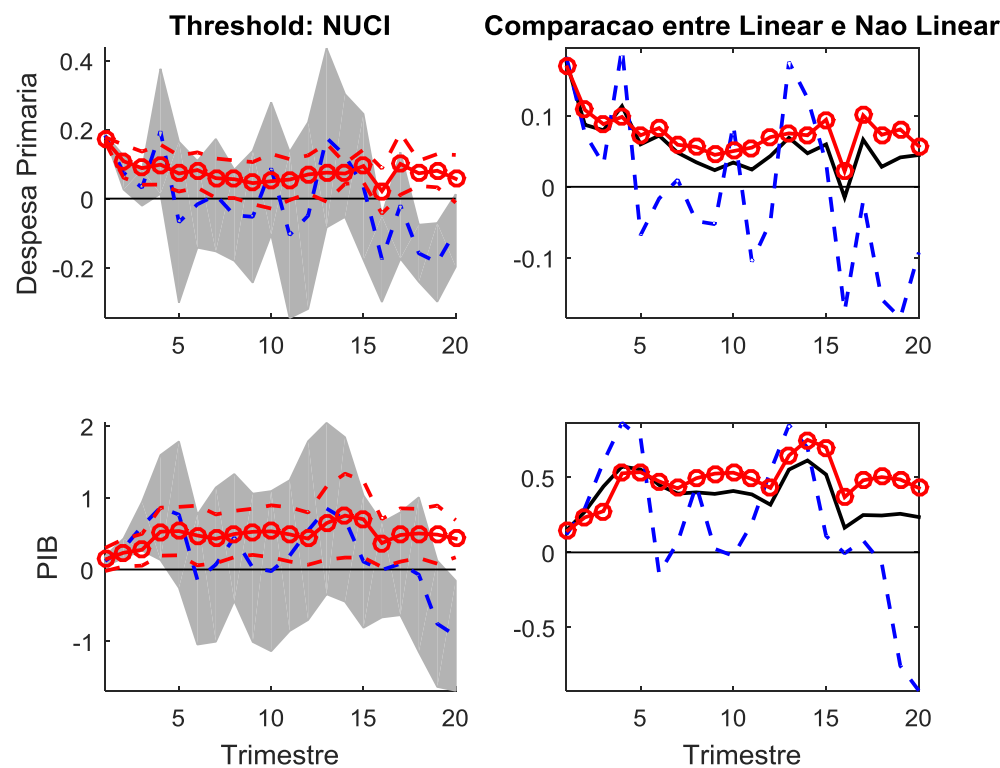

Fonte: Elaboração Própria.

Nota: Respostas do modelo não linear da despesa primária e do PIB a um choque de gastos primários de $1 \%$ do PIB. As áreas sombreadas correspondem ao intervalo de confiança de $95 \%$.

Figura 32 - Função Resposta ao Impulso do Modelo Não Linear, com Tendência: Threshold Taxa de Crescimento do PIB
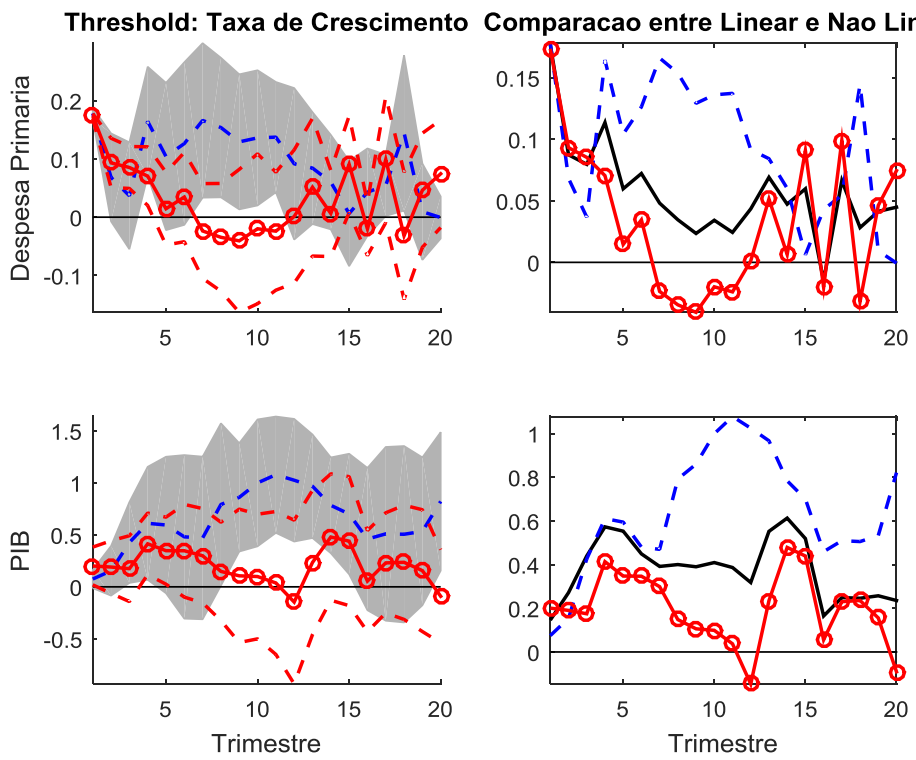

Fonte: Elaboração Própria.

Nota: Respostas do modelo não linear da despesa primária e do PIB a um choque de gastos primários de $1 \%$ do PIB. As áreas sombreadas correspondem ao intervalo de confiança de $95 \%$. 
Figura 33 - Função Resposta ao Impulso do Modelo Não Linear, com Tendência: Threshold Taxa de Desemprego
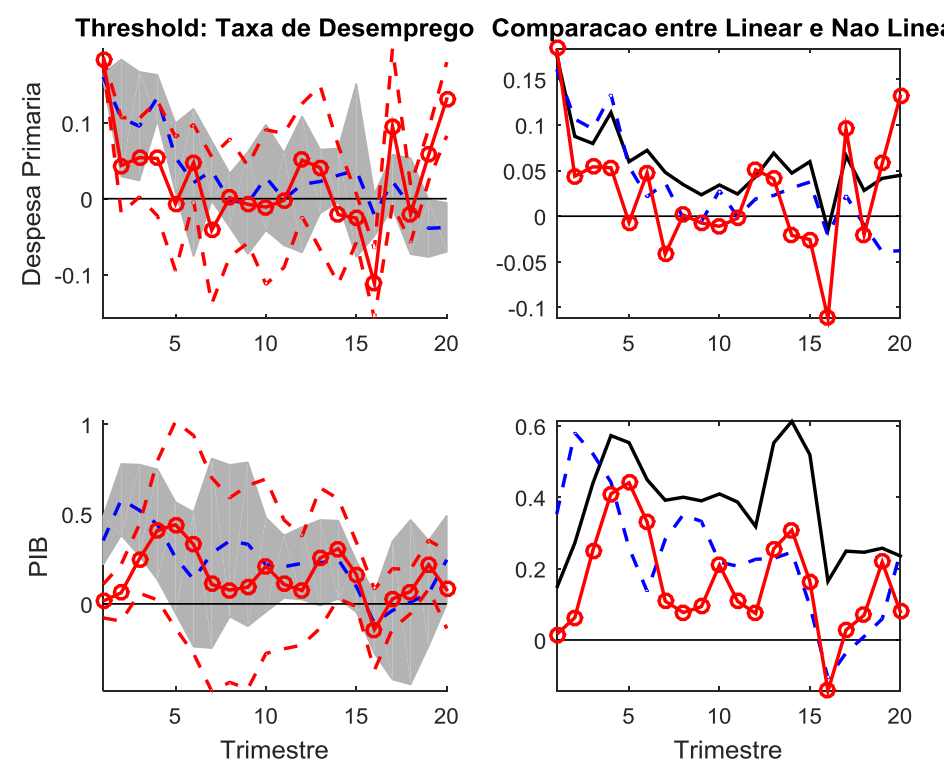

Fonte: Elaboração Própria.

Nota: Respostas do modelo não linear da despesa primária e do PIB a um choque de gastos primários de $1 \%$ do PIB. As áreas sombreadas correspondem ao intervalo de confiança de $95 \%$.

Figura 34 - Função Resposta ao Impulso do Modelo Não Linear, com Tendência: Threshold Datação da CODACE
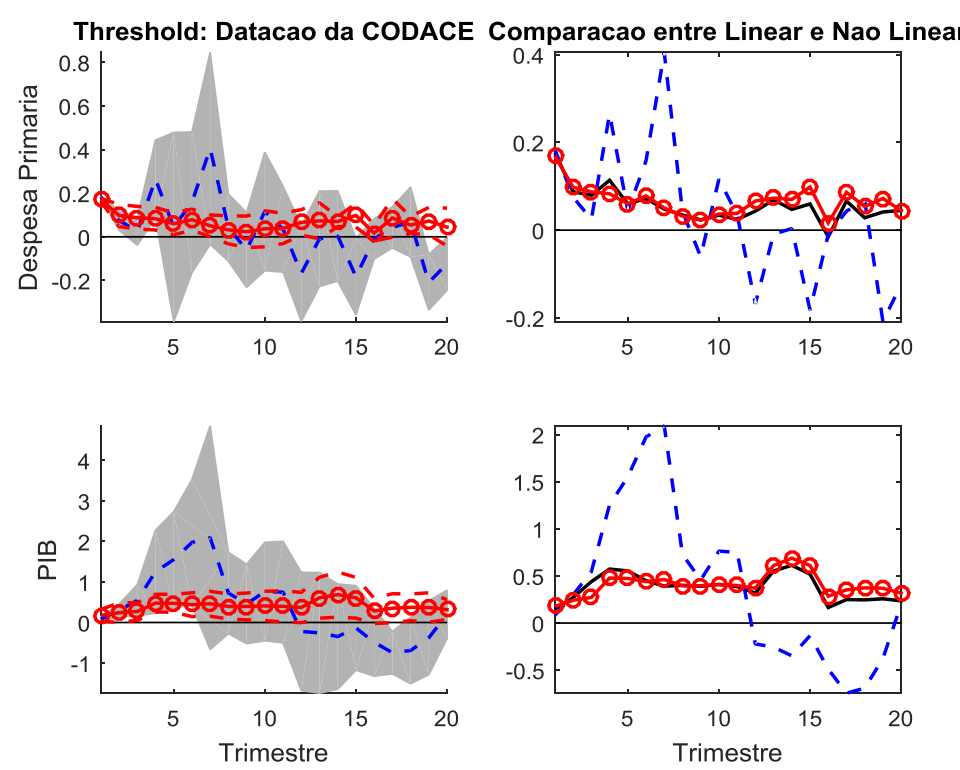

Fonte: Elaboração Própria.

Nota: Respostas do modelo não linear da despesa primária e do PIB a um choque de gastos primários de $1 \%$ do PIB. As áreas sombreadas correspondem ao intervalo de confiança de $95 \%$.

Figura 35 - Função Resposta ao Impulso do Modelo Linear com PIB Potencial: Despesa Primária e PIB 

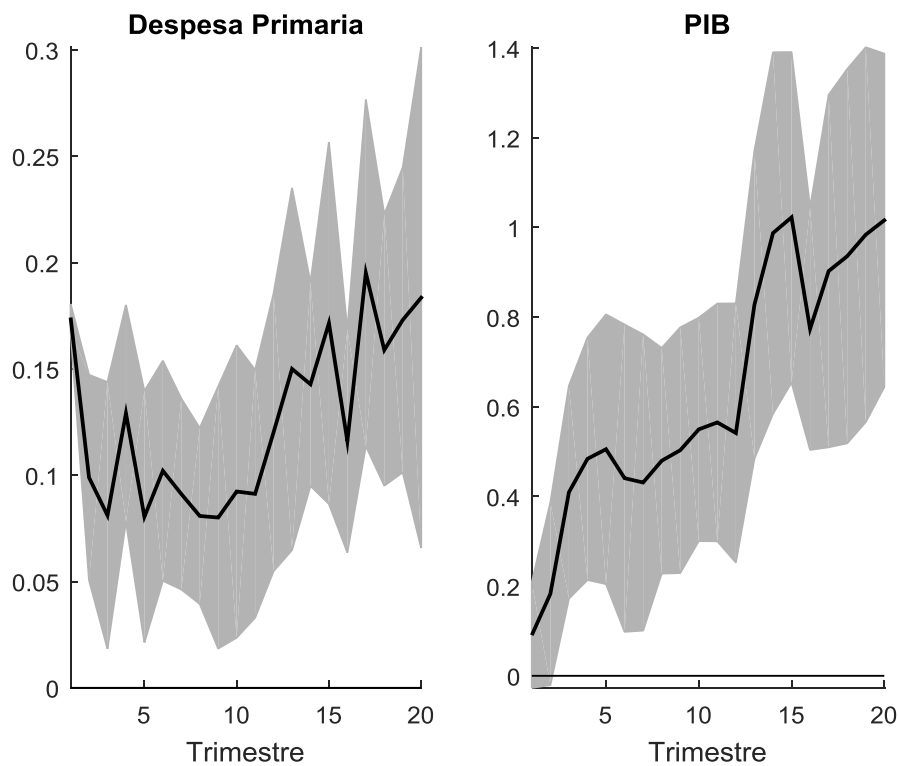

Fonte: Elaboração Própria.

Nota: Resposta da despesa primária e do PIB a um choque de gastos primários de $1 \%$ do PIB. As áreas sombreadas correspondem ao intervalo de confiança de $95 \%$.

Figura 36 - Função Resposta ao Impulso do Modelo Não Linear, com PIB Potencial: Threshold Hiato

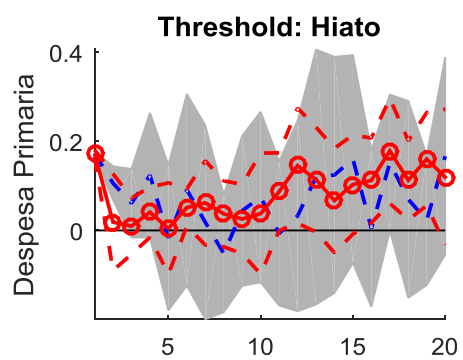

Comparacao entre Linear e Nao Linear
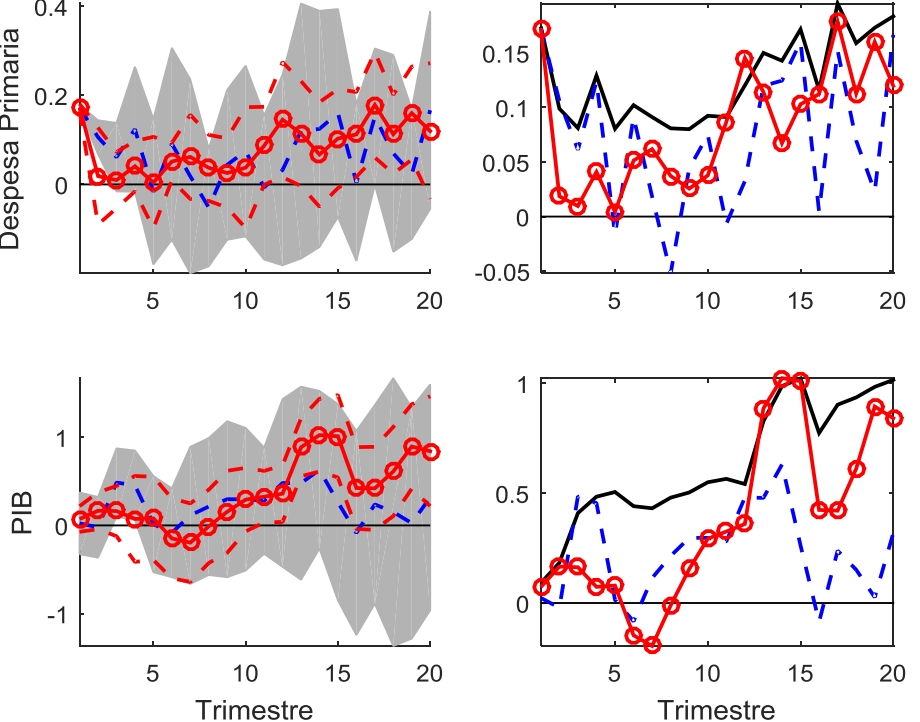

Fonte: Elaboração Própria.

Nota: Respostas do modelo não linear da despesa primária e do PIB a um choque de gastos primários de $1 \%$ do PIB. As áreas sombreadas correspondem ao intervalo de confiança de $95 \%$. 
Figura 37 - Função Resposta ao Impulso do Modelo Não Linear, com PIB Potencial:

\section{Threshold NUCI}

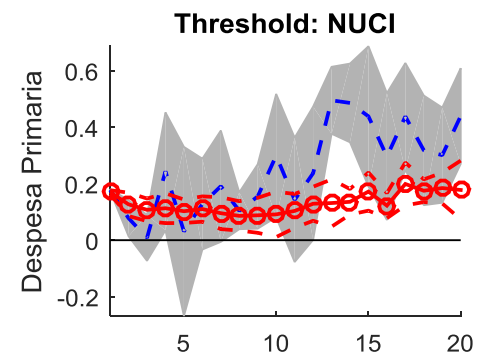

Comparacao entre Linear e Nao Linear
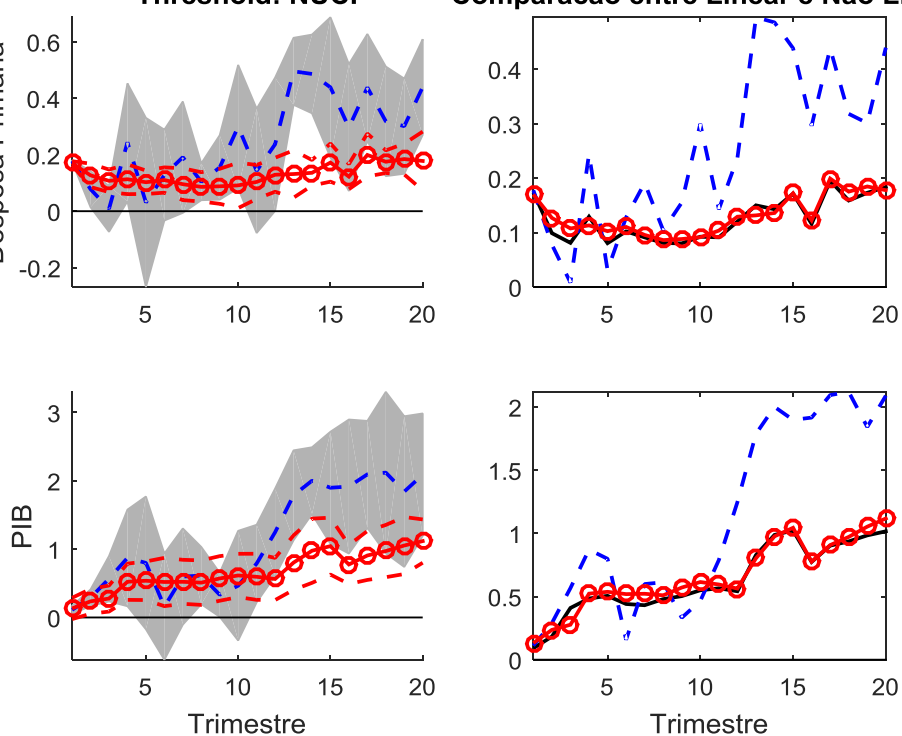

Fonte: Elaboração Própria.

Nota: Respostas do modelo não linear da despesa primária e do PIB a um choque de gastos primários de $1 \%$ do PIB. As áreas sombreadas correspondem ao intervalo de confiança de $95 \%$.

Figura 38 - Função Resposta ao Impulso do Modelo Não Linear, com PIB Potencial: Threshold Taxa de Crescimento do PIB
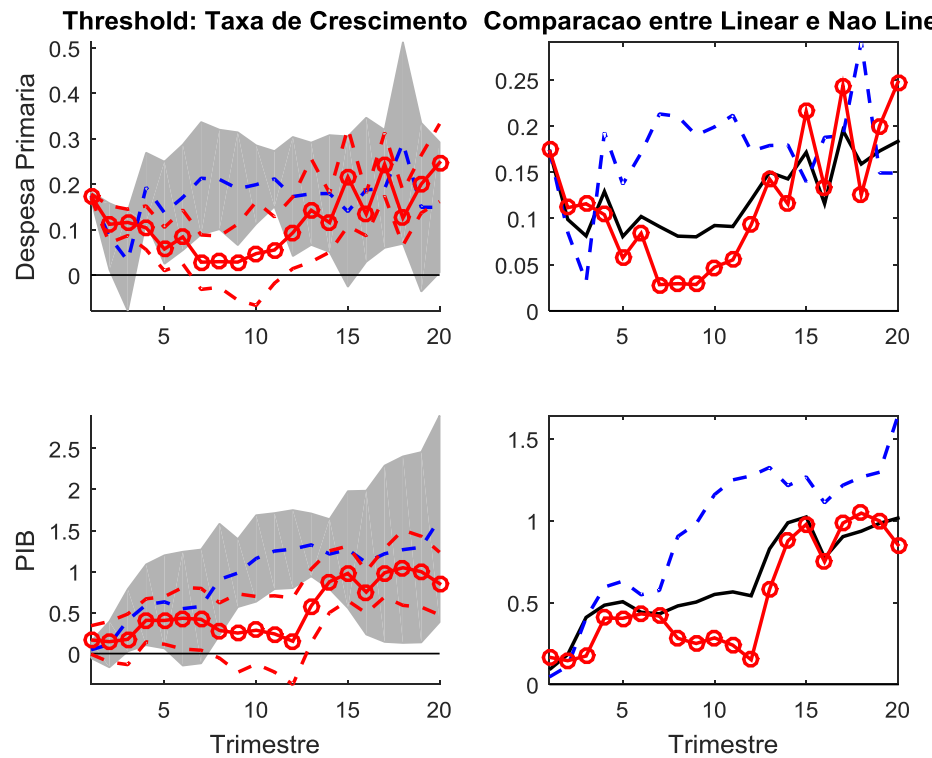

Fonte: Elaboração Própria.

Nota: Respostas do modelo não linear da despesa primária e do PIB a um choque de gastos primários de $1 \%$ do PIB. As áreas sombreadas correspondem ao intervalo de confiança de $95 \%$. 
Figura 39 - Função Resposta ao Impulso do Modelo Não Linear, com PIB Potencial:

Threshold Taxa de Desemprego
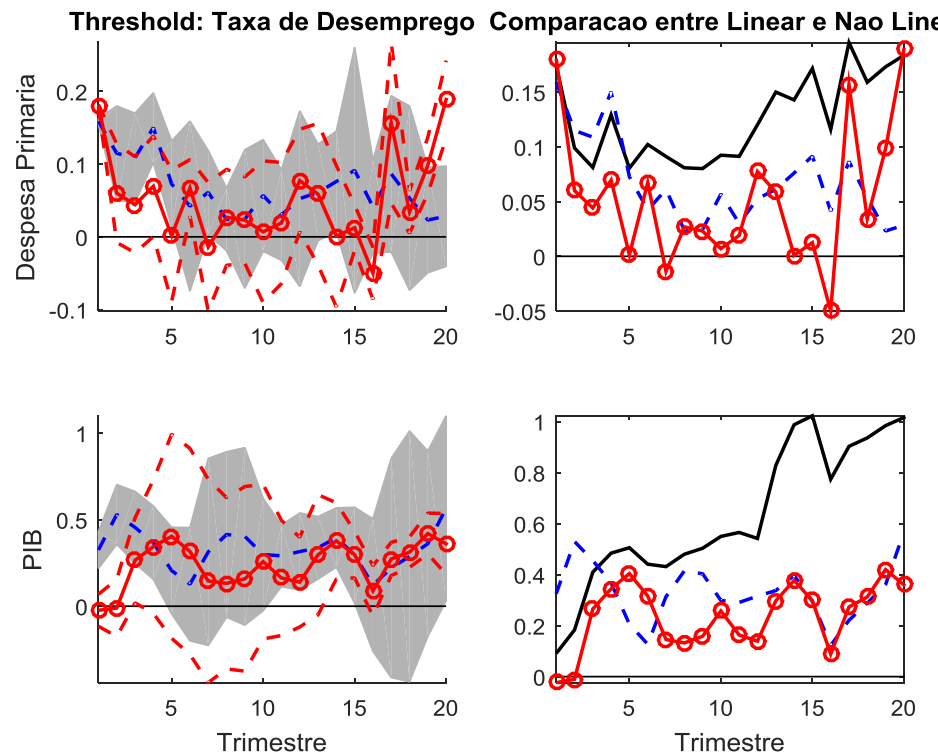

Fonte: Elaboração Própria.

Nota: Respostas do modelo não linear da despesa primária e do PIB a um choque de gastos primários de $1 \%$ do PIB. As áreas sombreadas correspondem ao intervalo de confiança de $95 \%$.

Figura 40 - Função Resposta ao Impulso do Modelo Não Linear, com PIB Potencial: Threshold Datação da CODACE
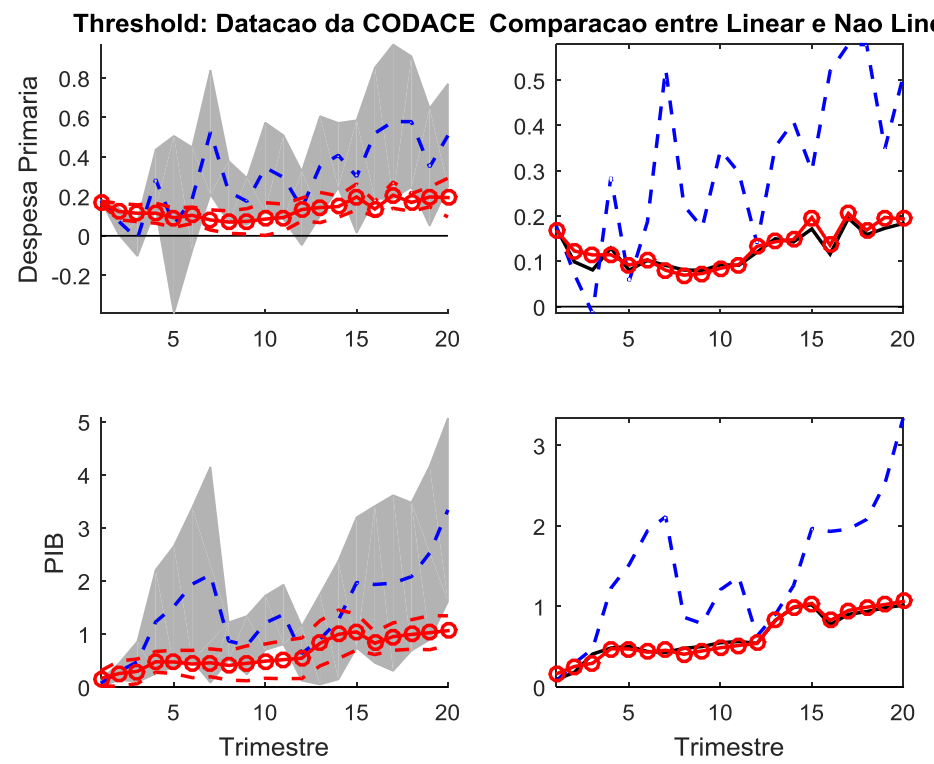

Fonte: Elaboração Própria.

Nota: Respostas do modelo não linear da despesa primária e do PIB a um choque de gastos primários de $1 \%$ do PIB. As áreas sombreadas correspondem ao intervalo de confiança de $95 \%$. 
Figura 41 - Função Resposta ao Impulso do Modelo Não Linear: Variável de Transição Hiato

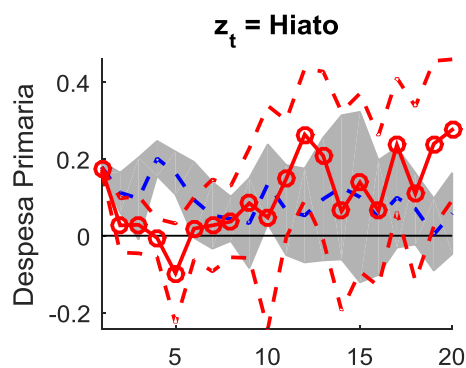

Comparacao entre Linear e Nao Linear
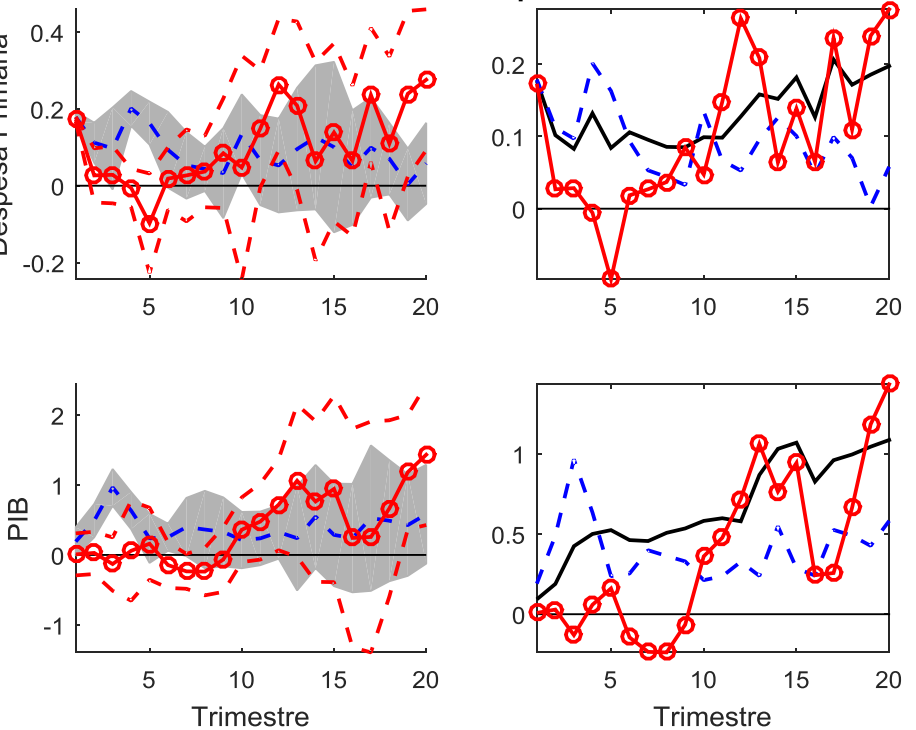

Fonte: Elaboração Própria.

Nota: Respostas do modelo não linear da despesa primária e do PIB a um choque de gastos primários de $1 \%$ do PIB. As áreas sombreadas correspondem ao intervalo de confiança de $95 \%$.

Figura 42 - Função Resposta ao Impulso do Modelo Não Linear: Variável de Transição NUCI
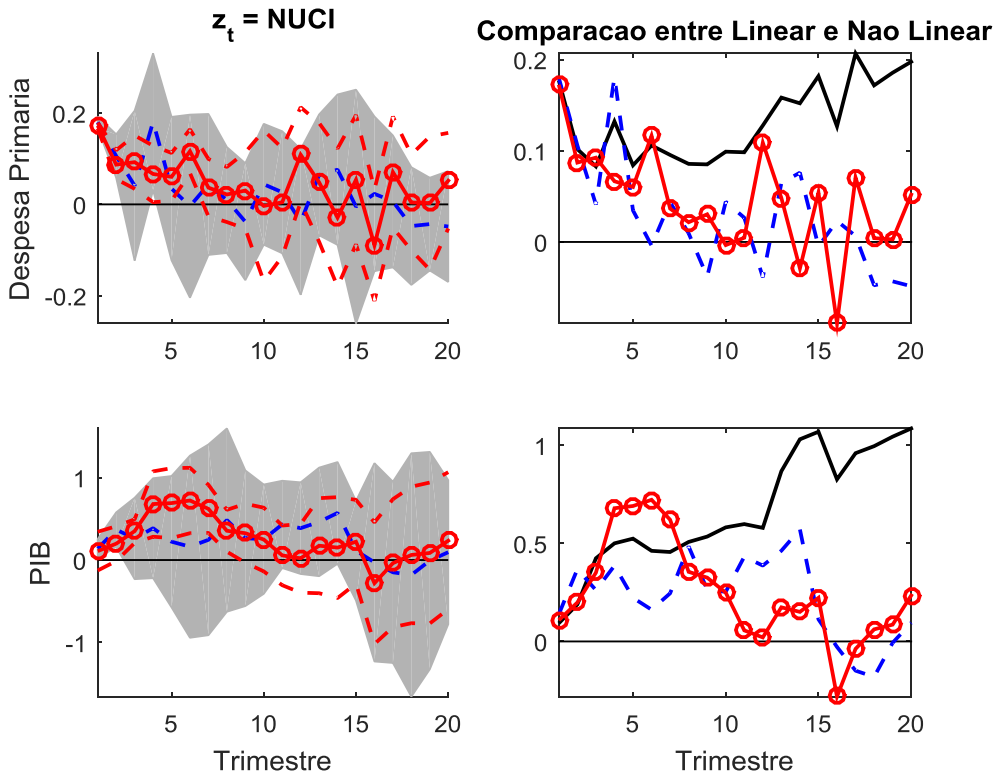

Fonte: Elaboração Própria.

Nota: Respostas do modelo não linear da despesa primária e do PIB a um choque de gastos primários de $1 \%$ do PIB. As áreas sombreadas correspondem ao intervalo de confiança de $95 \%$. 
Figura 43 - Função Resposta ao Impulso do Modelo Não Linear: Variável de Transição Taxa de Crescimento do PIB
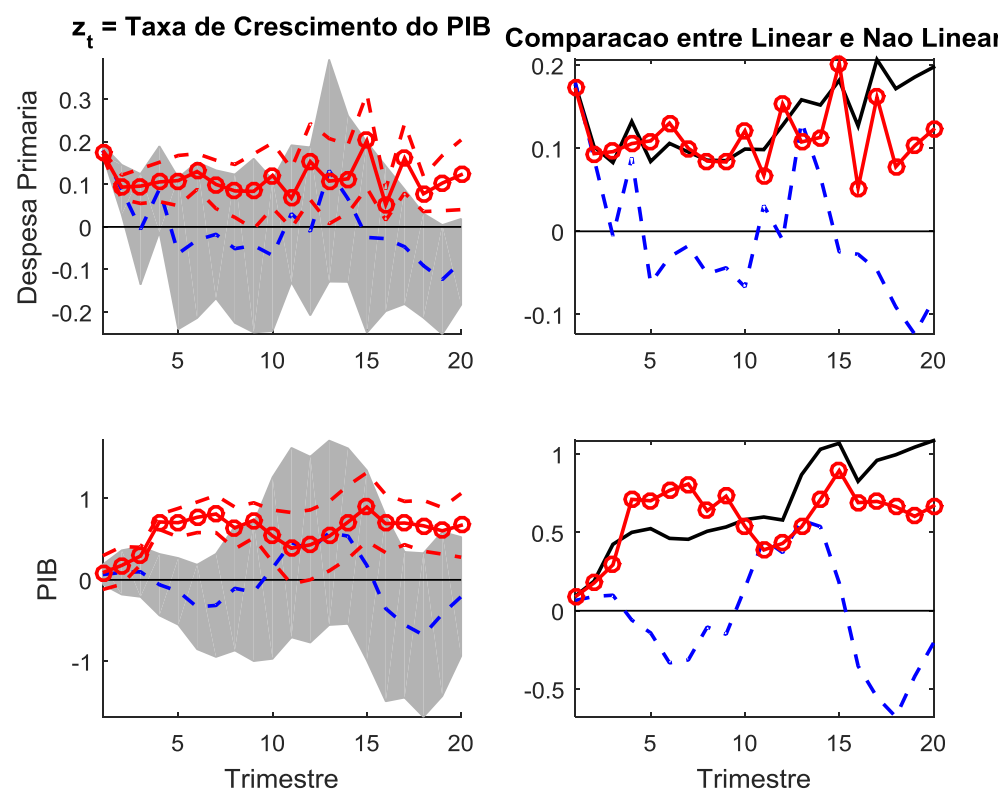

Fonte: Elaboração Própria.

Nota: Respostas do modelo não linear da despesa primária e do PIB a um choque de gastos primários de $1 \%$ do PIB. As áreas sombreadas correspondem ao intervalo de confiança de $95 \%$.

Figura 44 - Função Resposta ao Impulso do Modelo Não Linear: Variável de Transição Taxa de Desemprego
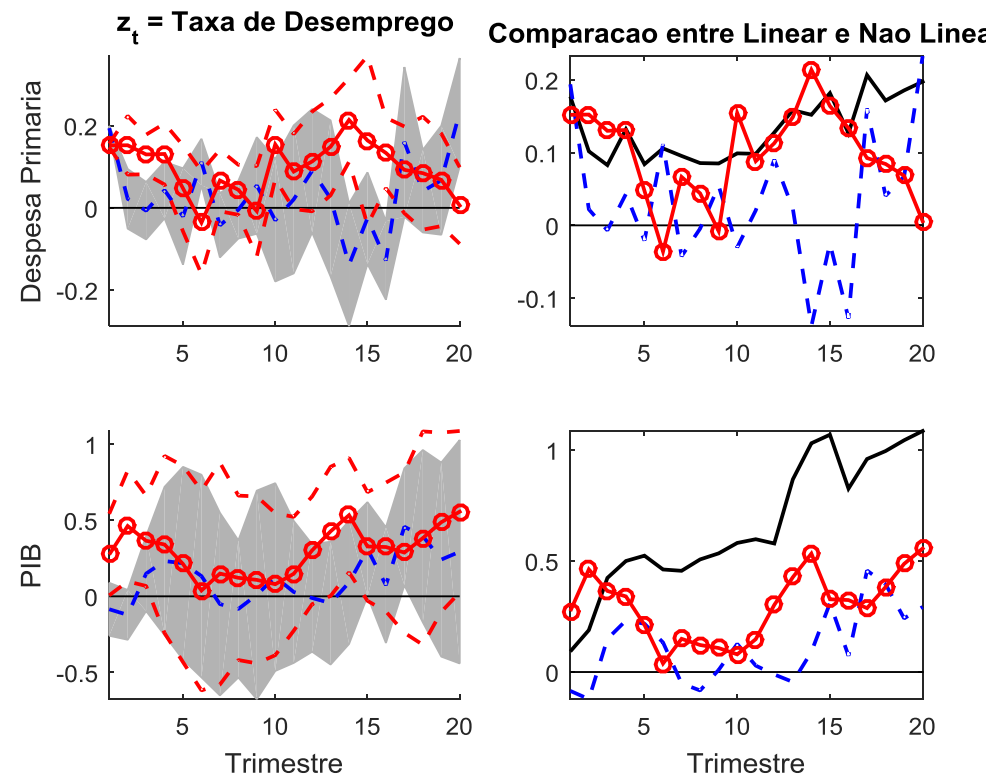

Fonte: Elaboração Própria.

Nota: Respostas do modelo não linear da despesa primária e do PIB a um choque de gastos primários de $1 \%$ do PIB. As áreas sombreadas correspondem ao intervalo de confiança de $95 \%$. 
Figura 45 - Função Resposta ao Impulso do Modelo Linear até 2014.1: Despesa Primária e PIB
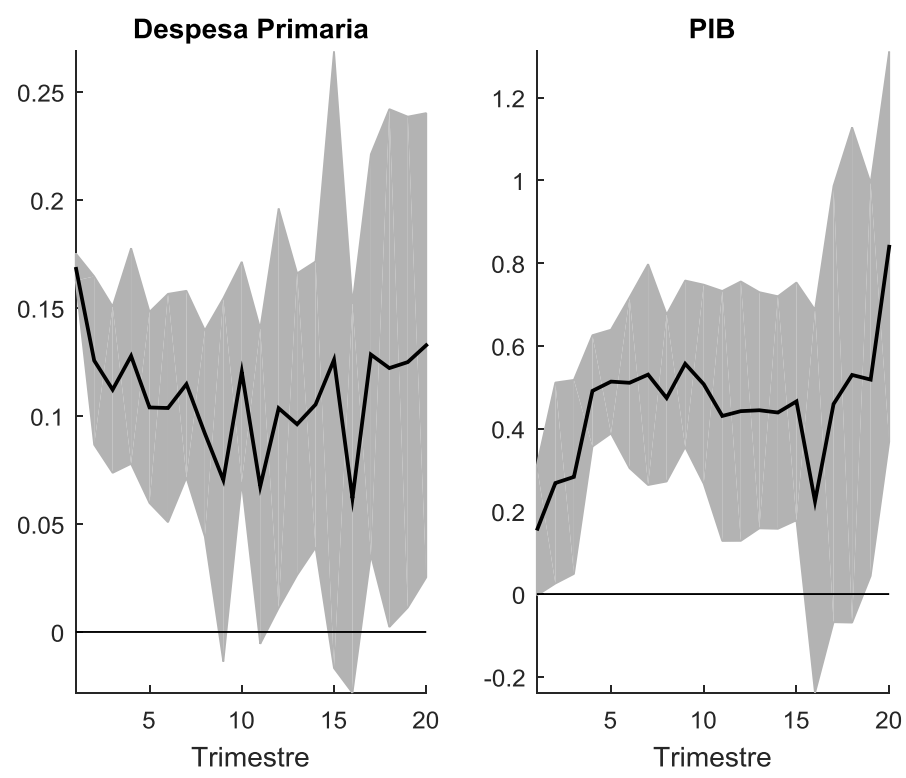

Fonte: Elaboração Própria.

Nota: Resposta da despesa primária e do PIB a um choque de gastos primários de $1 \%$ do PIB. As áreas sombreadas correspondem ao intervalo de confiança de $95 \%$.

Figura 46 - Função Resposta ao Impulso do Modelo Não Linear até 2014.1: Threshold Hiato
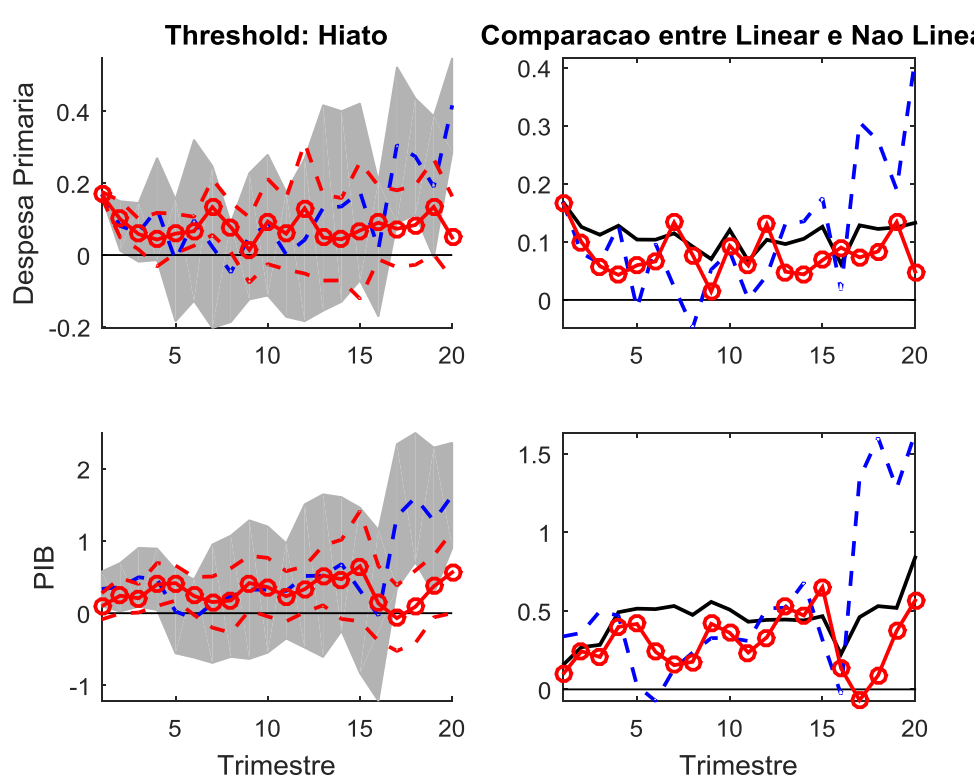

Fonte: Elaboração Própria.

Nota: Respostas do modelo não linear da despesa primária e do PIB a um choque de gastos primários de $1 \%$ do PIB. As áreas sombreadas correspondem ao intervalo de confiança de $95 \%$. 
Figura 47 - Função Resposta ao Impulso do Modelo Não Linear até 2014.1: Threshold NUCI

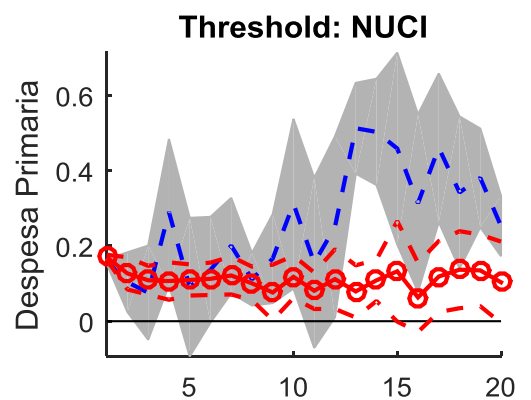

\section{Comparacao entre Linear e Nao Linear}
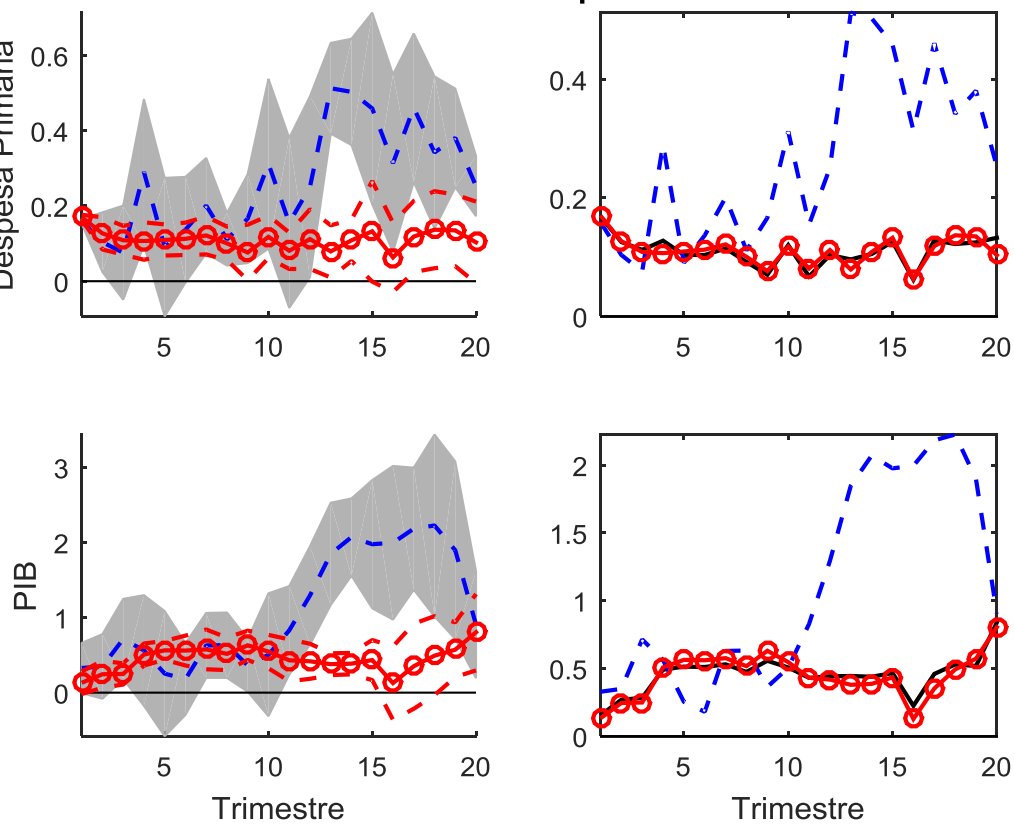

Fonte: Elaboração Própria.

Nota: Respostas do modelo não linear da despesa primária e do PIB a um choque de gastos primários de $1 \%$ do PIB. As áreas sombreadas correspondem ao intervalo de confiança de $95 \%$.

Figura 48 - Função Resposta ao Impulso do Modelo Não Linear até 2014.1: Threshold Taxa de Crescimento do PIB
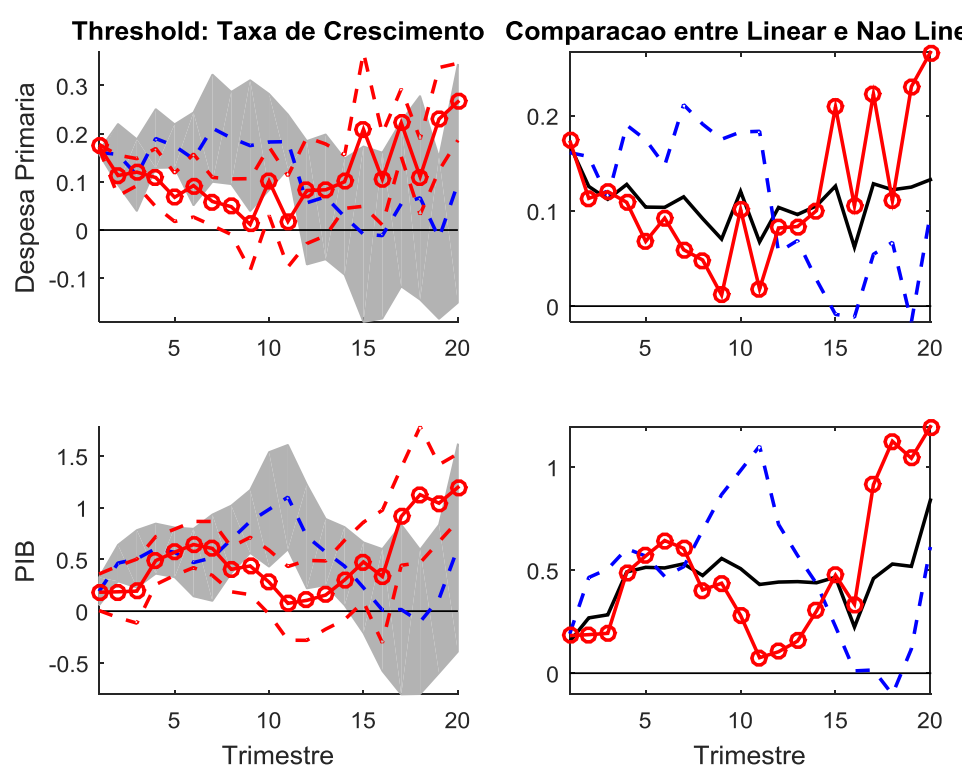

Fonte: Elaboração Própria.

Nota: Respostas do modelo não linear da despesa primária e do PIB a um choque de gastos primários de $1 \%$ do PIB. As áreas sombreadas correspondem ao intervalo de confiança de $95 \%$. 
Figura 49 - Função Resposta ao Impulso do Modelo Não Linear até 2014.1: Threshold Taxa de Desemprego
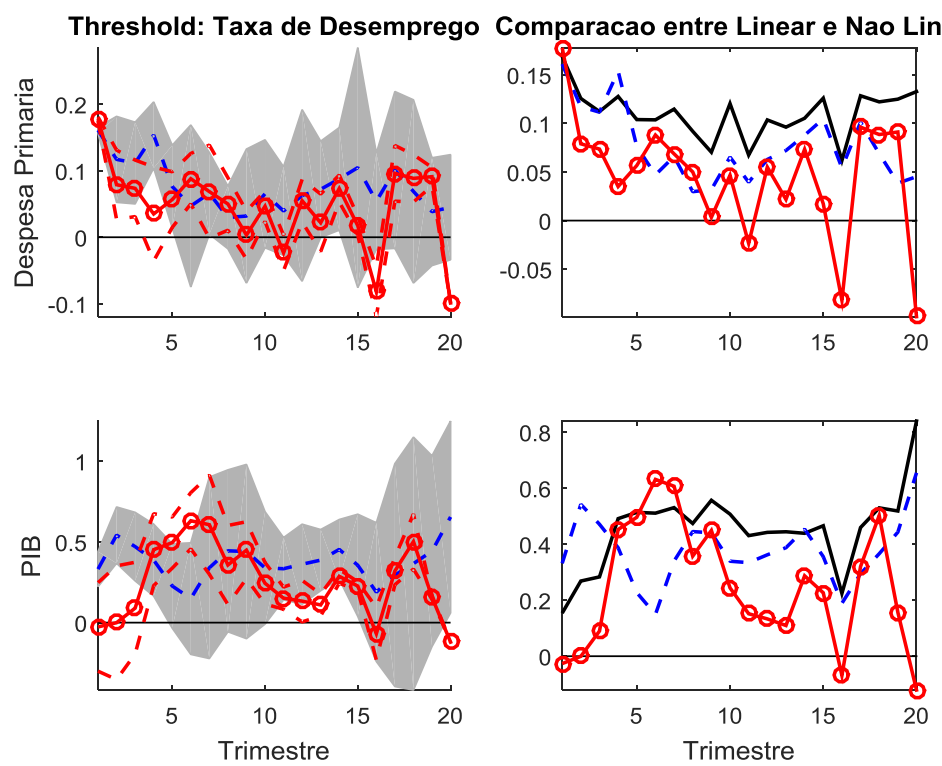

Fonte: Elaboração Própria.

Nota: Respostas do modelo não linear da despesa primária e do PIB a um choque de gastos primários de $1 \%$ do PIB. As áreas sombreadas correspondem ao intervalo de confiança de $95 \%$.

Figura 50 - Função Resposta ao Impulso do Modelo Não Linear até 2014.1: Threshold Datação da CODACE
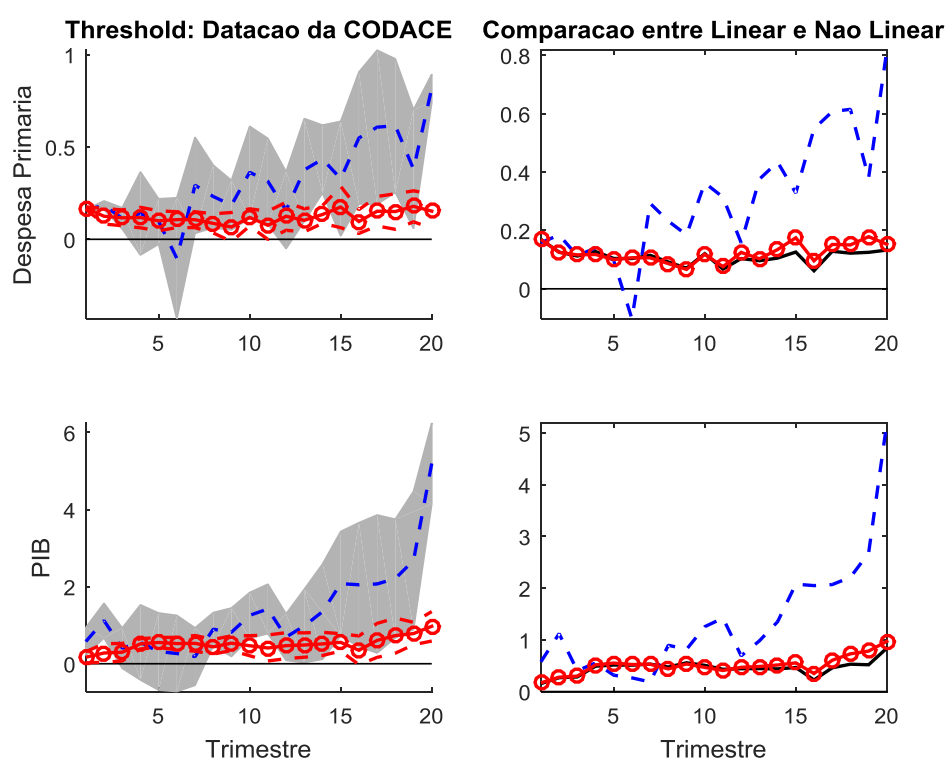

Fonte: Elaboração Própria.

Nota: Respostas do modelo não linear da despesa primária e do PIB a um choque de gastos primários de $1 \%$ do PIB. As áreas sombreadas correspondem ao intervalo de confiança de $95 \%$. 
Figura 51 - Função Resposta ao Impulso do Modelo Linear, deflacionado pelo Deflator do PIB: Despesa Primária e PIB
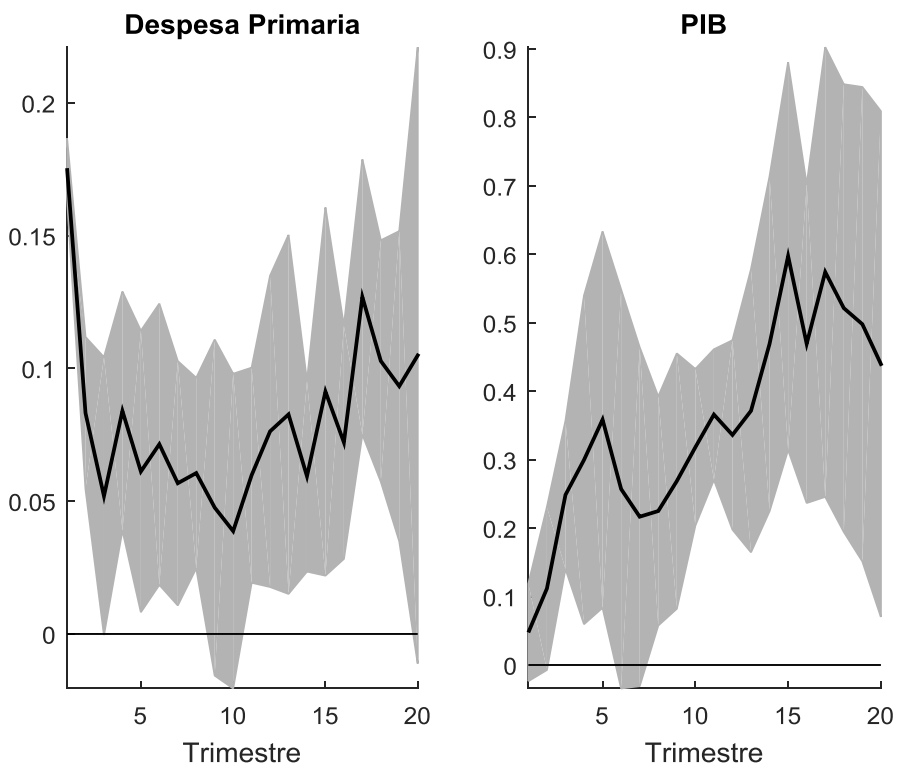

Fonte: Elaboração Própria.

Nota: Resposta da despesa primária e do PIB a um choque de gastos primários de $1 \%$ do PIB. As áreas sombreadas correspondem ao intervalo de confiança de $95 \%$.

Figura 52 - Função Resposta ao Impulso do Modelo Não Linear deflacionado pelo Deflator do PIB: Threshold Hiato

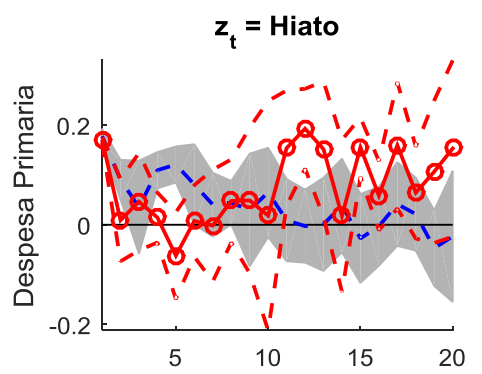

Comparacao entre Linear e Nao Linear
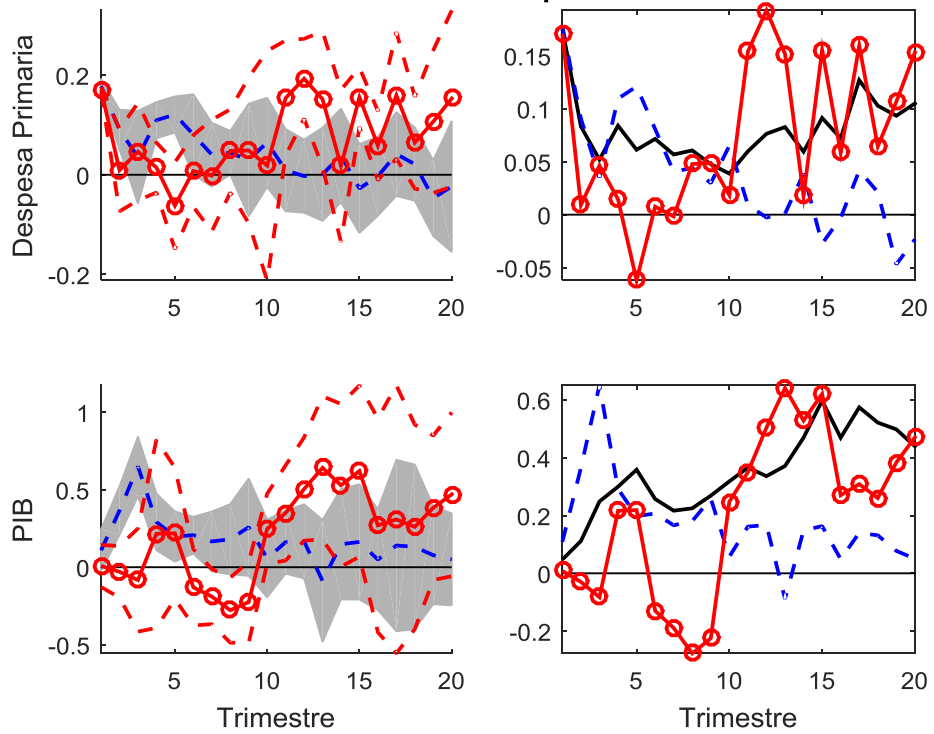

Fonte: Elaboração Própria.

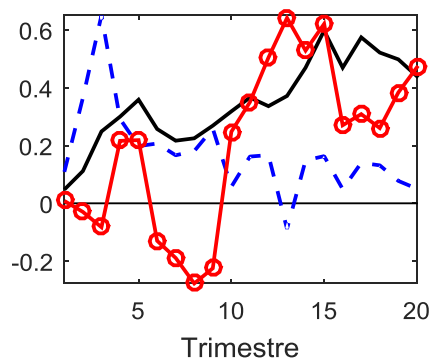

Nota: Respostas do modelo não linear da despesa primária e do PIB a um choque de gastos primários de $1 \%$ do PIB. As áreas sombreadas correspondem ao intervalo de confiança de $95 \%$. 
Figura 53 - Função Resposta ao Impulso do Modelo Não Linear deflacionado pelo Deflator do PIB: Threshold NUCI

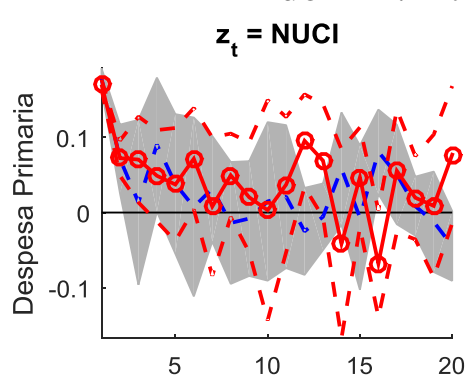

Comparacao entre Linear e Nao Linear
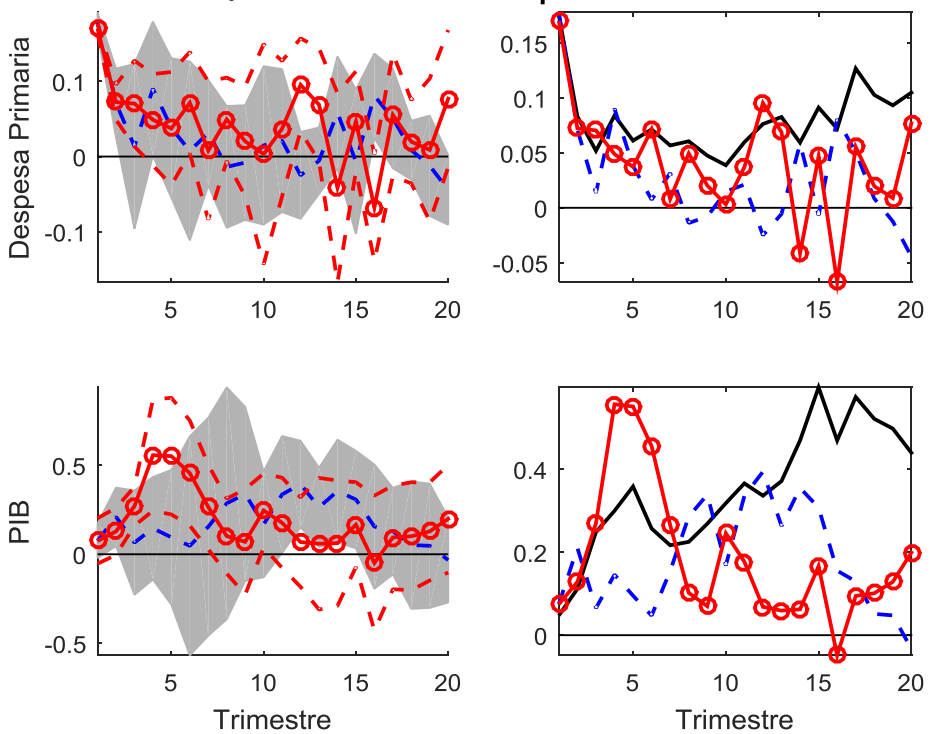

Fonte: Elaboração Própria.

Nota: Respostas do modelo não linear da despesa primária e do PIB a um choque de gastos primários de $1 \%$ do PIB. As áreas sombreadas correspondem ao intervalo de confiança de $95 \%$.

Figura 54 - Função Resposta ao Impulso do Modelo Não Linear deflacionado pelo Deflator do PIB: Threshold Taxa de Crescimento do PIB
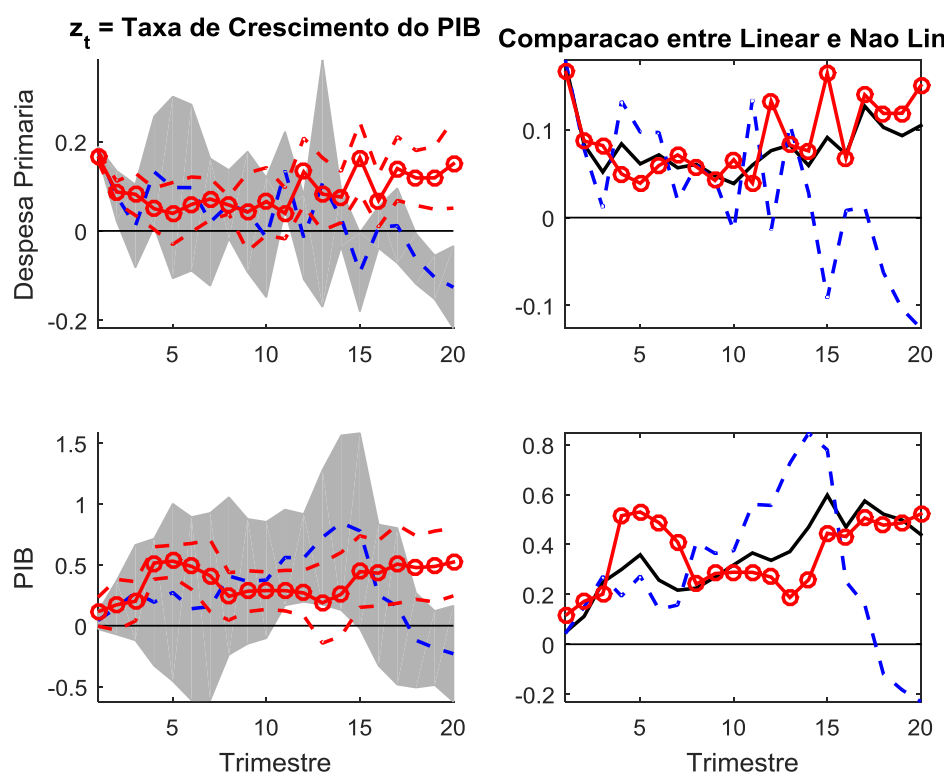

Fonte: Elaboração Própria.

Nota: Respostas do modelo não linear da despesa primária e do PIB a um choque de gastos primários de $1 \%$ do PIB. As áreas sombreadas correspondem ao intervalo de confiança de $95 \%$. 
Figura 55 - Função Resposta ao Impulso do Modelo Não Linear deflacionado pelo Deflator do PIB: Threshold Taxa de Desemprego

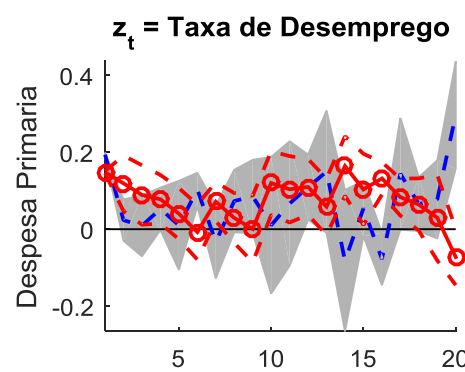

Comparacao entre Linear e Nao Linear
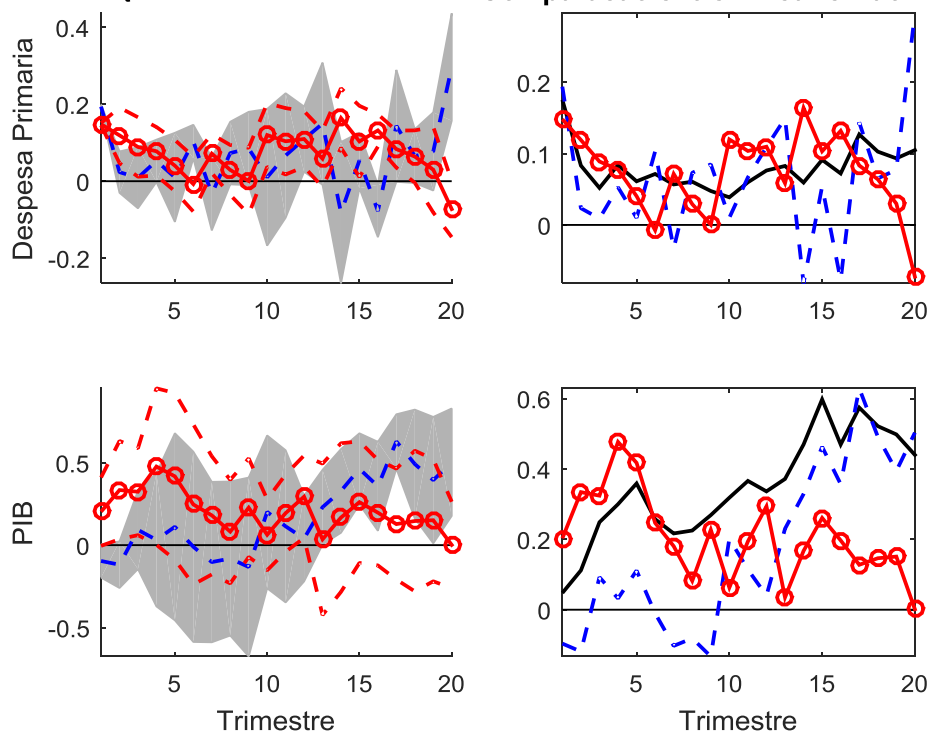

Fonte: Elaboração Própria.

Nota: Respostas do modelo não linear da despesa primária e do PIB a um choque de gastos primários de $1 \%$ do PIB. As áreas sombreadas correspondem ao intervalo de confiança de $95 \%$.

Figura 56 - Função Resposta ao Impulso do Modelo Linear, deflacionado pelo Deflator do PIB e com a carga tributária bruta: Despesa Primária e PIB
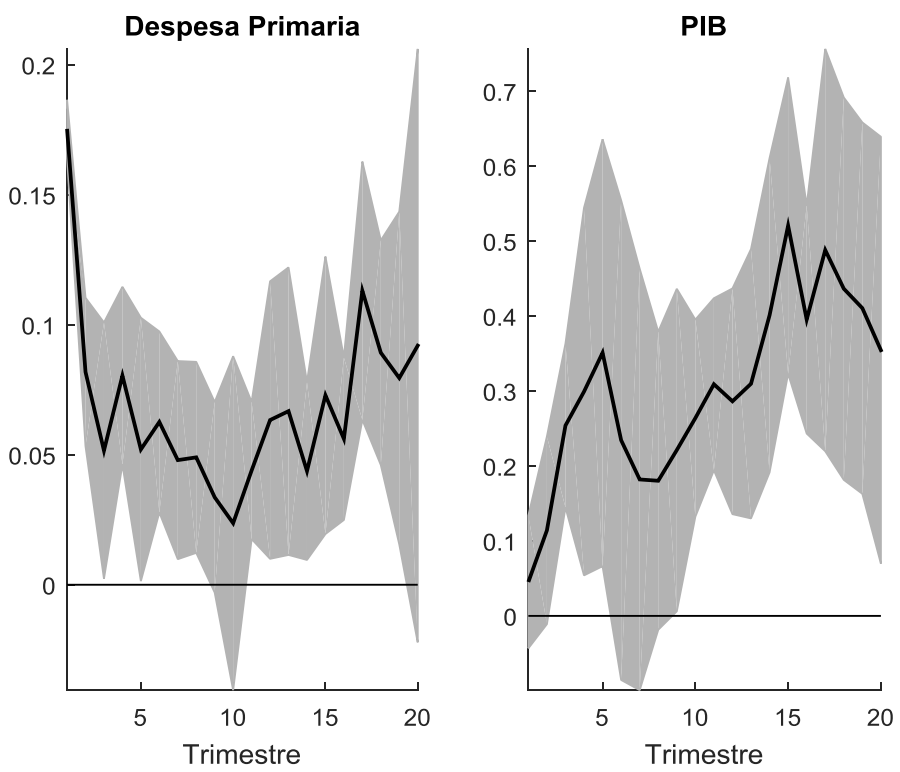

Fonte: Elaboração Própria.

Nota: Resposta da despesa primária e do PIB a um choque de gastos primários de $1 \%$ do PIB. As áreas sombreadas correspondem ao intervalo de confiança de $95 \%$. 
Figura 57 - Função Resposta ao Impulso do Modelo Não Linear deflacionado pelo Deflator do PIB e com a carga tributária bruta: Threshold Hiato
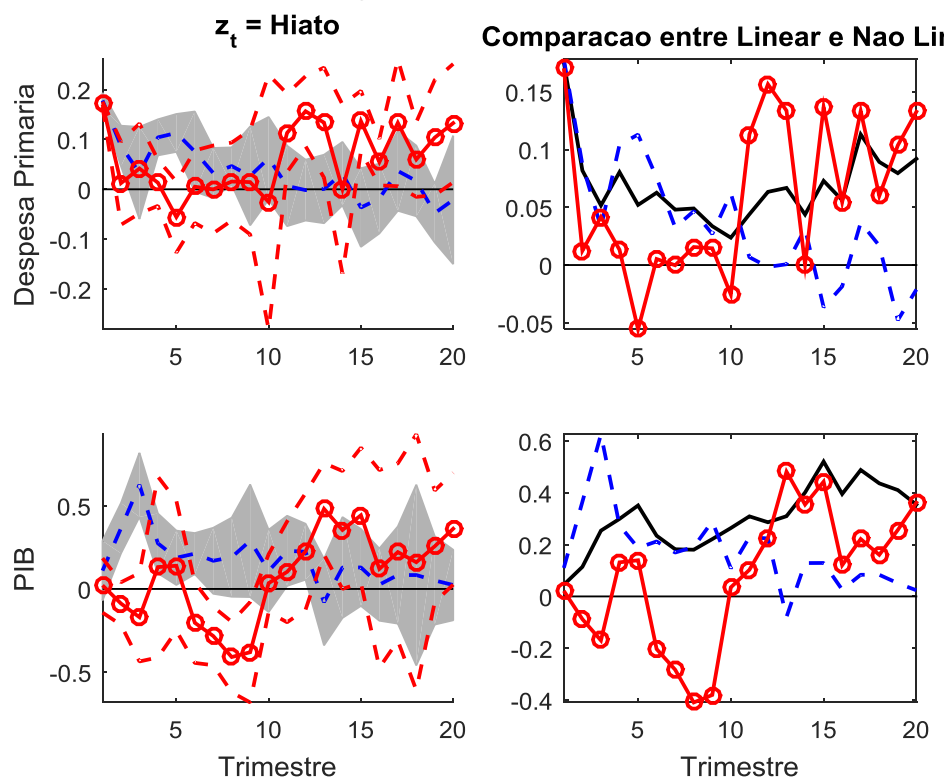

Fonte: Elaboração Própria.

Nota: Respostas do modelo não linear da despesa primária e do PIB a um choque de gastos primários de $1 \%$ do PIB. As áreas sombreadas correspondem ao intervalo de confiança de $95 \%$.

Figura 58 - Função Resposta ao Impulso do Modelo Não Linear deflacionado pelo Deflator do PIB e com a carga tributária bruta: Threshold NUCI
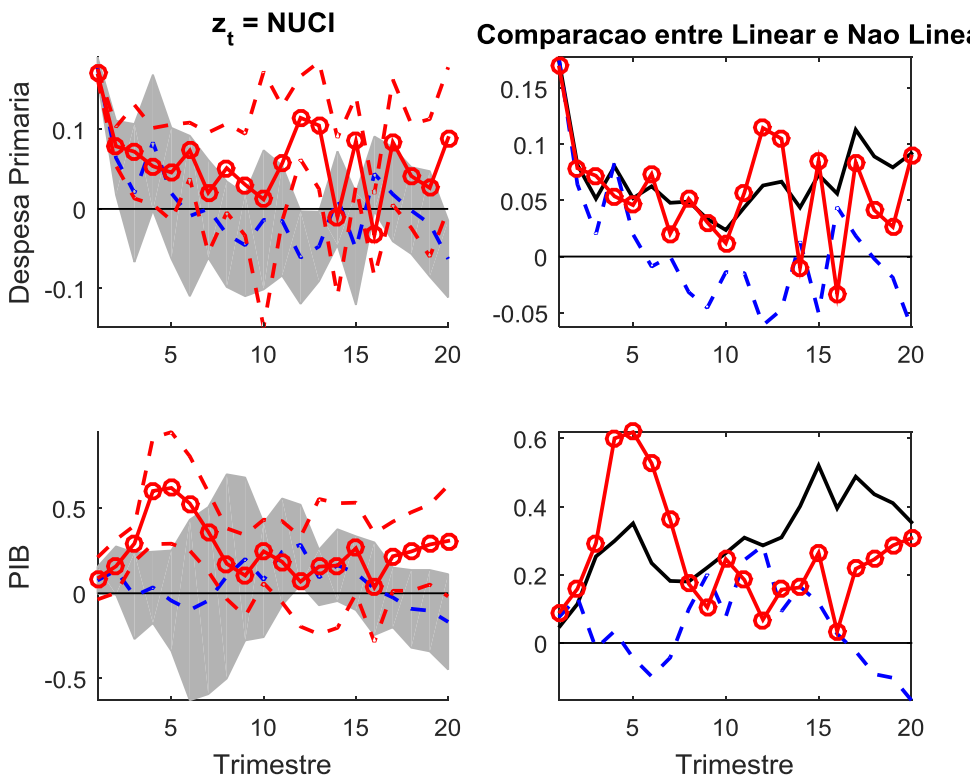

Fonte: Elaboração Própria.

Nota: Respostas do modelo não linear da despesa primária e do PIB a um choque de gastos primários de $1 \%$ do PIB. As áreas sombreadas correspondem ao intervalo de confiança de $95 \%$. 
Figura 59 - Função Resposta ao Impulso do Modelo Não Linear deflacionado pelo Deflator do PIB e com a carga tributária bruta: Threshold Taxa de Crescimento do PIB
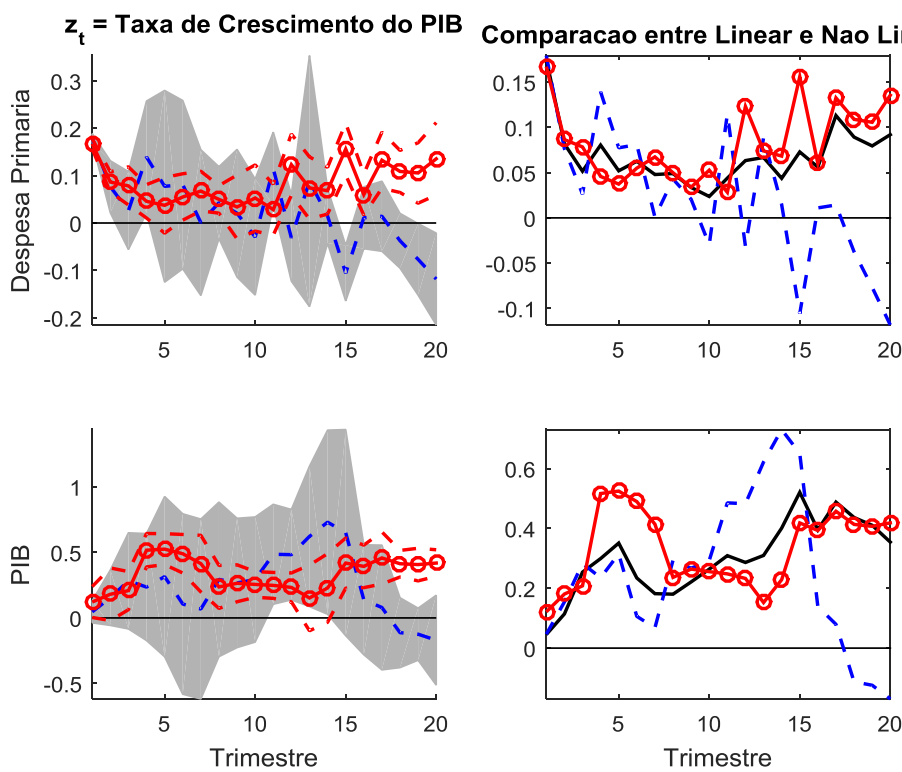

Fonte: Elaboração Própria.

Nota: Respostas do modelo não linear da despesa primária e do PIB a um choque de gastos primários de $1 \%$ do PIB. As áreas sombreadas correspondem ao intervalo de confiança de $95 \%$.

Figura 60 - Função Resposta ao Impulso do Modelo Não Linear deflacionado pelo Deflator do PIB e com a carga tributária bruta: Threshold Taxa de Desemprego
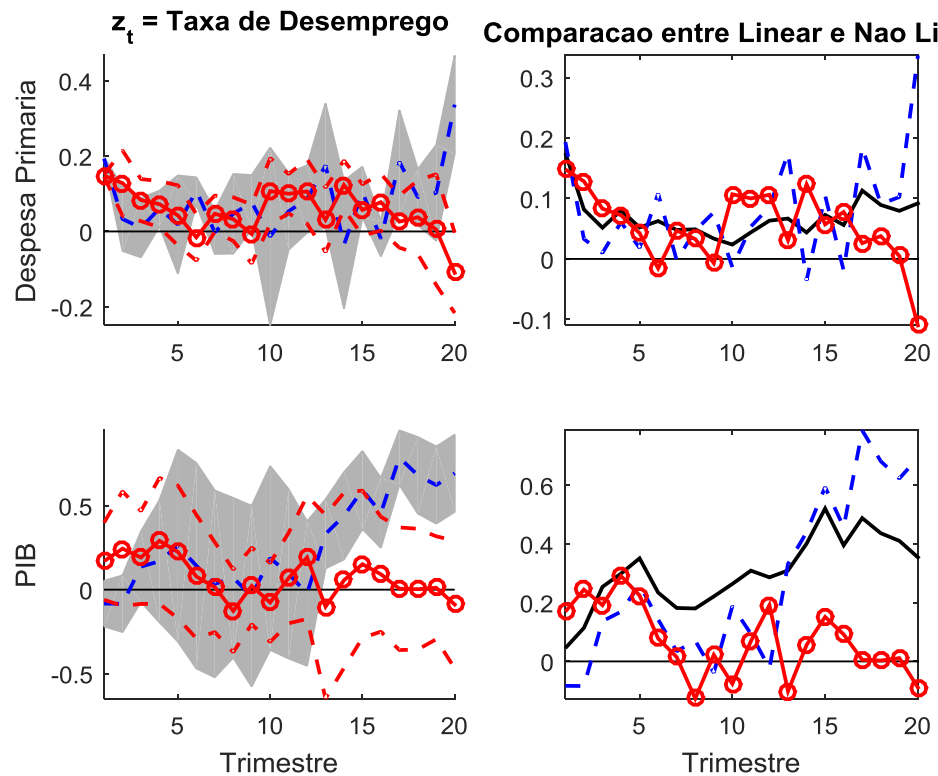

Fonte: Elaboração Própria.

Nota: Respostas do modelo não linear da despesa primária e do PIB a um choque de gastos primários de $1 \%$ do PIB. As áreas sombreadas correspondem ao intervalo de confiança de $95 \%$. 